\title{
Untersuchung mechanischer Eigenschaften von Zellen mit dem Kraftmikroskop - Einfluss von Myosin II
}

\author{
Dissertation \\ zur Erlangung des Doktorgrades \\ der Mathematisch-Naturwissenschaftlichen Fakultäten \\ der Georg-August-Universität zu Göttingen
}

vorgelegt von

Arne Schäfer

aus Göttingen

Göttingen 2003

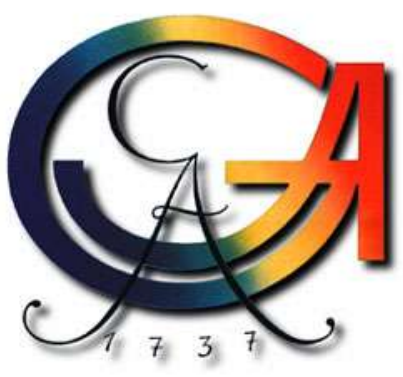




\section{Inhaltsverzeichnis}

1. Einleitung und Grundlagen 5

1.1 Zielsetzung 1.2 Cytoskelet und Zellmechanik

1.2 Cytoskelett und Zellmechanik 5

1.2.1 Das Cytoskelett

1.2.2 Aktin-Filamente 6

1.2.3 Das Motorprotein Myosin II 9

1.2.4 Zellbewegung 9

1.2.5 Fibroblasten 11

1.3 Myosin-Leichtketten-Kinase Inhibitor 11

1.4 Rasterkraftmikroskopie $\quad 12$

2. Material und Methoden $\quad 15$

$\begin{array}{ll}2.1 \text { Zellen } & 15\end{array}$

2.1.1 Zelllinien 15

2.1.2 Präparation 16

$\begin{array}{ll}2.2 \text { Inhibitoren } & 19\end{array}$

2.2.1 BDM 20

$\begin{array}{lll}2.2 .2 & \text { ML-7 } & 20\end{array}$

$\begin{array}{ll}2.3 \text { Mikroskope } & 21\end{array}$

2.3.1 Optische Mikroskope $\quad 21$

2.3.2 Atomic Force Microscope (AFM) 22

3. Messungen 28

3.1 Videomessungen 28

$\begin{array}{ll}3.2 \text { AFM-Messungen } & 30\end{array}$

3.2.1 Fehlerquellen 30

3.2.2 Kraftkurven-Modus 31

3.2.3 Bild-Modus 31

3.2.4 Force-Volume-Mode $\quad 33$

4. Datenauswertung 35

4.1 Videostatistik $\quad 35$

4.2 AFM-Daten $\quad 35$

4.2.1 Kraft-Karten $\quad 35$

4.2.2 Zeitliche Änderung des Young-Moduls 37

4.2.3 Höhenabhängigkeit des Young-Moduls 39

5. Ergebnisse und Diskussion 41

5.1 Videostatistik 41

5.2 AFM-Daten 42

5.2.1 Der Zellkörper $\quad 42$

5.2.2 Die Lamellipodien $\quad 45$

5.2.3 Vergleichende Ergebnisse $\quad 50$

5.3 Statistik der AFM-Messungen $\quad 52$

5.4 Diskussion $\quad 53$

6. Zusammenfassung $\quad 57$

7. Literatur $\quad 58$

Danksagung $\quad 61$

Lebenslauf $\quad 62$ 


\section{Abbildungsverzeichnis}

Abb. 1: Gewebekulturzelle mit blau gefärbten Cytoskelett 6

Abb. 2: Aktin-Filamente 7

Abb. 3: $\quad$ Leitsaum am Wachstumskegel einer Nervenzelle $\quad 7$

Abb. 4: $\quad$ Wandernde Keratozyte 8

Abb. 5: Schematische Darstellung der Actin-Filamente in 8

Abb. 6: Schematische Darstellung eines Myosin II Proteins 9

Abb. 7: $\quad$ Myosin II sorgt für den Aufbau von Spannung 10

Abb. 8: $\quad$ Hypothetisches Schema für die Fortbewegung einer kriechenden Zelle $\quad 10$

Abb. 9: $\quad$ Phosphorylierung von Myosin II Proteinen 12

Abb. 10: $\quad$ Schematischer Aufbau des AFM 13

Abb. 11: $\quad$ Aufnahmen von NRK Zellen über einen Zeitraum von $30 \mathrm{~min}$

Abb. 12: $\quad$ Aufnahmen von 3T3 Zellen über einen Zeitraum von $30 \mathrm{~min}$

Abb. 13: $\quad$ Cryo-Tank / Halterung für die Cryo-Röhrchen 16

Abb. 14: Brutschrank für die Zellen / sterile vertikale Werkbank 17

Abb. 15: T-25, -75 Flaschen und Petrischalen gefüllt mit Nährmedium 18 im Brutschrank

Abb. 16: Axiovert 25 im Zellkulturlabor / 21

Axiovert S 100 mit Metallplattform und Kamera

Abb. 17: AFM-Chip mit Cantilevern in verschiedenen Vergrößerungen 22

Abb. 18: $\quad$ AFM-Chip 23

Abb. 19: Die Fluidzelle bei 6,4 facher Vergrößerung mit und ohne Chip 23

Abb. 20: AFM-Scanner (mit Vergrößerung) / 25

AFM-Scanner mit Fluidzelle (mit Vergrößerung) /

AFM-Halterung

Abb. 21: Gesamtaufbau des AFM 26

Abb. 22: $\quad$ Gesamtaufbau der AFM-Meßvorrichtung 27

Abb. 23: $\quad$ Videoexperiment mit 3T3-Zellen 29

Abb. 24: Kraftkurve auf einem harten Untergrund / 31

Kraftkurve auf einem weichen Untergrund (Zelle)
AFM-Bild einer 3T3-Zelle in verschiedenen Vergrößerungen

$\begin{array}{lll}\text { Abb. 25: } & \text { AFM-Bild einer 3T3-Zelle in verschiedenen Vergrößerungen } & 32 \\ \text { Abb. 26: } & \text { AFM in Betrieb } & 32\end{array}$

Abb. 27: Kraftkarte eines Bereichs einer NRK-Zelle 33

Abb. 28: $\quad$ Elastizitäts-Karte eines Bereichs einer NRK-Zelle 36

Abb. 29: $\quad$ 1-dimensionale Darstellung einer Elastizitäts-Karte 37

Abb. 30: $\quad$ Zeitliche Abfolge von Histogrammen 38

Abb. 31: Young-Modul in Abhängigkeit der Zeit 38

Abb. 32: Logarithmus des Young-Moduls in Abhängigkeit der Zelldicke 40

Abb. 33: Zeitserie von Elastizitätskarten eines NRK-Zellkörpers 43

Abb. 34: Histogramme zu den Elastizitätskarten 43

Abb. 35: Young-Modul in Abhängigkeit der Zeit 44

Abb. 36: Zeitserie von Elastizitätskarten eines NRK-Lamellipodium $\quad 45$

Abb. 37: Histogramme zu den Elastizitätskarten 46

Abb. 38: $\quad$ Young-Modul in Abhängigkeit der Zeit 46 
Abb. 39: $\quad$ Der Logarithmus des Young-Moduls in Abhängigkeit der Dicke $(\mathrm{t}=0 \mathrm{~min})$

Abb. 40: Der Logarithmus des Young-Moduls in Abhängigkeit der Dicke $(t=30 \mathrm{~min})$

Abb. 41: Der Logarithmus des Young-Moduls in Abhängigkeit der Dicke $(t=60 \mathrm{~min})$

Abb. 42: $\quad$ Der Logarithmus des Young-Moduls in Abhängigkeit der Dicke $(t=120 \mathrm{~min})$

Abb. 43: Höhenabhängige Darstellung für NRK-Zelle und BDM-Inhibitor

\section{Tabellenverzeichnis}

Tabelle 1: $\quad$ BDM-Konzentrationen 28

Tabelle 2: $\quad$ ML-7-Konzentrationen 28

Tabelle 3: Langzeit-Videoexperimente $\quad 30 / 41$

Tabelle 4: $\quad$ Statistik der Zellreaktionen auf die Inhibitoren 41

Tabelle 5: Zusammenfassung der Zellstatistik $\quad 42$

Tabelle 6: $\quad$ Vergleich des Young-Moduls bei Zelldicke 0,6 $\mu \mathrm{m}$

Tabelle 7: $\quad$ Vergleich des Young-Moduls bei Zelldicke 0,8 $\mu \mathrm{m}$

Tabelle 8: $\quad$ Vergleich des Young-Moduls bei Zelldicke 0,4 $\mu \mathrm{m}$

Tabelle 9: $\quad$ Faktoren der Elastizitätsverringerung 50

Tabelle 10: Zusammenfassung der AFM-Experimente 52

Tabelle 11: Zusammenfassung der positiven Ergebnisse 52

Tabelle 12: $\quad$ Faktoren der Verringerung des Young-Moduls 53 


\section{Einleitung und Grundlagen}

\subsection{Zielsetzung}

In der vorliegenden Dissertation wird der Einfluß des Motorproteins Myosin II auf die Elastizität von Fibroblasten Zelllinien untersucht. Die Änderung der Elastizität (Young-Modul) der Zelle nach der „Deaktivierung“ des Myosin II läßt Rückschlüsse auf die Struktur der Zelle speziell auf das Cytoskelett und die Aktin-Filamente zu.

Dass die Spannung und die Elastizität der Zelle auf das Aktinfilament-Netzwerk zurückzuführen ist, zeigten schon „Rotsch\&Radmacher, 2000“, indem sie mit speziellen Chemikalien das AktinNetzwerk schädigten. Sie fanden drastische Änderungen der Morphologie und eine Verringerung der Zellelastizität um den Faktor $\sim 3$.

Ziel der vorliegenden Arbeit ist es, den maßgeblichen Einfluß des Myosin II auf die Zellmechanik (Fortbewegung und Elastizität) zu untersuchen und eine Verringerung der Zellhärte nach Hemmung des Myosin II zu zeigen. Dadurch wäre ein Beweis erbracht, dass ein großer Teil der Spannung des Actin-Filament-Systems durch das Myosin II aufgebaut wird.

Dies soll erreicht werden durch den Einsatz bekannter Myosin II-Inhibitoren. Die daraus resultierenden Änderungen der zellulären Prozesse werden optisch mit Hilfe der Videomikroskopie und kraftmikroskopisch mit dem Rasterkraftmikroskop (engl. „Atomic Force Microscope, AFM) aufgezeichnet, ausgewertet und mit den Beobachtungen unbehandelter Zellen verglichen.

Für die durchgeführten Experimente wurden die Zelllinien NRK (Nierenzellen von Ratten) und 3T3 (Embryozellen von Mäusen) als Standard Fibroblasten und die bekannten Myosin II Inhibitoren (Hemmstoffe) BDM und ML-7 verwendet. Wir erwarten nach Zugabe des jeweiligen Inhibitors eine Einstellung der Zellbewegung und eine Änderung der ausgedehnten Morphologie der Zellen in eine sphärische Form. Begleitend zu diesen optischen Veränderungen eine Verringerung des Young-Moduls der Zellen. Weiterhin erwarten wir eine Regeneration der Zelle nach einem Abbau des Inhibitors.

\subsection{Cytoskelett und Zellmechanik}

\subsubsection{Das Cytoskelett}

Die Fähigkeit der Eukaryontenzellen, verschiedene Formen anzunehmen und gerichtete Bewegung auszuführen, beruht auf dem Cytoskelett.

Das Cytoskelett stellt einen Funktionskomplex aus Proteinen mit hohem Organisationsniveau innerhalb der Zelle dar. Die beteiligten Proteine bilden durch Polymerisation ausgedehnte Filamente und verbinden damit Proteinkomplexe und Organellen in verschiedenen Teilen der Zelle. Es stellt die Maschinerie für Bewegung innerhalb der Zelle bereit und dient der Tierzelle, die keine steife Zellwand besitzt, als mechanische Stütze und inneres Gerüst für das großvolumige Cytoplasma (siehe Abb. 1).

Im Gegensatz zu einem Skelett aus Knochen ist das Cytoskelett eine sehr dynamische Struktur, die sich ständig neu organisieren kann. 
Innerhalb des Cytoskeletts gibt es drei Haupttypen von Proteinfilamenten, die sich aus unterschiedlichen Protein-Monomeren zusammensetzen:

- die Aktin-Filamente

- die Mikrotubuli

- die Intermediärfilamente

Diese drei Filamenttypen allein könnten einer Zelle weder Form noch notwendige Festigkeit verleihen. Sie greifen auf eine große Anzahl von „Zubehör-Proteinen“ zurück, welche die Filamente untereinander und mit anderen Zellbestandteilen verbinden. Diese Proteine sorgen außerdem für den Transport der Organellen entlang der Filamente und für die Bewegung der Filamante selbst.

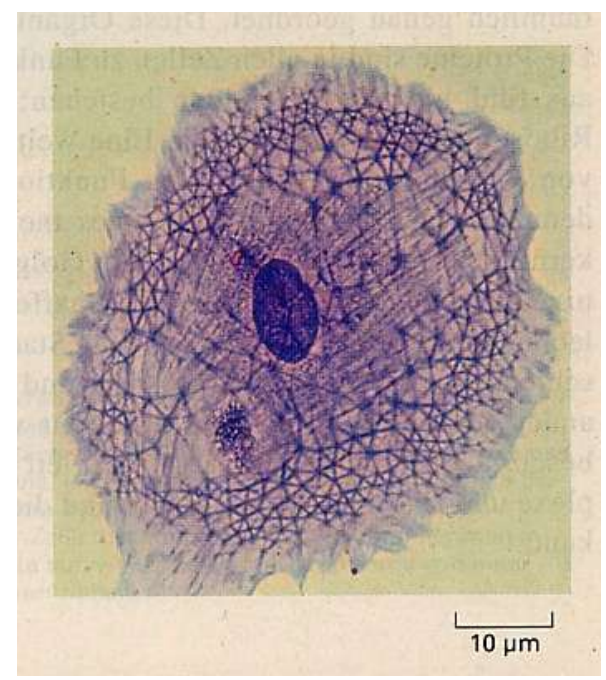

Abbildung 1: Gewebekulturzelle mit blau gefärbten Cytoskelett (Alberts et al., 1994)

\subsubsection{Aktin-Filamente}

Wir betrachten nun die für die vorliegende Arbeit wichtigen Aktin-Filamente etwas genauer. Aktin-Filamente sind flexible, zweisträngige, helikale Polymere aus dem Protein Aktin (mit 5\% der gesamten Proteinmenge häufigstes Zellprotein). Sie sind polare Gebilde, deren Enden unterschiedliche Eigenschaften haben: ein langsam wachsendes minus-Ende und ein schneller wachsendes plus-Ende.

Angeordnet sind sie zu vielfältigen linearen Bündeln, flächigen Netzen und räumlichen Gelen. Die quervernetzten Ansammlungen und Bündel sind wesentlich kräftiger als ein einzelnes AktinFilament.

Unter anderen bilden Aktin-Filamente unmittelbar unter der Plasmamembran der Zelle zusammen mit einem Geflecht von verschiedenen Aktin-bindenden Proteinen die Zellrinde. Dieses Geflecht ist sehr dynamisch und steuert mit verschiedenen Myosinen die Bewegung der Zelloberfläche.

Einzelne Bereiche der Plasmamembran sorgen für die Ausbildung unterschiedlicher Strukturen auf der Grundlage von Aktin-Filamenten. Räumlich begrenzte Signale aus der Umgebung, die auf einen Teil der Zelloberfläche einwirken, können lokal eine Neustrukturierung der Aktin-haltigen Zellrinde bewirken. Umgekehrt kann die Zellrinde auch die Zellmembran stark beeinflussen und z.B. die Plasmamembran nach außen drücken und so lange, dünne Mikrospikes oder 
blattähnliche Lamelliopodien bilden. Auf diese Weise kann die Aktin-Zellrinde die Bewegung der gesamten Zelloberfläche beeinflussen.

Abbildung 2 (A) zeigt eine elektronenmikroskopische Aufnahme von negativ gefärbten AktinFilamenten. In (B) ist eine schematische Darstellung eines Aktin-Filaments zu sehen.

Die Aktin-Filamente sind also in der Lage, eine Zelle über eine Oberfläche zu bewegen und die jeweilige Form und Polarität der Zelle aufrecht zu halten.

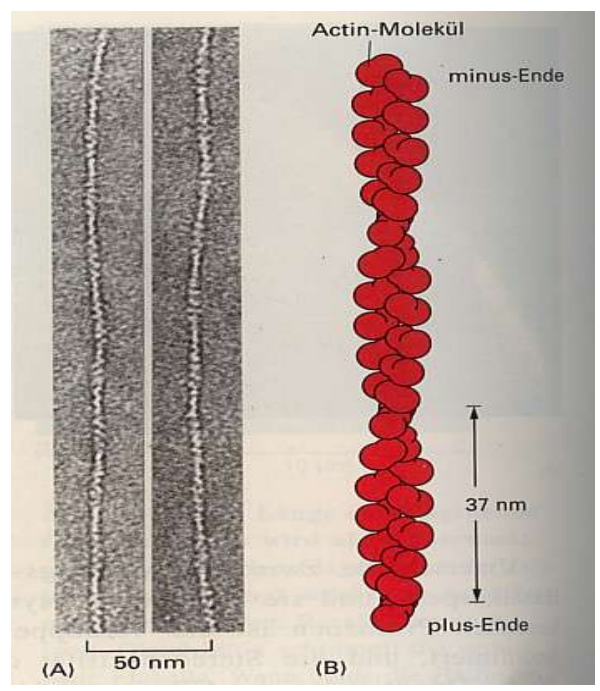

Abbildung: 2 Aktin-Filamente (Alberts et al., 1994)

Das Verhalten von Aktin auf verschiedene Chemikalien und die Auswirkungen auf die Zelle und ihre Bewegung wurde untersucht in Rotsch\&Radmacher, 2000.

Dynamische Fortsätze aus Actin-Filamenten auf der Oberfläche sind im Allgemeinen ein Kennzeichen von Tierzellen. Viele Gewebezellen können selbstständig über eine Unterlage wandern. Der Leitsaum eines kriechenden Fibroblasten streckt in regelmäßigen Abständen dünne, flächige Fortsätze aus, die Lamellipodien, die ein dichtes Geflecht aus Aktin-Filamenten enthalten (siehe Abb. 3).

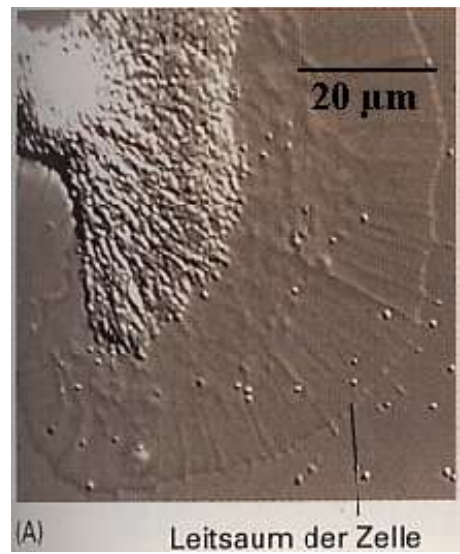

Abbildung 3: Leitsaum am Wachstumskegel einer Nervenzelle (Alberts et al., 1994) 
Das Beispiel einer sich bewegenden Keratozytenzelle (Fisch-Epidermiszellen) zeigt deutlich, dass in der abgeflachten Vorderkante der Zelle reichlich Aktin-Filamente vorhanden sind.

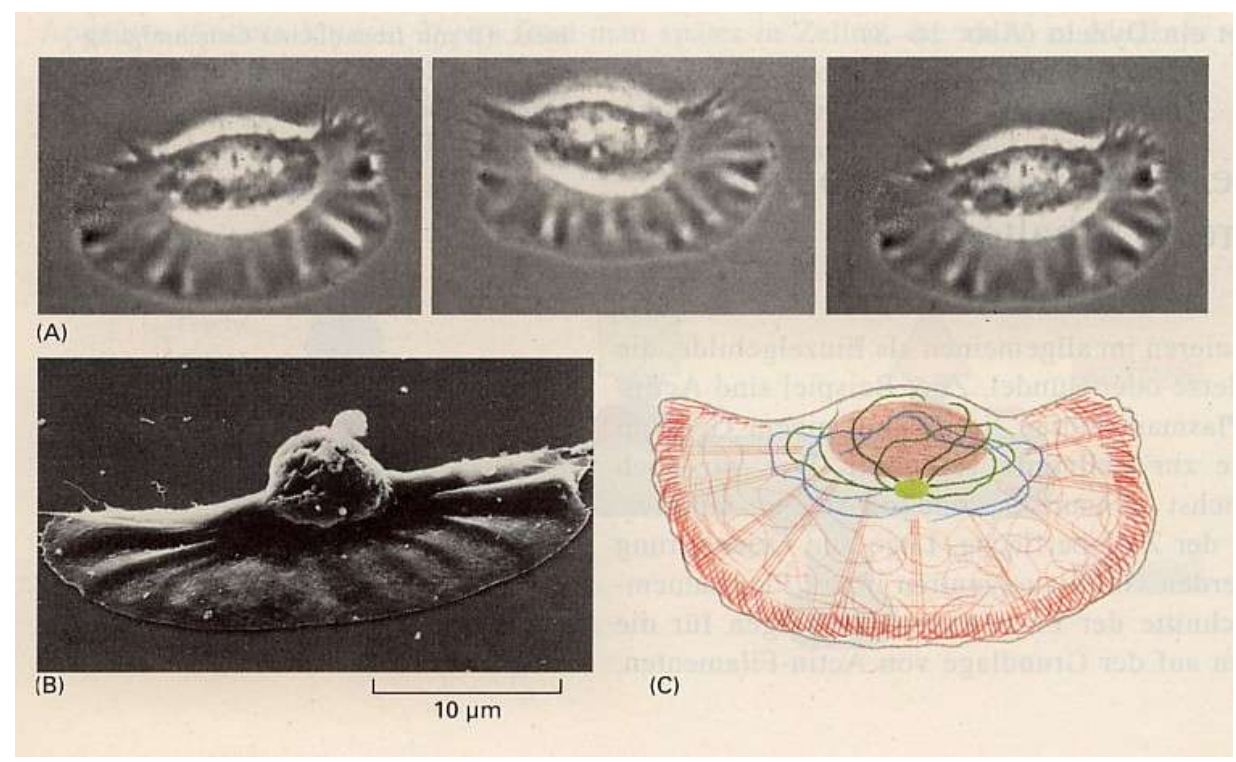

Abbildung 4: Wandernde Keratozyte (Alberts et al., 1994)

Abbildung 4 (A) zeigt lichtmikroskopische Aufnahmen einer wandernden Keratozytenzelle aufgenommen in 15 Sekunden Abständen. (B): Rasterelektronenmikropische Aufnahme; (C) räumliche Teilung des Cytoskeletts: deutlich erkennbar die roten Aktin-Filamente an der abgeflachten Vorderkante der Zelle - Mikrotubuli (grün) und Intermediärfilamente (blau) in der Nähe des Zellkerns.

Lamellipodien sind bewegliche Gebilde, die sich sehr schnell bilden und wieder verschwinden können. Das geschieht, indem das Aktin an der Vorderseite des Leitsaumes ständig polymerisiert, während es im Zellinneren hingegen fortlaufend depolymerisiert. Insgesamt liegt so ungefähr $50 \%$ des gesamten Aktins in unpolymerisierten Form vor. In einem „Tretmühlenmechanismus“ werden ständig Monomere von einem Ende (an dem sie depolymerisiert sind ) zum anderen Ende transportiert, an welchem diese dann wieder angelagert werden (polymerisieren)

(siehe Abb. 5).

Dieses dynamische Verhalten der Aktin-Filamente am Leitsaum ist entscheidend für die gerichtete Bewegung der Zellen.

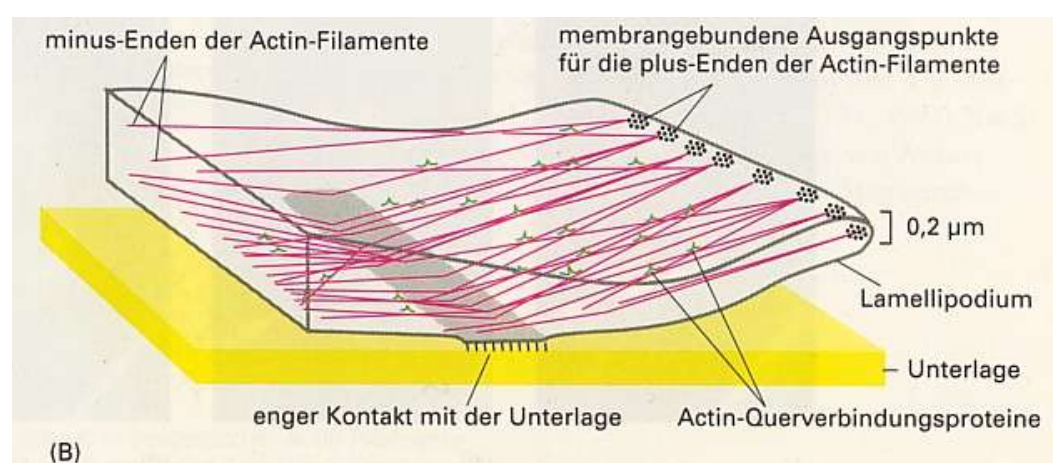

Abbildung 5: Schematische Darstellung der Aktin-Filamente in einem Lamellipodium (Alberts et al., 1994) 


\subsubsection{Das Motorprotein Myosin II}

Das Aktin ist an sehr vielfältigen Strukturen beteiligt. Die Grundstruktur der Aktin-Filamente ist dabei stets die gleiche. Verantwortlich für die Vielfältigkeit des Aktins ist die große Anzahl Aktinbindender Proteine, die sich an die Aktin-Filamente heften und deren Eigenschaften und Funktionen beeinflussen.

Eine Art dieser Proteine sind die Myosine, als Motorproteine sind sie für das ständige Polymerisieren und Depolymerisieren und somit für die Zellbewegung von großer Bedeutung.

Das in den Muskeln vorkommende Myosin gehört zu der Unterfamilie Myosin II.

Das Myosin II hat zwei Köpfe und einen langen, stabförmigen Schwanz, welcher aus zwei langen gleichartigen schweren Ketten besteht, die jeweils im Komplex mit zwei leichten Ketten vorliegen (siehe Abb. 6). Die beiden Köpfe besitzen sowohl ATPase- als auch Bewegungsaktivität. Stimuliert durch die Bindung zum Aktin hydrolysiert Myosin ATP zu ADP und $\mathrm{P}$ und bewegt sich mit der gewonnen Energie vom minus-Ende zum plus-Ende an den Aktion-Filamenten entlang.

Eine wichtige Aufgabe der Schwänze besteht darin, die Polymerisation zu bipolaren Filamenten $\mathrm{zu}$ ermöglichen. Dies ist entscheidend für die Funktion des Myosin II, die darin besteht, Gruppen entgegengesetzt orientierter Aktin-Filamente aneinander vorbeigleiten zu lassen. Myosin II. kommt in großen Mengen in der Zellrinde vor und ist wahrscheinlich verantwortlich für die Zugkräfte in den Streßfasern und einen großen Teil der Kraft, die die Zelloberfläche straff hält.

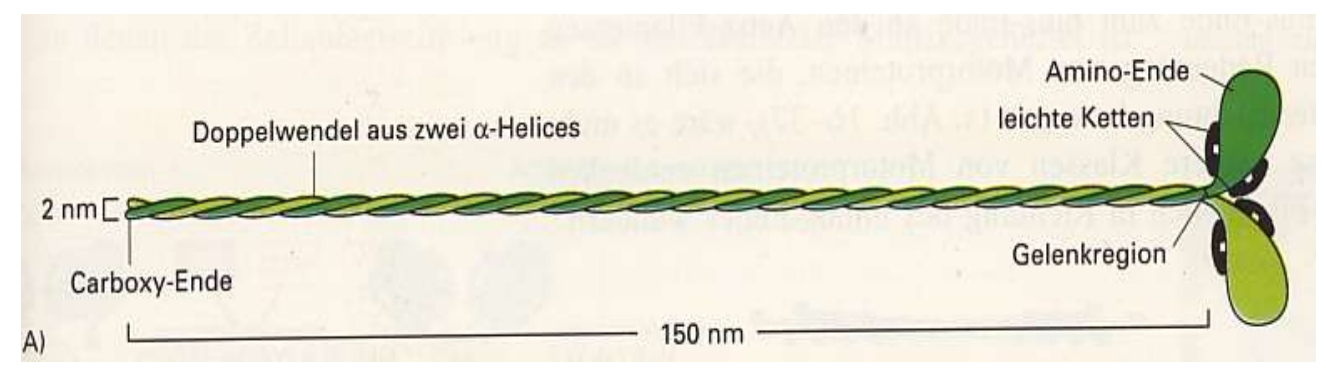

Abbildung 6: Schematische Darstellung eines Myosin II Proteins (Alberts et al., 1994)

\subsubsection{Zellbewegung}

Bis heute ist der genaue Prozeß der zellulären Bewegung unbekannt. Die Kriechbewegung von Tierzellen gehört zu den Phänomenen, die sich auf molekularer Ebene am schwersten erklären lassen. Verschiedene Teile der Zelle verändern sich gleichzeitig und es gibt kein erkennbares Bewegungsorganell. Mögliche Erklärungen sind osmotische Kräfte (hervorgerufen durch das Aktin-Netzwerk), temperaturabhängige Schwankungen oder die aktive Krafterzeugung durch das Myosin II, welches hier genauer betrachtet werden soll.

Alle bekannten Myosine hydrolysieren ATP und bewegen sich mit der dabei gewonnen Energie entlang der Aktin-Filamente. Sie heften sich dabei an entgegengesetzt orientierte Aktin-Filamente an und sorgen so für einen Aufbau von Spannung in den Filamenten (siehe Abb. 7). 


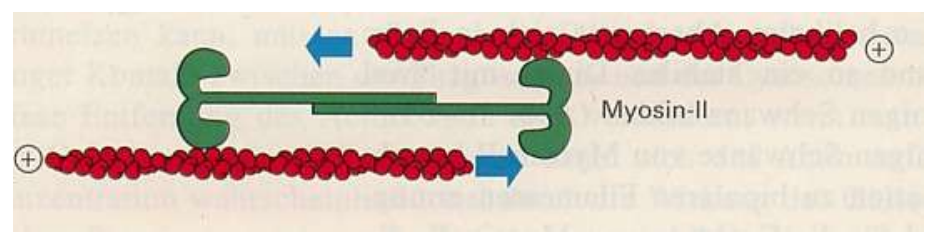

Abbildung 7: Myosin II sorgt für den Aufbau von Spannung (Alberts et al., 1994)

Innerhalb dieses Modells kann die Kriechbewegung von Tierzellen grob in drei Einzelstadien eingeteilt werden (siehe Abb. 8) (Stossel, 1993, Alberts et al., 1994):

- die Ausstülpung

- die Anheftung

- der Zug

Bei der Austülpung werden Aktin-reiche Lamellipodien über das Substrat nach vorn gestreckt, die treibende Kraft ist hierbei wahrscheinlich die Polymerisation des Aktins im Leitsaum.

Anschließend folgt die Anheftung der Aktin-Filamente in der Zellrinde an die Unterlage. Bei Fibroblasten ist dies mit den Enden der Streßfasern assoziiert. Für den Zug, der die Zelle nach vorne bringt, gibt es zwei unterschiedliche Erklärungsversuche: der vordere Teil zieht sich aktiv zusammen wie ein Muskel und zieht den hinteren Teil nach oder die Aktin-haltige Zellrinde schiebt sich durch Polymerisation der Aktin-Filamente vorwärts und die dabei entstehende Spannung zieht den hinteren Teil der Zelle nach.

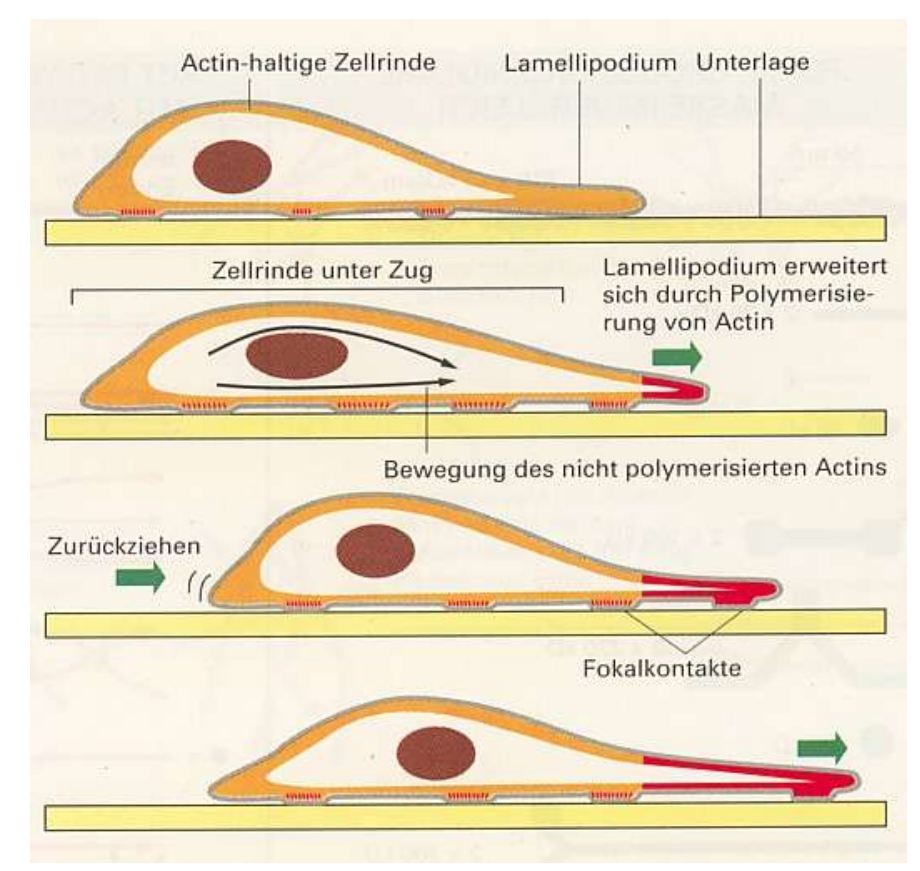

Abbildung 8: Hypothetisches Schema für die Fortbewegung einer kriechenden Zelle (Alberts et al., 1994) 


\subsubsection{Fibroblasten}

Wir betrachten nun die Fibroblasten, die in der vorliegenden Arbeit als Versuchszellen benutzt werden. Fibroblasten gehören zur Familie der Bindegewebszellen. Sie sind, wie alle Bindegewebezellen, auf die Ausscheidung einer kollagenen extrazellulären Matrix spezialisiert. Fibroblasten sind in den Bindegeweben im ganzen Körper verteilt; wird das Gewebe verletzt, wandern Fibroblasten in die Wunde, teilen sich und stellen große Mengen kollagener Matrix her, welche hilft, das beschädigte Gewebe zu reparieren. Die Möglichkeit an Oberflächen von Wunden zu existieren und ihre Fähigkeit als einzelne Zelle zu überleben, läßt sie zu einem bevorzugten Objekt der Zellforschung werden.

Der Hauptgrund für die Wahl von Fibroblasten war nicht ihre einfache Kultivierung, sondern ihre Fähigkeit der fortlaufenden Bewegung und der weitläufigen Ausbildung von Lamellipodien. Dies macht sie für die Messungen von Zellmechanik besonders attraktiv. Andere Zelltypen wie z.B. die angesprochenen Keratozyten wurden wegen $\mathrm{zu}$ hoher oder zu geringer Bewegungsaktivität nicht verwendet.

\subsection{Myosin-Leicht-Ketten-Kinase Inhibitoren}

Wie unter Abschnitt 1.2 beschrieben, wird die Spannung der Aktin-Filamente vermutlich durch das Motorprotein Myosin II aufgebaut. Wir wollen den Vorgang des Spannungsaufbaus nun etwas genauer betrachten. Eine Unterbrechung der Aktivität des Myosin II oder seiner Kopplung an das Aktin und die Reaktion der Zelle auf diesen Eingriff läßt Rückschlüsse auf die tatsächliche Bedeutung des Myosin II auf die Zellprozesse zu.

In den beiden Köpfen des Myosin II sind jeweils zwei leichte Ketten enthalten (siehe Abb. 6). Die beiden Ketten unterscheiden sich darin, dass eine während der Bewegung phosphoryliert. Das ist ein Vorgang, bei dem an eine Aminosäure-Seitenkette eines Proteins kovalent eine Phosphatgruppe angehängt wird. Dadurch kann es zu einer Änderung der Konformation (Aktivierung oder Deaktivierung) des Proteins kommen. Die reversible Protein-Phosphorylierung ist ein Kontrollmechanismus für Aktivität von Zell-Proteinen. Übertragen oder entfernt werden die Phosphatgruppen durch Proteinkinasen von ATP-Molekülen und durch ProteinPhosphatasen. Wird die Kette phosphoryliert kann sie mit einem Aktin-Filament in Verbindung treten und so für Bewegung sorgen. Wird sie hingegen dephosphoryliert, dissoziiert sich der Myosin II-Kopf vom Aktin-Filament und wird inaktiv. Katalysiert wird die Phosphorylierung durch das Enzym Myosin-Leichtketten-Kinase. Die Tätigkeit der Myosin-Leichtketten-Kinase wird durch $\mathrm{Ca}^{2+}$ reguliert, einem überall vorkommenden interzellulären Botenstoff. Angetrieben wird der ganze Zyklus durch die Energiegewinnung aus der Hydrolysierung von ATP zu ADP. Auch die Hydrolysierung wird durch ein Enzym katalysiert, der Myosin-ATPase. 


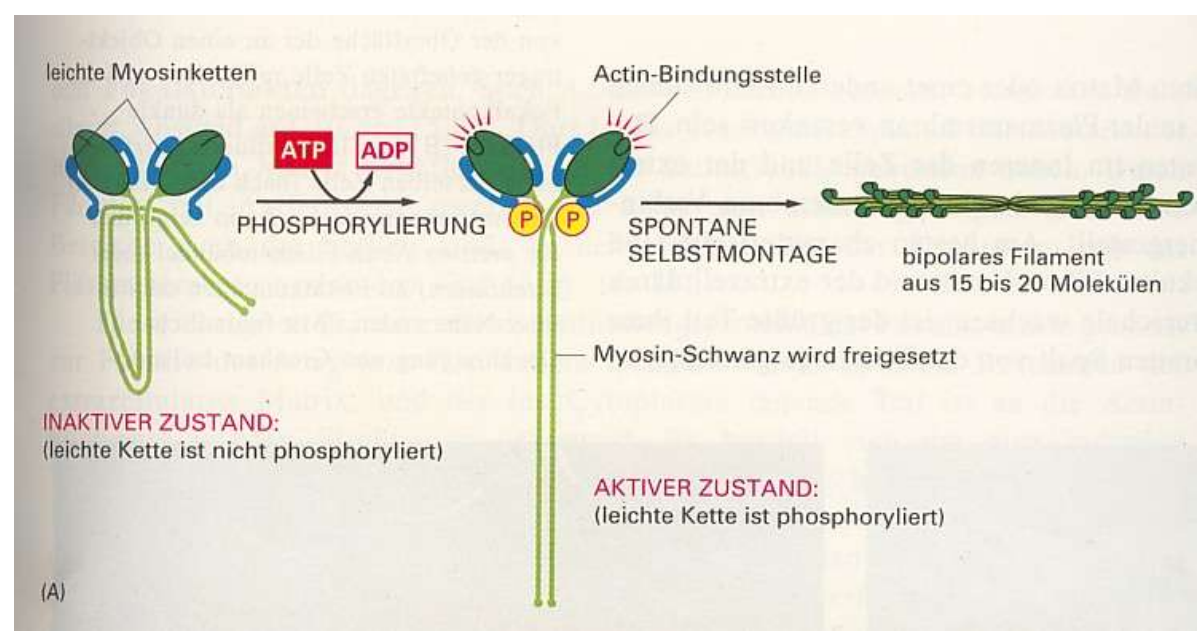

Abbildung 9: Phosphorylierung von Myosin II Proteinen (Alberts et al., 1994)

In Abbildung 9 wird die Bedeutung der Phosphorylierung veranschaulicht. Nachdem eine der beiden leichten Ketten phosphoryliert wurde, ändert sich die Konformation dieses Kopfes und Aktin-bindende Stellen werden freigelegt und der Myosin-Schwanz löst sich vom Kopf. Dadurch kann sich das Myosin II an Aktin-Filamente anlagern und mit anderen Myosin-Molekülen kurze biopolare Filamente bilden.

Inhibitoren sind Hemmstoffe, die ausgesuchte zelluläre Prozesse auf verschiedene Arten reversibel unterbinden. Die für unsere Experimente ausgewählte Chemikalie BDM (siehe Kapitel 2) wirkt als Inhibitor für die Myosin-ATPase und verhindert so die nötige Energiezufuhr für die Phosphorylierung. Der zweite Inhibitor, ML-7 wirkt spezifischer direkt hemmend auf die Myosin-Leichtketten-Kinase. Dadurch wird die Phosphorylierung verhindert und der Myosin IIKopf führt nicht die Konformationsänderung durch, die für eine Bindung an ein Aktin-Filament nötig wäre.

\subsection{Rasterkraftmikroskopie}

Bevor wir auf die Arbeitsweise des Rasterkraftmikroskopes (engl. „Atomic Force Microscope, AFM) eingehen, werden kurz andere Methoden hochauflösender Mikroskopie erwähnt, um sie später mit dem AFM vergleichen zu können.

Mit Lichtmikroskopen ist eine Vergrößerung bis etwa 1.000fach möglich.

Ein Elektronenstrahl besitzt eine wesentlich geringere Wellenlänge als Licht, damit können Vergrößerungen bis zum 100.000fachen erzeugt werden. Grundsätzlich werden zwei elektronenmikroskopische Verfahren unterschieden: Rasterelektronenmikroskopie und Transmissionselektronenmikroskopie. Bei der Rasterelektronenmikroskopie wird die Oberfläche von Untersuchungsobjekten mit einem Elektronenstrahl abgetastet (gerastert). Bei der Transmissionselektronenmikroskopie werden Ultradünnschnitte eines Objektes von Elektronen durchstrahlt. Für die Transmissionselektronenmikroskopie sind sehr dünne $(60-70 \mathrm{~nm})$ Proben und innerhalb des Mikroskops ein Vakuum erforderlich, damit der Elektronenstrahl die Probe durchdringen kann und nicht von Gasmolekülen absorbiert wird. Für das Rasterelektronenmikroskop ist eine Oberfläche nötig, die Elektronen reflektiert. Präparate werden deshalb mit einer Gold- oder Kohlenstoffschicht bedampft.

Aufgrund der benötigten Randbedingungen dieser Mikroskope ist eine Untersuchung lebender Proben unmöglich. 
Eine ganz neue Art von Mikroskopen bilden die Rastersondenmikroskope, die ihren Ursprung in der Raster-Tunnel-Mikroskopie (RTM) haben. Mit dem RTM werden die Tunnelströme zwischen der Probe und einer in deren Nahfeld positionierten Sonde detektiert (Binnig\&Rohrer, 1982). Das Prinzip der Rastersondenmikroskopie ist bei allen Verfahren gleich, eine Spitze (Sonde) tastet die Oberfläche der Probe in sehr geringem Abstand ab und sammelt dabei Signale, die durch einen Rechner in Bilder umgewandelt werden.

Weil das RTM ebenfalls auf leitende Oberflächen beschränkt ist, wurde die Entwicklung des AFM vorangetrieben. Mit dem AFM sind Untersuchungen nicht-leitender Oberflächen und Messungen in Flüssigkeiten und damit unter beinahe physiologischen Bedingungen möglich (Binnig et al., 1986; Drake et al., 1989; Radmacher et al., 1992; Fritz et al., 1994; Radmacher et al., 1994 I).

Bei dem AFM werden Wechselwirkungskräfte zur Abbildung ausgenutzt, die anziehenden „van der Waals Kräfte“ und die abstoßenden „Coulomb Wechselwirkungskräfte“. Diese Kräfte wirken auf eine an einem Federbalken aufgehängte Meßspitze. Die durch diese Kräfte bewirkte Verbiegung der Feder wird mit einem Laserstrahl, der auf die Rückseite der Feder fokusiert wird, ausgemessen (siehe Abb. 10). Die jeweilige Kraft zwischen Probe und Spitze wird durch die Apparatur konstant gehalten, somit kann die z-Position der Spitze registriert werden. Wird die Spitze nun in $x$-y-Richtung bewegt, so erhält man für jeden Punkt eine Information über die zPosition der Spitze und somit ein 2-dimensionales Höhenbild der Oberfläche.

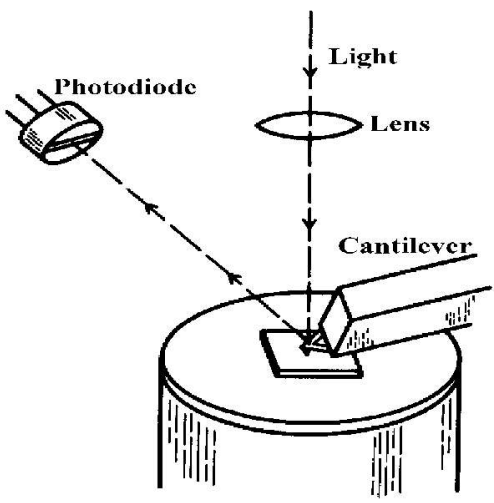

Abbildung 10: Schematischer Aufbau des AFM

Bei dem Kraftmikroskop gibt es zwei verschiedene Betriebsarten: den Kontakt- und den NichtKontakt-Modus. Im Kontakt-Modus befindet sich die Feder in mechanischen Kontakt mit der Probe während beim Nicht-Kontakt-Modus die Spitze so positioniert wird, dass sie die Elektronenhülle der Probe nicht durchdringt. Ein Mittelweg beider Modi stellt der TappingModus dar, bei dem die Spitze innerhalb einer Schwingungsperiode einmal kurz die Oberfläche berührt.

Da mit den AFM Messungen in Flüssigkeiten und unter beinahe physiologischen Bedingungen möglich sind und die zu untersuchenden biologischen Proben nicht zwangsläufig beschädigt oder zerstört werden, ist es ein ideales Werkzeug für die Untersuchung von lebenden Zellen (Radmacher, 1997; Rotsch\&Radmacher, 2000), Membranen (Haydon et al., 1996; Kolb et al., 1998) und Proteinen (Fritz et al., 1994; Walters et al., 1997). 
Untersuchungen von Zellen mit dem AFM wurden schon in zahlreichen Arbeiten durchgeführt u.a. an Blutzellen (Radmacher et al., 1996), Kardiomyozyten (Herzzellen) (Hofmann et al., 1997), Fibroblasten (Radmacher et al., 1994; Pelham\&Wang, 1997; Rotsch et al., 1999; Lo et al. 2000; Rotsch\&Radmacher, 2000; Schäfer et al. in Press), Osteoblasten (knochenbildene Zellen) (Domke et al., 2000) und MDCK Zellen (Nierenzellen) (Hoh\&Schoenberger, 1994; A-Hassan et al., 1998,).

Es ist also dem AFM möglich, qualitativ elastische Eigenschaften von lebenden Zellen zu bestimmen und auf diese Weise Informationen über das Cytoskelett zu bekommen. 


\section{Material und Methoden}

\subsection{Zellen}

\subsubsection{Zelllinien}

In der vorliegenden Arbeit wurden die Fibroblasten-Zelllinien „NRK“ und „3T3“ verwendet, die aus normalen Nierenzellen der Ratte bzw. aus den Embryozellen der Swiss Albino Maus hergestellt werden. Aus Körperzellen von Tieren und Menschen werden sog. Primärkulturen angelegt und subkultiviert. Diese Kulturen aus „normalen“ Zellen haben den großen Nachteil, der begrenzten Lebensdauer von wenigen Wochen. Bei jeder Teilung einer Zelle werden die Abschnitte an den Enden der Chromosomen - Telomere - ein wenig kürzer, bis eine Teilung nicht mehr möglich ist. Tumorzellen dagegen besitzen das Enzym Telomerase, welches die Chromosomenenden immer wieder erneuert. Primärkulturen wurden durch z.B. Zugabe von Viren zu Tumorzellen transformiert und erhalten so eine verlängerte Lebenserwartung von einigen Monaten und eine erhöhte Teilungsrate.
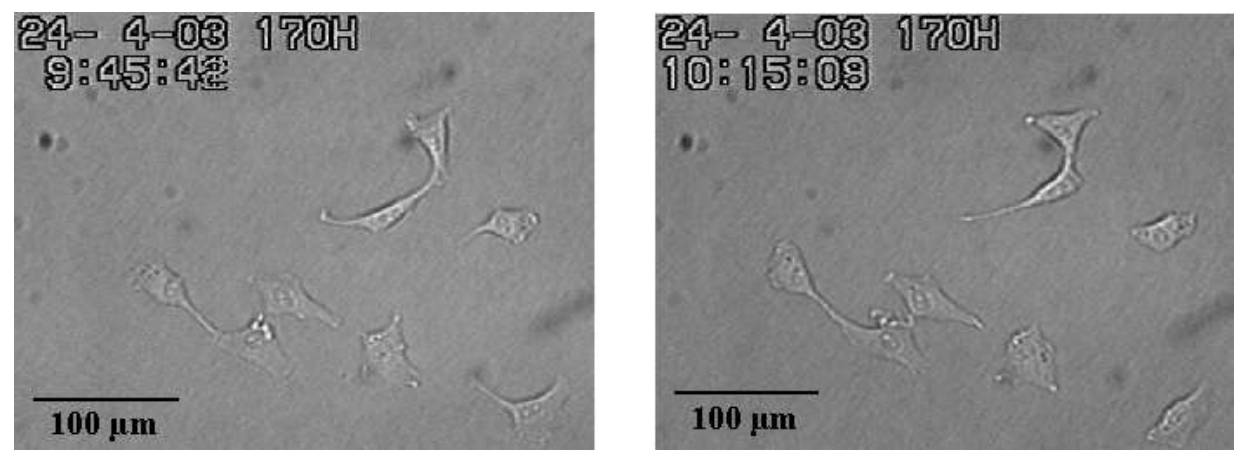

Abbildung 11: Aufnahmen von NRK Zellen über einen Zeitraum von $30 \mathrm{~min}$
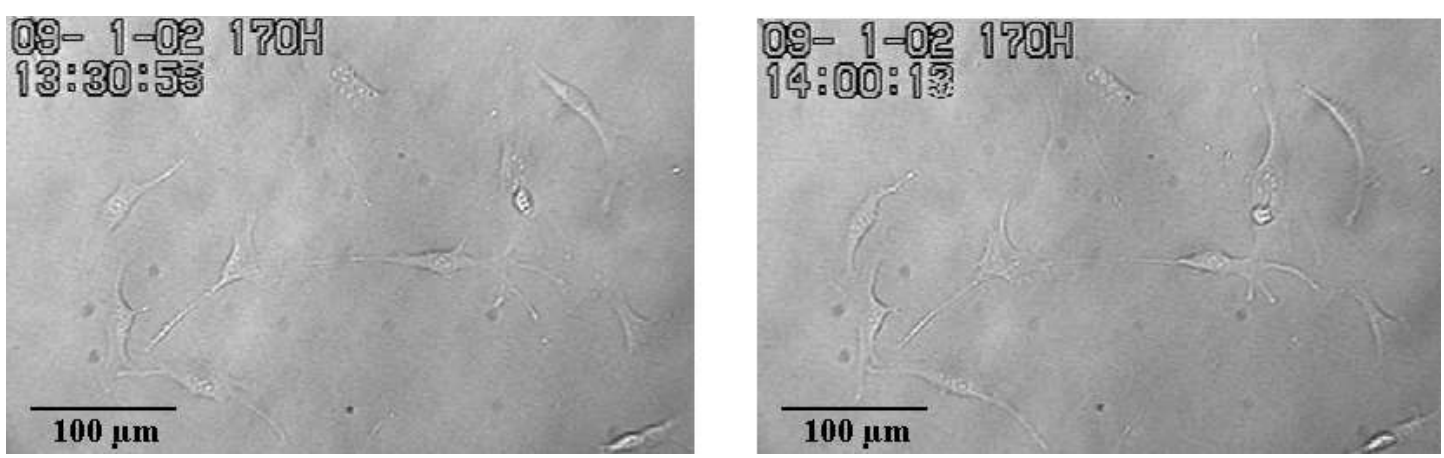

Abbildung 12: Aufnahmen von 3T3 Zellen über einen Zeitraum von $30 \mathrm{~min}$

Fertig transformierte Zelllinien jeder Art können aus Zellsammlungen bestellt werden. Die Zelllinien, die wir benutzten, stammen von „European Collection of cell cultures“

(http://www.ecacc.org.uk/) :

- NRK : ecacc Nr. 86032002

- 3T3 : ecacc Nr. 85022108 
Abbildung 11 und 12 zeigen Bilder aus dem optischen Mikroskop. Zu sehen sind die NRK bzw. 3T3 Zellen in 200 facher Vergrößerung. Deutlich ist die ausgedehnte unregelmäßige Morphologie der Zellen und Lamellipodien, die am vorderen Teil der Zelle liegen, zu erkennen. Diese dienen als Indikatoren für die Bewegung. Länge und Breite der Zellen sind abhängig von dem Grad der Ausdehnung. Die Dimensionen liegen aber im Bereich von $15-30 \mu \mathrm{m}$. Zwischen den jeweils linken und rechten Abbildungen liegt ein Beobachtungszeitraum von $30 \mathrm{~min}$. Die Änderung der Morphologie und die von den Zellen zum Teil zurückgelegte Wegstrecke ist trotz der schlechten Bildqualität deutlich zu erkennen.

\subsubsection{Präparation}

\section{Lagerung}

Die Zellen werden vom Großhandel in einer Styroporkiste geliefert, wo sie mit Trockeneis $\left(\mathrm{CO}_{2}\right)$ auf $-80^{\circ}$ Celsius gehalten werden.

Für die längere Lagerung werden die Zellen in einem 40 Liter Cryo-Tank in flüssigem Stickstoff bei $-135^{\circ}$ Celsius eingefroren. Dazu werden die Zellen mit Nährmedium $+10 \%$ DMSO $+20 \%$ FCS in ein $2 \mathrm{ml}$ Cyro-Röhrchen (Nunclon, Naperville, IL) gegeben und in einer Halterung in dem Cyro-Tank versenkt. Das normalerweise für die Zellen tödliche DMSO wird in das Medium gegeben, da es beim Einfrieren die Bildung von Eiskristallen im Wasser verhindert, welche die Zellmembranen ansonsten beschädigen würden. Um die Temperatur konstant zu halten, müssen alle 4 Wochen 20 Liter Stickstoff nachgefüllt werden, da durch Verdampfung Flüssigkeit verloren geht.

Es ist wichtig, die Zellen langsam einzufrieren, da es im Wasser sonst trotz der Zugabe von DMSO zu Kristallbildungen kommt. Um einen langsamen Einfriervorgang zu ermöglichen, werden die Zellen zuerst in einem mit Schaumstoff isolierten Gefäß 10-12 Stunden lang der Gasphase des Stickstoff ausgesetzt (- $80^{\circ}$ Celsius). Anschließend werden sie dann in den CyroTank versenkt. Dies ermöglicht bei regelmäßigem Nachschub von flüssigem Stickstoff eine jahrelange Lagerung der Zellen.

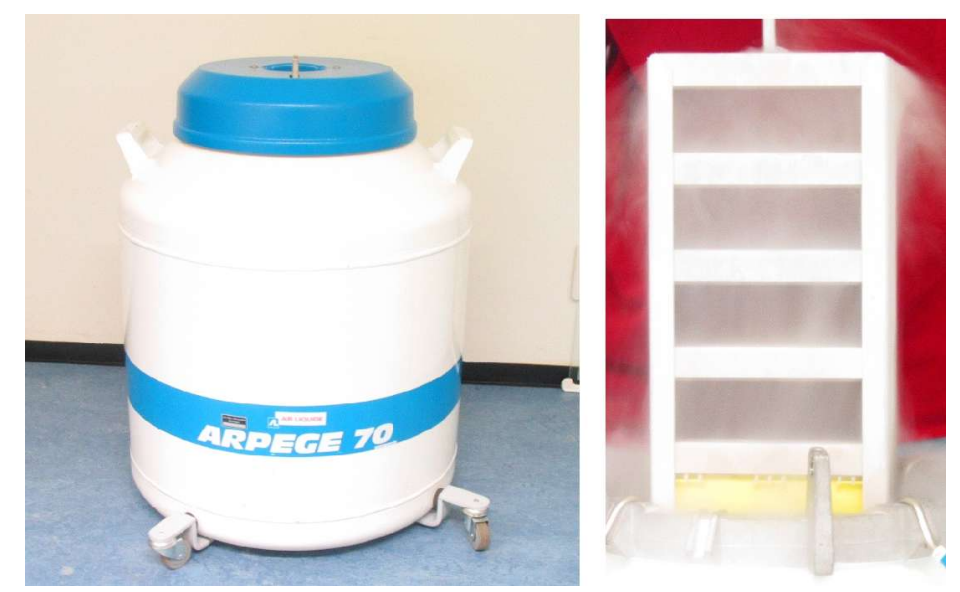

Abbildung 13: links: Cryo-Tank, rechts: Halterung für die Cryo-Röhrchen 


\section{Auftauen}

Im Gegensatz zum Einfrieren muss das Auftauen schnell durchgeführt werden, damit die Zellen nicht unnötig lange dem schädlichen DMSO ausgesetzt sind. Dazu werden die Cyro-Röhrchen mit den Zellen in ein $37^{\circ}$ Celsius Wasserbad gelegt. Ist die Probe aufgetaut, werden die Zellen mit ihrem oben beschriebenen Medium $\left(1,5 \mathrm{ml}\right.$ mit $\sim 10^{6}$ Zellen) in ein $15 \mathrm{ml}$ Zentrifugenröhrchen gegeben und mit $10 \mathrm{ml}$ - auf $37^{\circ}$ Celsius vorgewärmten - Nährmedium aufgefüllt. 5 Minuten lang wird die Probe mit 1000 U/min bei Raumtemperatur zentrifugiert, um das DMSO aus der Probe entfernen zu können.

Die folgenden Arbeitsschritte werden in einer vertikalen sterilen Werkbank von Heraeus Typ HS 18 (Hanau, Deutschland) durchgeführt. Diese Werkbank verhindert durch Luftzirkulation und Filteranlagen, dass Verunreinigungen durch die Luft in den Arbeitsbereich eindringen können. Mit einer Pasteur-Pipette wird nun das Medium mit dem DMSO abgesaugt und durch $10 \mathrm{ml}$ neues Medium ersetzt. Die Zellen werden durch mehrmaliges Pipettieren resuspendiert und dann in eine T-75 Flasche (Trans Tech Publications Inc., Zürich, Schweiz) ausgesetzt. Das Medium ist mit 10\% FCS und 1\% L-Glutamin angereichert, die für das Wachstum der Zellen notwendig sind. $\mathrm{Um}$ das Wachstum von Bakterien $\mathrm{zu}$ verhindern wird außerdem 1\% Penicillin/Streptomycin dazu gegeben. Das verbrauchte Medium muss alle 2-3 Tage gewechselt werden. Um den Zellen eine optimale Umgebung für ihr Wachstum zu geben, werden die Zellen in einem Brutschrank (Heraeus) bei 95\% Luftfeuchtigkeit (um das Verdampfen der Flüssigkeit zu verhindern), 5\% $\mathrm{CO}_{2}$-Atmossphäre (damit der PH-Wert des Mediums stabil bleibt) und $37^{\circ}$ Celsius (Körpertemeratur) aufbewahrt.
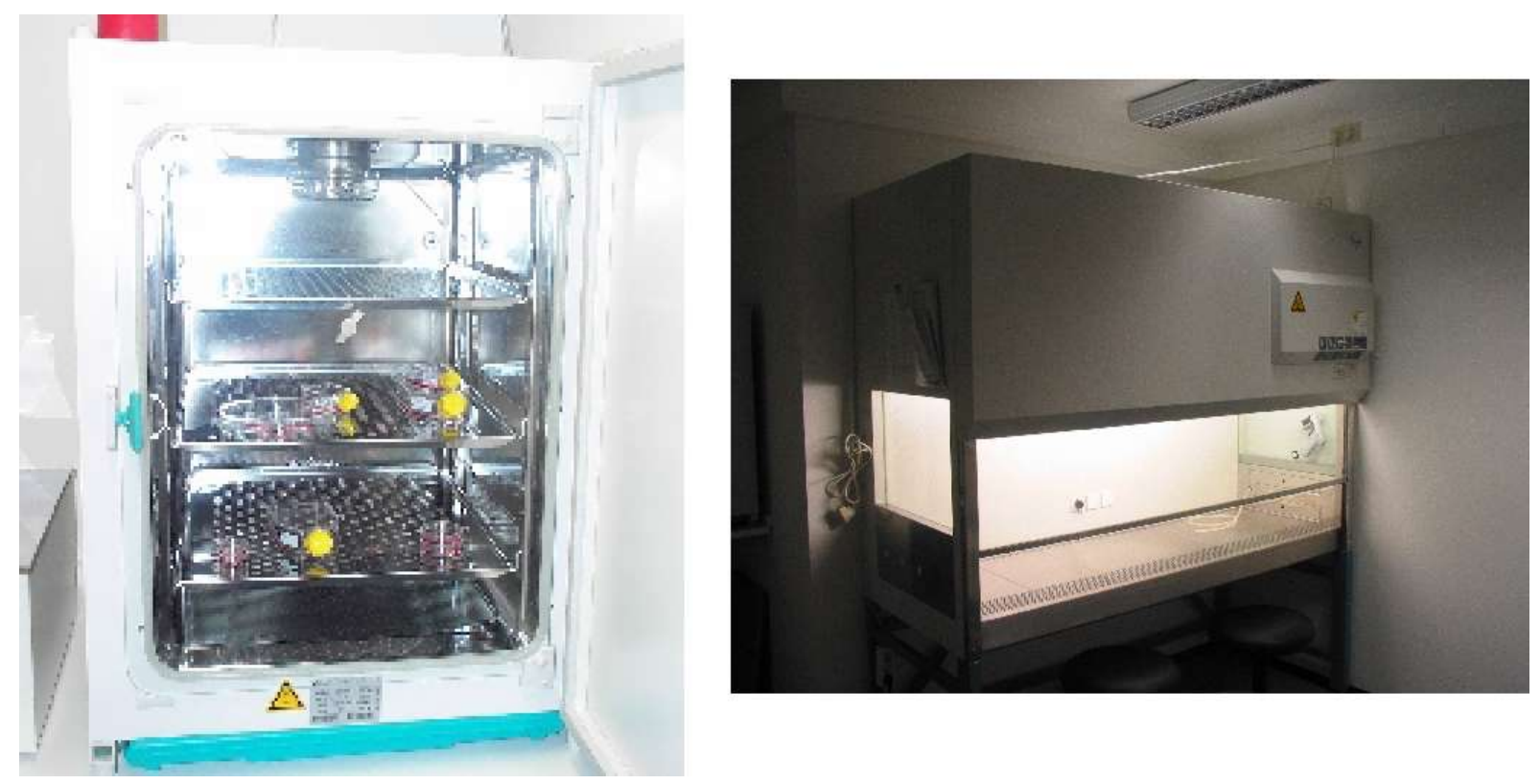

Abbildung 14: links: Brutschrank für die Zellen, rechts: sterile vertikale Werkbank

\section{Subkultivieren}

Die Zellen haften sich am Boden des Probenbehälters fest und wachsen als Monolayerkultur. Alle 4-5 Tage haben sich die Zellen durch Teilungen so weit vermehrt, dass sie über $70 \%$ des Behälterbodens bedecken. Dadurch würden sie nicht mehr mit genügend Substrat versorgt werden und könnten sich morphologisch verändern. Für Experimente könnten sie in diesem Stadium nicht mehr verwendet werden.

Unter der sterilen Werkbank wird nun das alte Medium abgesaugt, anschließend werden die Zellen mit PBS „gewaschen“ (von Mediumresten gereinigt). Zum Ablösen der Zellen vom 
Plastikboden wird nun $1 \mathrm{ml}$ Trypsin auf die Zellen gegeben. Nach einer Einwirkzeit von 1 Minute wird das Trypsin wieder entfernt. Es ist wichtig, dass das Trypsin nicht zu lange auf die Zellen einwirkt, da es als proteinspaltendes Enzym schädlich für die Zellmembranen ist. Nachdem die Zellen vom Boden abgelöst wurden, werden sie in $10 \mathrm{ml}$ neuem Medium resuspendiert und in neuen Flaschen ausgesetzt. Für eine T-75 Flasche werden $1 \mathrm{ml}$ dieser Probe auf $10 \mathrm{ml}$ Medium gegeben.

So können die Zellen über mehrere Wochen im wachsenden Zustand gehalten werden. Es ist darauf zu achten, dass jede neue Flasche gleichzeitig eine neue Passage („Generation“) ist.

\section{Aussetzen in Petrischalen}

Wir haben festgestellt, dass die Behandlung mit Trypsin die Bewegungseigenschaften der Zellen nachteilig beeinflußt, deshalb wird beim Aussetzen der Zellen für Messungen auf Trypsin verzichtet.

Zum Ablösen wird stattdessen ein Siliconschraber (Trans Tech Publications Inc., Zürich, Schweiz) benutzt. Alle anderen Arbeitsschritte sind mit dem Subkultivieren identisch. In die mit $2 \mathrm{ml}$ Medium gefüllte Petrischalen (Nunclon, Naperville, IL) werden 1-2 Tropfen Zellen in Medium aus der Pipette (ca. 50-100 $\mu$ l, das entspricht 5*10 Zellen) gegeben. Nach 12 Stunden sind die Zellen wieder auf dem Boden adhäriert (d.h. ausgebreitet und gefestigt) und können nun für die Messungen verwendet werden.

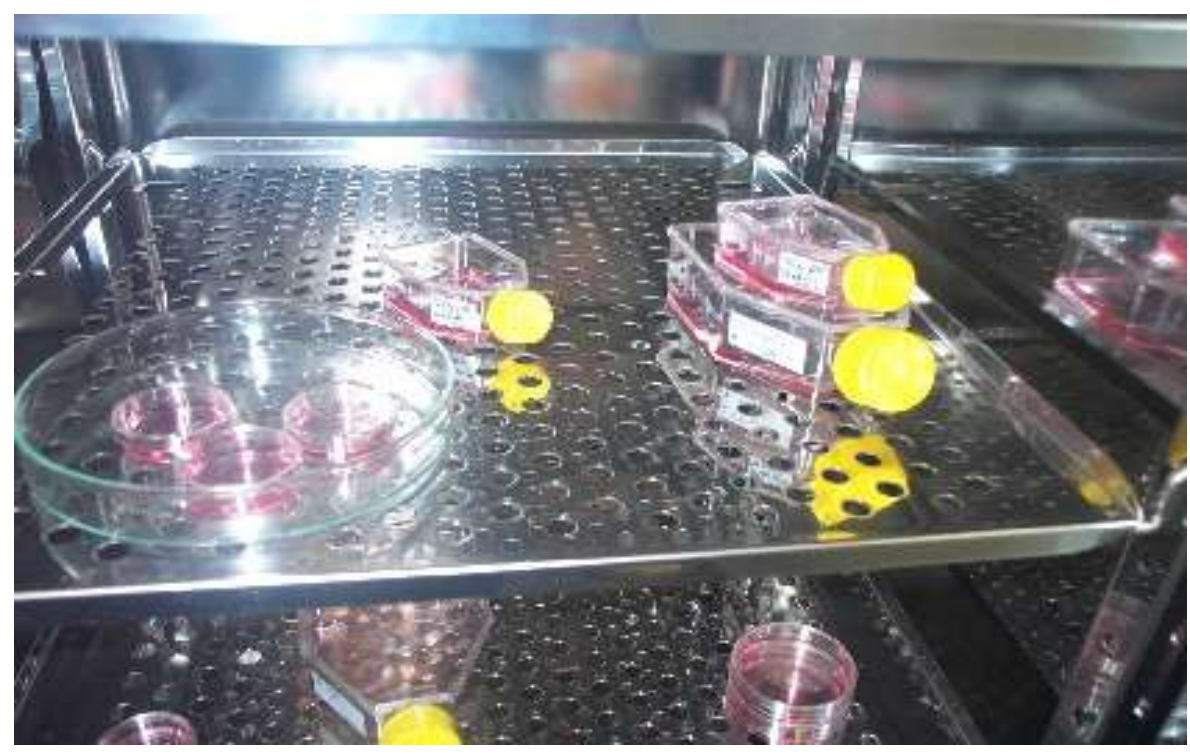

Abbildung 15: T-25, -75 Flaschen und Petrischalen gefüllt mit Nährmedium im Brutschrank 


\section{Materialien}

Für beide Zelllinien wurden folgende Chemikalien verwendet, deren Anwendung in den letzten Abschnitten erläutert wurde:

1. Dulbecco's modified Eagle’s medium (DMEM), Nährmedium der Zellen Biochrom Seromed Nr. F0435

2. Penicillin/Streptomycin,

Biochrom Seromed Nr. A2213

3. L-Glutamin,

Biochrom Seromed Nr. K0283

4. Fetal Calf Serum (FCS), enthält Wachstumsfaktoren und Hormone

Biochrom Seromed Nr. S0115

5. Trypsin $(0,05 \%$ in PBS),

Biochrom Seromed Nr. L2143

6. Phosphat-gepufferte Kochsalzlösung (phosphate-buffered saline, PBS - PH: 7,4)

Sigma (als Tabletten) Nr. P4417

7. Dimethylsulfoxid (DMSO)

Sigma Nr. D2650

Als Hilfsmittel und Werkzeuge wurden die normalen Laborgegenstände verwendet: Pinzetten (Größe 2 o. 3), Gilson-Pipetten (1000 $\mu \mathrm{l})$ mit entsprechenden Spitzen, $35 \mathrm{~mm}$ Plastikpetrischalen von Nunclon T-75 und T-25 Plastikflaschen von Trans Tech Publications Inc..

Weitere Informationen über die Arbeit in der Zellkultur sind in dem Buch „Zell- und Gewebekultur“, Spektrum Akademischer Verlag zu finden.

\subsection{Inhibitoren}

Um das Ziel der Arbeit - die Erforschung der Auswirkung von Myosin II auf das AktinNetzwerk und damit auf die Zellspannung - zu erreichen, wurden zwei Chemikalien ausgewählt, die die Aktivierung des Motorproteins Myosin II verhindern.

Aus der Literatur sind die beiden Myosin-Light-Chain-Kinasen (MLCK) Inhibitoren 2,3Butanedione 2-Monoxime (BDM, $\mathrm{C}_{4} \mathrm{H}_{7} \mathrm{NO}_{2}$ ) und (5-Iodonaphthalene-1-sulfonyl) homopiperazine, HCL (ML-7, $\mathrm{C}_{15} \mathrm{H}_{17} \mathrm{IN}_{2} \mathrm{O}_{2} \mathrm{~S} \bullet \mathrm{HCL}$ ) bekannt. Weitere Informationen über BDM sind in den Vorgängerarbeiten Saitoh et al., 1987; Krarup et al., 1998; Kelley et al. 2000 bzw. für ML-7 in Higuchi\&Takemori, 1988; Phillips\&Altschuld, 1996 und in Pelham\&Wang, 1999 nachzulesen.

Die Inbibitoren sind bei Calbiochem (http://www.calbiochem.com) unter folgenden Bestellnummern erhältlich:

- BDM : Cat. No. 203984

- ML-7 : Cat. No. 475880 


\subsubsection{BDM}

Das BDM wird in einer Menge von $500 \mathrm{mg}$ geliefert und kann bei $4^{\circ}$ Celsius 2 Jahre gelagert werden.

Es wurde eine Stammlösung angesetzt in der 1,011 g (Molekular Gewicht: 101.1) in $50 \mathrm{ml}$ Medium gegeben wurde. Die sich daraus ergebene Lösung mit einer Konzentration von $200 \mathrm{mM}$ wurde in $1 \mathrm{ml}$-Portionen in Eppendorf Reaktionsgefäße für eine längere Lagerung bei $-18^{\circ}$ Celsius eingefroren.

Für die AFM-Versuche mit den Zellen wurden dann für die NRK $150 \mu 1$ und für die 3T3 35-75 $\mu \mathrm{l}$ entnommen und in die mit $1 \mathrm{ml}$ Medium gefüllte Petrischale gegeben. Daraus ergibt sich eine Versuchskonzentration des BDM von $15 \mathrm{mM}$ für die NRK und 7-15 mM für die 3T3.

Während des Zeitraumes der Messungen wurden drei verschiedene Stammlösungen angesetzt, um Einflüsse durch längere Lagerung oder schlechte Grundsubstanz anzuschließen.

\subsubsection{ML-7}

Das ML-7 wird in der geringen Menge von $1 \mathrm{mg}$ geliefert. Es muß geschützt vom Licht aufbewahrt werden und ist in diesem Zustand bei $4^{\circ}$ Celsius 2 Jahre haltbar. Calbiochem gibt vor, dass das ML-7 in DMSO und 50\% Ethanol $(10 \mathrm{mM})$ gelöst werden soll. Um die Zellen möglichst vor schädlichen Einflüssen zu bewahren, haben wir auf das Ethanol verzichtet und durch Vorversuche die kritische Menge von DMSO herausgefunden (siehe Abschnitt 3.1). Daraus ergab sich, dass wir $1 \mathrm{mg}$ ML-7 in $110 \mu \mathrm{l}$ DMSO aufgelöst und sie anschließend 1:10 verdünnt haben. Die resultierende Stammlösung von $1 \mathrm{ml}$ besaß eine Konzentration von 200 $\mu \mathrm{M}$. Die einzelnen Gefäße wurden mit Aluminiumfolie lichtdicht umwickelt und im Kühlschrank gelagert. Calbiochem gibt eine Haltbarkeit der Stammlösung bei $4^{\circ}$ Celsius von 6 Monaten an.

Für die AFM-Versuche mit den Zellen wurden dann für die NRK $65 \mu \mathrm{l}$ und für die 3T3 50-60 $\mu \mathrm{l}$ entnommen und in die mit $1 \mathrm{ml}$ Medium gefüllte Petrischale gegeben. Daraus ergibt sich eine Versuchskonzentration des ML-7 von 13-14 $\mu \mathrm{M}$ für die NRK und 10-14 $\mu \mathrm{M}$ für die 3T3.

Zwei Stammlösungen wurden während des Meßzeitraums angesetzt, um wie bei dem BDM Einflüsse durch längere Lagerung auszuschließen. 


\subsection{Mikroskope}

\subsubsection{Optische Mikroskope}

Während der Zellkultur wurde für Zellbeobachtungen vor und nach den Präparationen ein Axiovert 25 (Zeiss, Germany) verwendet. Es besitzt eine Vergrößerung von einem Faktor 50-320 und verschiedene Kontrastfilter und ist so für die Kontrolle des Zellwachstums gut geeignet.

Für den AFM-Aufbau benutzen wir das Axiovert S 100 (Zeiss, Germany). Der große Vorteil der Axiovert Mikroskope ist die Möglichkeit, die Probe von unten zu beobachten und auf der Oberseite eine Plattform aufzubauen, welche es dem Benutzer ermöglicht, die zu untersuchende Probe und alle nötigen Geräte dort zu positionieren. Der Vergrößerungsfaktor kann bis auf 400 eingestellt werden, so dass auch kleinere Details der Zelle gut zu erkennen und so mit dem AFM anzufahren sind. Die Axiovert Mikroskope haben mehrere Ausgänge, so dass es möglich ist, einen Videorecorder und eine Kamera anzuschließen. Dies machte eine Videomikroskopie (siehe Kapitel 3) und eine Beobachtung der Zellen während der AFM-Messung möglich. Weitere Details über die Mikroskope sind auf der Homepage von Zeiss unter http://www.zeiss.de zu finden.

Die verwendete Kamera war eine „High Performance CCD Kamera“ (Chromaphor, Germany; http://www.chromaphor.de); zusammen mit dem SVHS Time Lapse Video Recorder AGTL700 von Panasonic (Panasonic, Germany; http://www.panasonic.de) war es möglich Zeitrafferaufnahmen zu machen. Der Videorecorder macht alle 1,12 Sekunden eine Aufnahme, das entspricht einem Zeitraffer-Faktor von 57. 18 Stunden Meßzeit werden in einem ca. 20 Minuten Film zusammengefasst. Dies erlaubt einen Überblick der Zellbewegung, die zu langsam von statten geht $(\mu \mathrm{m} /$ Stunde), um für den Menschen im Detail erfassbar zu sein.
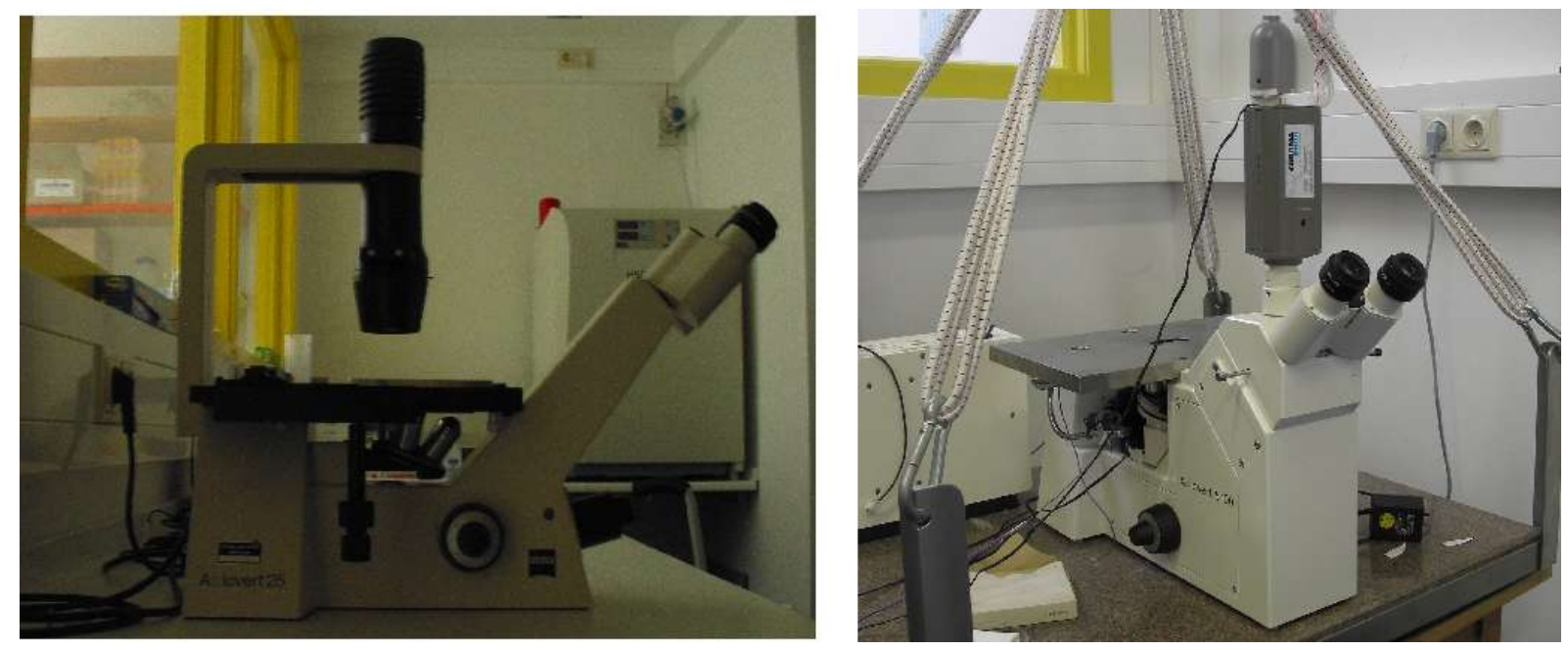

Abbildung 16: links: Axiovert 25 im Zellkulturlabor rechts: Axiovert S 100 mit Metallplattform und Kamera 


\subsubsection{Atomic Force Microscope (AFM)}

Das grundsätzliche Prinzip des AFM wurde im Abschnitt 1.4 erläutert. In diesem Kapitel soll nun nach der theoretischen Betrachtung der reale Versuchsaufbau beschrieben und seine wichtigsten Komponenten vorgestellt und erklärt werden.

\section{Cantilever}

Direkt über der Probe und während der Messung in physikalischen Kontakt ist der Cantilever oder Blattfeder positioniert. Bei der Messung kommt es zu einer mechanischen Wechselwirkung der Feder mit dem zu vermessenen Oberflächenprofil des Untergrunds. Die Auslenkung der Feder wird durch einen auf die Oberseite des Cantilevers fokusierten Laserstrahl vermessen und auf dem Bildschirm als Auslenkungsprofil dargestellt. Da es sich bei dem Cantilever um eine Feder mit definierter Federkonstante handelt, gibt es einen direkten Zusammenhang zwischen der Auslenkung der Feder und der auf sie wirkenden Kraft.

Die Cantilever aus Silizium-Nitrid befinden sich an der Spitze eines Chips aus Pyrex-Glass. Diese Chips werden ähnlich der Chips in der Elektronikindustrie durch Ätzung hergestellt und befinden sich bei Lieferung noch in den Wafern (Halbleiterscheiben) und müssen vor den Messungen erst vereinzelt werden. Da die Eigenschaften der Federn entscheidend für ihr Meßverhalten und die späteren Ergebnisse sind, ist es sehr wichtig genaue und verlässliche Informationen über ihre Beschaffenheit zu haben. Es gibt verschiedene Arten von Chips, die sich in Material und Anzahl bzw. Beschaffenheit der Federn unterscheiden.
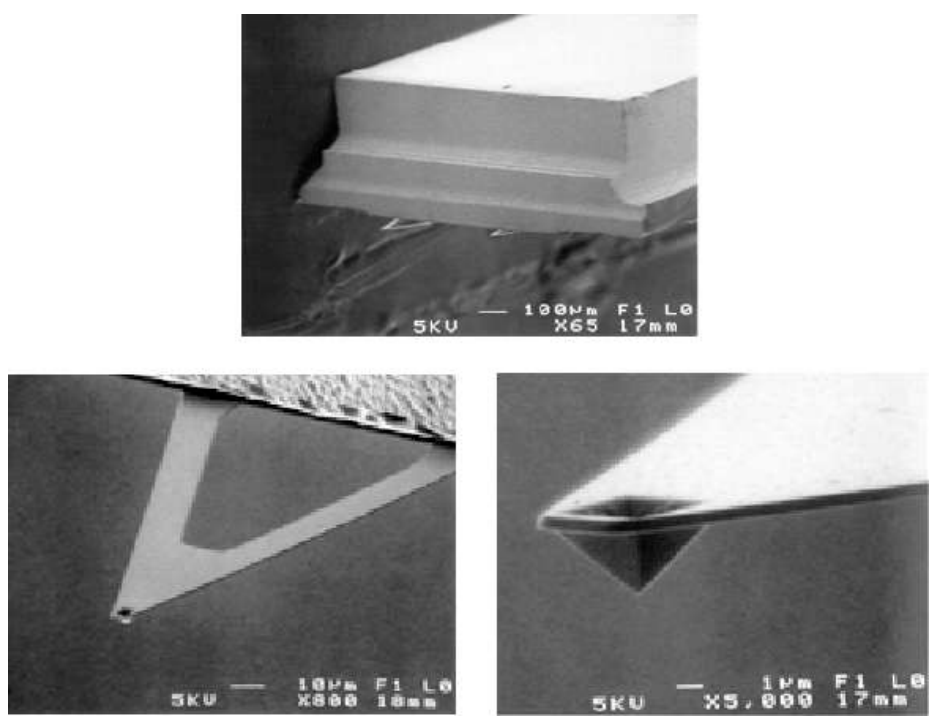

Abbildung 17: AFM-Chip mit Cantilevern in verschiedenen Vergrößerungen (www.veeco.com $/$ html/product_bytechnology.asp)

In Abbildung 17 ist oben deutlich der Chip mit 2 Federn zu sehen. Die unteren beiden Aufnahmen zeigen eine Vergrößerung der einzelnen Feder, in der auch die Pyramide mit der Meßspitze zu erkennen ist.

Die von uns benutzten Chips sind von Park Scientific Instruments, sog. Microlevers aus der Reihe MSCT - AUHW. Dieser Chip besitzt 2 Federn auf der Unter-, 4 Federn auf der Oberkante und ist an der Oberfläche mit Gold bedampft. Für die Messungen dieser Arbeit wurde die längste $(320 \mu \mathrm{m})$ Feder mit einem Öffnungswinkel von $35^{\circ}$ und einer Federkonstante von 0,01 N/m verwendet. 


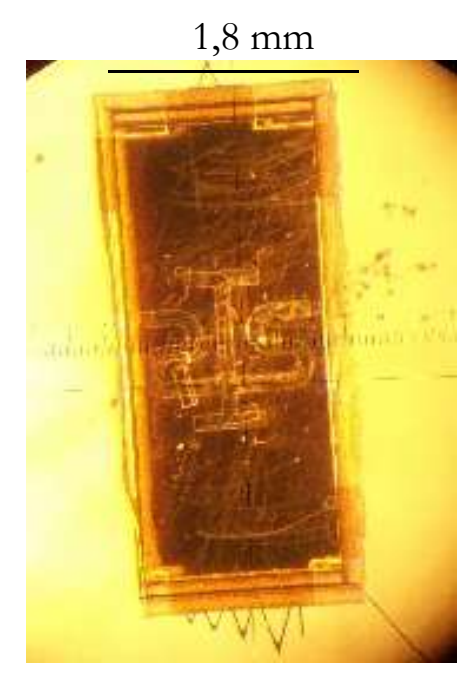

Abbildung 18: AFM-Chip

Abbildung 18 zeigt einen typischen in dieser Arbeit verwendeten AFM-Chip. Die Orginallänge beträgt 3,6 $\mathrm{mm}$ und die Breite 1,8 $\mathrm{mm}$. Deutlich sind unten die 4 verschieden langen Federn und der einzelne Steg zu sehen. Auf der oberen Seite fehlt eine der beiden Federn. Bei unsachgemäßer Behandlung können die Federn leicht beschädigt werden.

Weitere Informationen über Cantilever sind auf der Seite http://www.spmtips.com oder http://www.veeco.com zu finden.

\section{Fluidzelle}

Es ist eine spezielle Halterung nötig, um den Chip mit dem AFM-Scanner zu verbinden und ihn fest zu arretieren. Außerdem ist es wichtig, dass das Piezoelement des Scanners nicht mit Flüssigkeit der Probe in Verbindung kommt, da sonst die Gefahr einen Kurzschlusses besteht, der den Piezo zerstören würde.
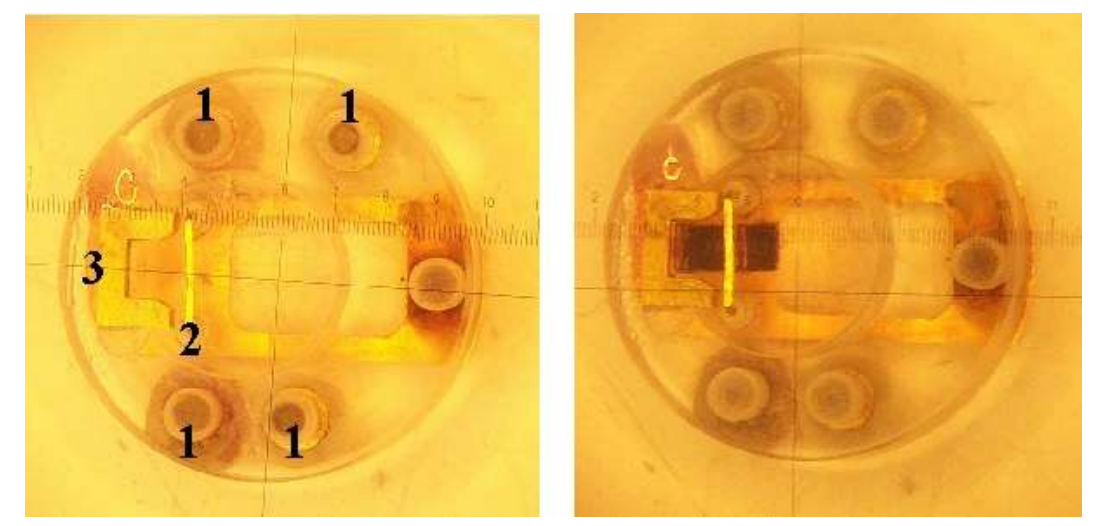

Abbildung 19: Die Fluidzelle bei 6,4 facher Vergrößerung mit und ohne Chip 
Die Fluidzelle besteht aus Glas, hat einen Durchmesser von 1,3 cm und eine Dicke von 0,4 cm. Auf dem linken Bild der Abbildung 19 sehen wir die Fluidzelle, die für die Messungen dieser Arbeit verwendet wurde; eine Standart Fluidzelle für die BioScope-Serie. Auf der Rückseite sind Löcher (1) eingebohrt, welche zur Befestigung an dem AFM-Scanner dienen. Der Chip wird unter den mit Gold bedampften Bügel (2) und mit dem Ende gegen die Halterung (3) geschoben. Im rechten Bild ist die Fluidzelle mit eingebauten Chip zu sehen.

Die Fluidzelle wird nur zur Hälfte in das Medium eingetaucht und der Piezo zusätzlich noch mit einem Plastikprotektor abgeschirmt. Dadurch ist die Elektronik weitgehend vor Flüssigkeit geschützt.

\section{AFM-Scanner}

Der Scanner wird in einer Schiene der AFM-Halterung befestigt und kann dann durch Schrittmotoren in der z-Achse bewegt werden. So ist eine vorsichtige Annäherung an die Probe möglich, um weder die Zellen noch die Meßspitze zu beschädigen.

Im Inneren des Scanners befindet sich das Piezoelement. Einige kristalline Substanzen (z.B. Turmalin) besitzen im Normalzustand aus Symmetriegründen ein neutrales elektrisches Feld. Mechanischer Druck, der auf den Kristall ausgeübt wird, verschiebt das Feld und es entsteht ein elektrisches Dipolmoment. Legt man nun eine elektrische Spannung an, beobachtet man umgekehrt eine mechanische Verformung des Kristalls und eine einsetzende Schwingung. Dieses Phänomen wird als piezoelektrischer Effekt (piezein (griech.): drücken) bezeichnet. Kristalle mit dieser Eigenschaft nennt man daher Piezokristalle. Durch Anlegen einer definierten elektrischen Spannung erhält man eine maximale Auslenkung in x-y-Richtung von je $90 \mu \mathrm{m}$.

Sollte die Auslenkung der Feder seine größte Toleranz erreichen, regelt der Scanner automatisch nach, d.h. er fährt soweit nach oben, dass die Feder nicht beschädigt wird. Dadurch ist es möglich, auch Oberflächenprofile mit größeren Unebenheiten auszumessen. Die maximale Nachregelung liegt bei $6 \mu \mathrm{m}$. Die Informationen der z-Bewegung des Scanners werden in dem Höhenprofil wiedergeben. Eine Kombination des Auslenkungsprofils der Feder mit dem Höhenprofil des Scanners ergibt ein sehr genaues optisches Bild der Oberflächenbeschaffenheit. Auf der Abbildung 20 ist links der AFM-Scanner zu sehen. (1) sind die Regler, mit dem der Laserstrahl fokusiert und auf die AFM-Spitze positioniert wird. (2) ist ein kleines Kontrollfester, in dem der Laser-Spot bei Betrieb zu sehen ist. (3) Röhrchen mit dem Piezoelement; am unteren Ende befinden sich 4 Pins, auf die die Fluidzelle aufgesteckt wird. (4) aufgesteckte Fluidzelle. Die beiden unteren Bilder zeigen das Endstück des Scanner vergrößert, so dass die Pins und die aufgesteckte Fluidzelle deutlicher zu erkennen sind. Ganz rechts ist die Halterung des Scanner zu sehen, der Scanner wird in die Schiene (5) gesetzt. 

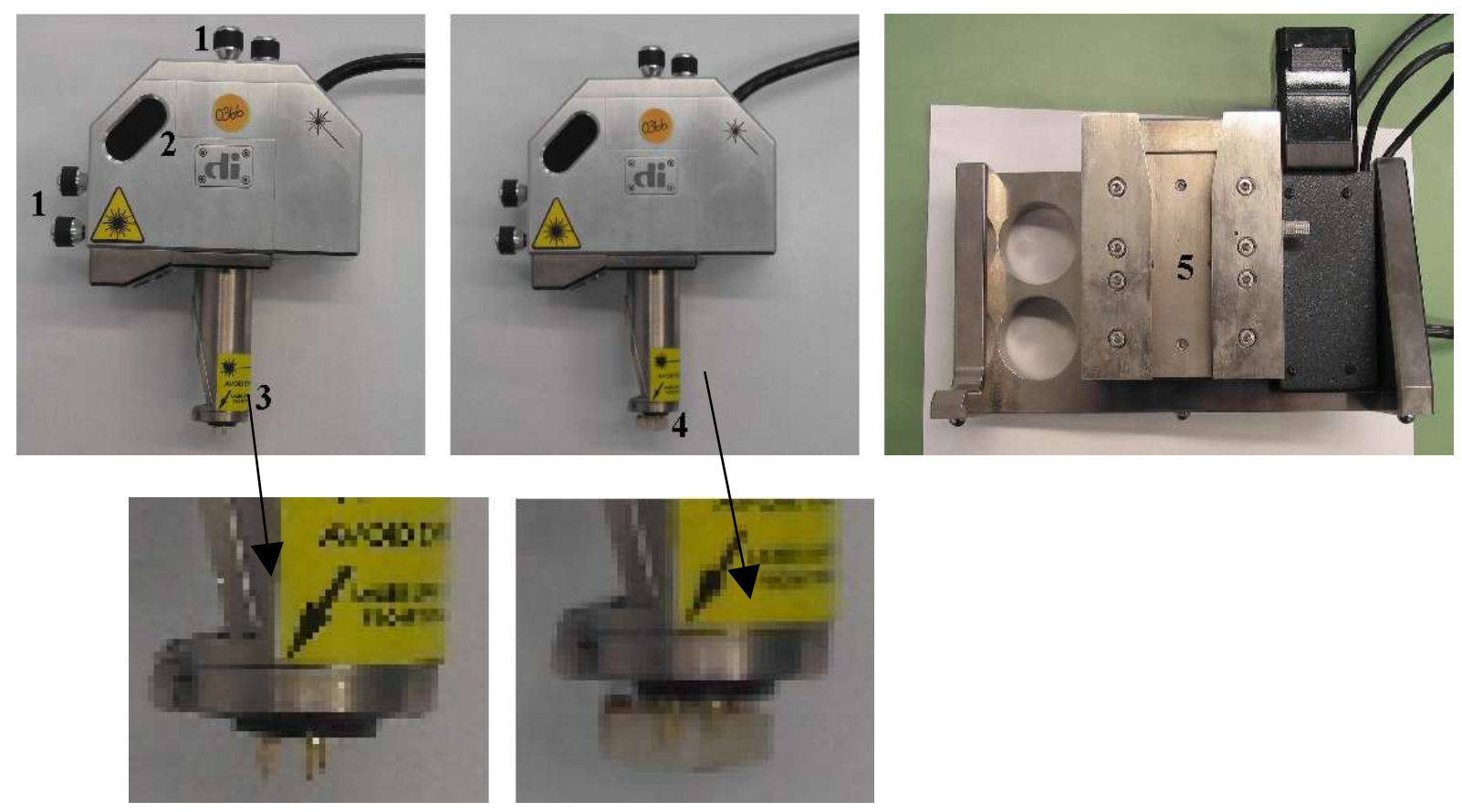

Abbildung 20: links: AFM-Scanner (mit Vergrößerung)

mitte: AFM-Scanner mit Fluidzelle (mit Vergrößerung) rechts: AFM-Halterung

\section{Temperatur- und $\mathrm{CO}_{2}$-Steuerung}

Wie schon unter Abschnitt 2.1 erläutert, benötigen die Zellen eine Umgebungstemperatur von möglichst $37^{\circ}$ Celsius und eine 5\%-CO - -Atmossphäre. Kleinere Schwankungen (34-38 Celsius und 4-6\% $\mathrm{CO}_{2}$ ) dieser Werte, wie auch eine gewisse Zeit (ca. $30 \mathrm{~min}$ ) ohne die optimale Umgebung überstehen die Zellen ohne Beeinträchtigung. Für die Dauer der Messung sind möglichst gute Bedingungen für die Zellen notwendig, um Veränderungen oder Schädigungen der Zellen durch äussere Einflüsse auszuschliessen.

Die unter Abschnitt 2.3.1 beschriebene Arbeitsplattform auf dem Axiovert Mikroskop wurde aus Metall angefertigt und an der Unterseite mit elektrischen Widerständen versehen. Läßt man einen elektrischen Strom durch die Widerstände fließen, so erhitzen sie sich und erwärmen so die Metallplatte. Die Petrischale wird in einer metallischen Halterung befestigt, so dass eine gute Wärmeleitung zwischen Metallplatte und der Flüssigkeit in der Petrischale besteht. Kontrolliert wird die Temperatur durch ein PT-100 Wärmeelement.

Um eine 5\%-CO $\mathrm{CO}_{2}$-Atmosspähre zu gewährleisten, wird der ganze AFM-Aufbau in einem relativ gasdichten Plastikkasten untergebracht, der mit einem $\mathrm{CO}_{2}$-Zufluß und einem $\mathrm{CO}_{2}$-Scanner versehen ist. Der $\mathrm{CO}_{2}$-Scanner wird mit dem Magnetventil der Gasflasche verbunden und kann so den Zufluß kontrollieren und den $\mathrm{CO}_{2}$ Gehalt bei $5 \%$ konstant halten. 


\section{Gesamtaufbau}

Abbildung 21 zeigt den Aufbau des AFMs kurz vor einer Messung. Die Kamera ist an dem oberen Ausgang des Axioverts angeschlossen und sendet die Bilder auf den Kontrollmonitor, so dass die AFM-Messungen vom Kontrollplatz aus beobachtet werden können. Der Scanner ist in die Halterung eingebaut und Fluidzelle mit Plastikschutz aufgesetzt. Noch befindet sich keine Probe unter dem Scanner, so dass die Plexiglasbox noch offen und die $\mathrm{CO}_{2}$ Zufuhr abgestellt ist.

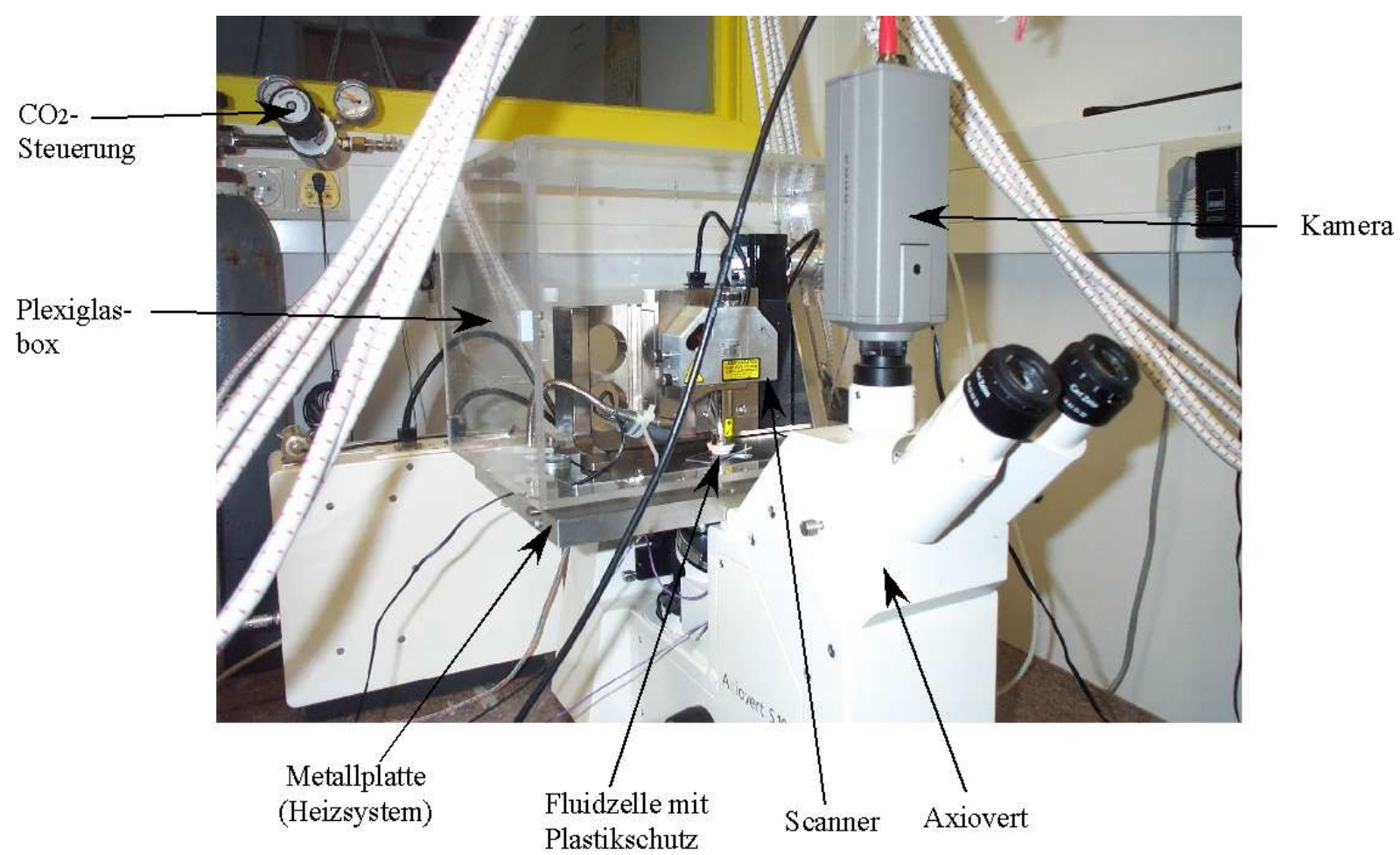

Abbildung 21: Gesamtaufbau des AFM

In Abbildung 22 ist der gesamte Versuchsaufbau zu sehen. Der AFM-Aufbau steht auf einer Granitplatte, die mit Gummiseilen angehoben werden kann. Dies dient zur Entkopplung des Versuchsaufbaus von den Gebäudeschwingungen. Diese Schwingungen oder die Erschütterungen durch z.B. Schritte im Labor können das leichte Schwingen der AFM-Spitze empfindlich stören oder sogar überlagern. In dem Gestell rechts davon befindet sich der Kontrollmonitor mit dem Time-Lapse-Videorecorder, einem der PC-Monitore, der Temperaturund $\mathrm{CO}_{2}$-Anzeige und dem Netzteil für die Heizwiderstände. Der PC mit der Meßsoftware, der das AFM steuert, der zweite Monitor und das Steuerelement des AFM (nicht im Bild) befinden sich auf dem Tisch ganz rechts. 


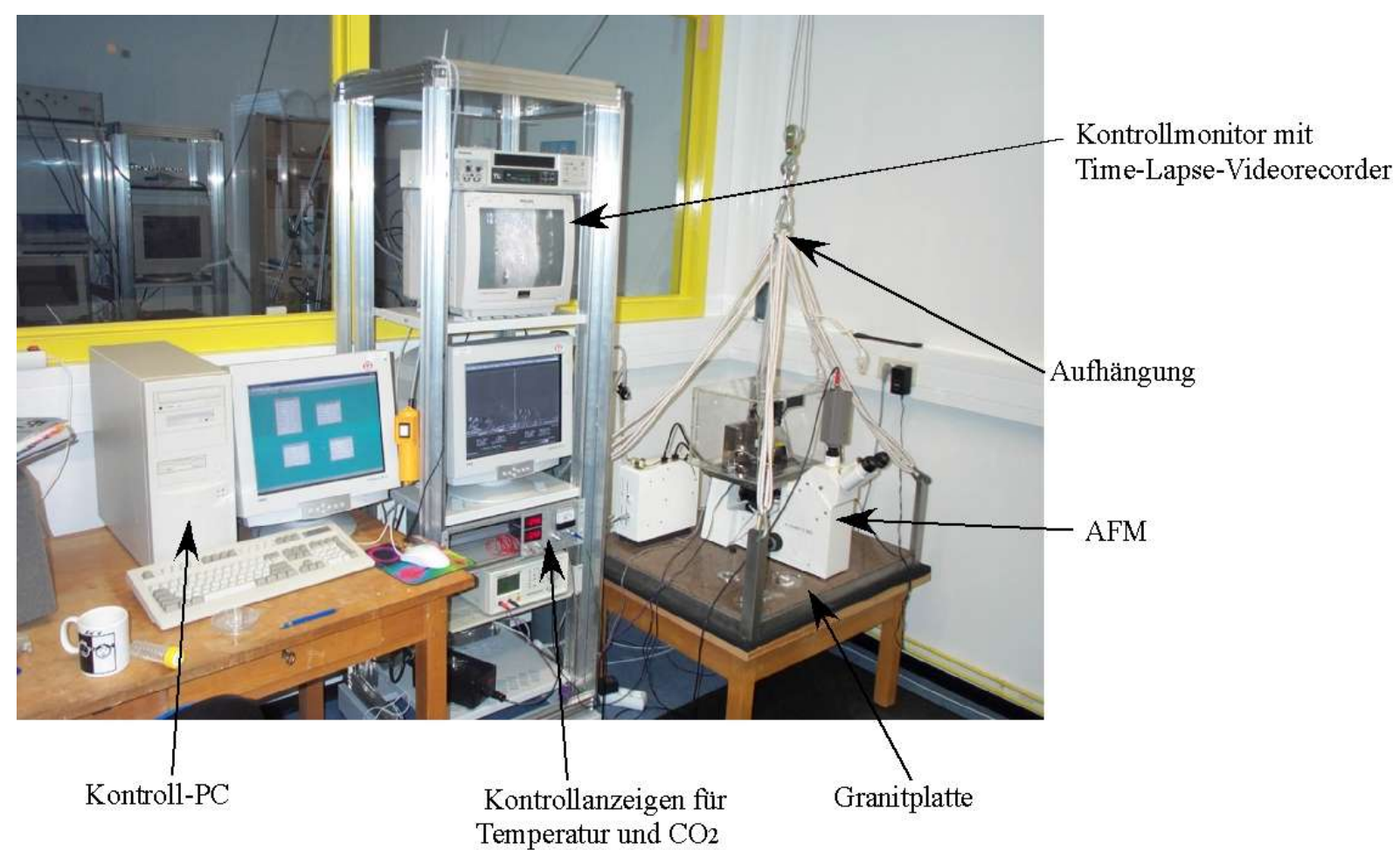

Abbildung 22: Gesamtaufbau der AFM-Meßvorrichtung 


\section{Messungen}

\subsection{Videomessungen}

Eine Einschränkung des AFM ist, dass nur eine Zelle pro Versuch beobachtet werden kann. Um eine bessere Statistik über die allgemeinen Reaktionen der Zellen auf die Inhibitoren zu bekommen, wurden vor den AFM-Messungen optische Videomessungen vorgenommen. Wir benutzen die an das Mikroskop angeschlossene CCD-Kamera, um die Reaktionen der Zellen mit dem Time-Lapse-Videorecorder aufzunehmen (siehe Abschnitt 2.3.1). Da die Meßzeiträume bis zu 10 Stunden betrugen, wurden die Videoaufnahmen im Zeitrafferverfahren aufgenommen.

Zuerst mußte die Reaktion der beiden Zelllinien auf die beiden verschiedenen Inhibitoren getestet und die oberen und unteren Grenzen der Verträglichkeit herausgefunden werden.

Wir konnten bei diesen Messungen mit Wasser gefüllte Schalen in die Plexiglasbox stellen, da keine empfindliche Piezoelektronik vorhanden war. Auf diese Weise wurde die Luftfeuchtigkeit im Versuchsaufbau deutlich erhöht und die Zellen konnten bis zu 10 Stunden beobachtet werden.

Die Proben positionierten wir so unter dem Mikroskop, dass eine möglichst große Anzahl einzelner Zellen in dem Sichtfeld zu sehen waren. Die ersten 30-45 min wurden die Zellen ohne Zusätze beobachtet; um eine Referenz zu dem Verhalten der Zellen nach Zugabe der Inhibitoren zu haben. Nach diesen 30-45 min wurde dann der Inhibitor in die Petrischale gegeben und die Reaktion der Zellen auf die Chemikalie aufgezeichnet.

Bei zu hoher Konzentration sterben die Zellen ab oder werden irreparabel geschädigt und bei zu niedriger Konzentration zeigen die Zellen nur schwache oder keine Reaktion.

Deshalb bestimmten wir in Kontroll-Messungen zuerst die Konzentrationen, bei denen die Zellen die gewünschten Reaktionen auf die Inhibitoren zeigen (siehe Abschnitt 1.1). In der Literatur (Pelham\&Wang, 1999) wird eine BDM-Konzentration von $20 \mathrm{mM}$ angegeben. Diese Konzentration diente als Startwert. Die 22 durchgeführten Langzeitmessungen mit den 3T3 und 17 mit den NRK ergaben folgende Werte:

Tabelle 1: BDM-Konzentrationen

\begin{tabular}{|l|l|l|l|}
\hline Zellline & obere Grenze & untere Grenze & optimale Konzentration \\
\hline 3T3 & $20 \mathrm{mM}$ & $2,5 \mathrm{mM}$ & $7-15 \mathrm{mM}$ \\
\hline NRK & $70 \mathrm{mM}$ & $10 \mathrm{mM}$ & $15 \mathrm{mM}$ \\
\hline
\end{tabular}

Die Startkonzentration wurde schrittweise erhöht, bis es zu einem Absterben der Zellen kam diesen Wert definierten wir als obere Grenze. Auf die gleiche Weise wurde die Konzentration verringert, bis keine Reaktion mehr beobachtet werden konnte - diesen Wert definierten wir als untere Grenze. Die Menge BDM, bei der die Zellen die gewünschte Reaktion hervor ruft, wurde als optimale Konzentration definiert und auch später bei den AFM-Versuchen verwendet. Auf die gleiche Weise bestimmten wir die verschiedenen Konzentrationen für den Inhibitor ML-7 bestimmt. Kelley et al. 2000 gibt eine ML-7 Konzentration von $\sim 20 \mu \mathrm{M}$ an. Aus den 15 bzw. 10 Experimenten für die NRK bzw. 3T3 Zellen ergeben sich folgende Werte:

Tabelle 2: ML-7-Konzentrationen

\begin{tabular}{|l|l|l|l|}
\hline Zellline & obere Grenze & untere Grenze & optimale Konzentration \\
\hline 3T3 & $20 \mu \mathrm{M}$ & $3,5 \mu \mathrm{M}$ & $10-12 \mu \mathrm{M}$ \\
\hline NRK & $50 \mu \mathrm{M}$ & $10 \mu \mathrm{M}$ & $13 \mu \mathrm{M}$ \\
\hline
\end{tabular}


Die NRK Zellen reagieren wesentlich unempfindlicher auf hohe Inhibitor-Konzentrationen als die 3T3 Zellen. Die Reaktionen beider Zelllinien und die optimale Arbeitskonzentration hingegen ist fast identisch.

Bei beiden Zelllinien beobachteten wir das bei höherer Konzentration die Wirkung des Inhibitors schneller einsetzt. Diesen Zusammenhang zwischen Inhibitor-Konzentration und Zeitpunkt bis zum Einsetzten der Wirkung fanden schon Rotsch\&Radmacher, 2000.

Der Inhibitor ML-7 wurde mit DMSO angesetzt, welches schädlich für die Zellen ist. Ähnlich wie für die Inhibitoren führten wir Kontroll-Messungen durch, um den Einfluss von DMSO auf die folgenden Messungen abschätzen zu können. Es wurden für jeden Zelltyp 2 Experimente mit reinem DMSO gemacht. Bei $400 \mu \mathrm{l}$ DMSO in $2 \mathrm{ml}$ Medium zeigten die Zellen erste Reaktionen. In der Stammlösung befindet sich nur 1\% der DMSO-Menge, die für eine Zellenreaktion notwendig wäre. Damit ist gesichert, dass das DMSO keinen Einfluß auf die weiteren Experimente hat.

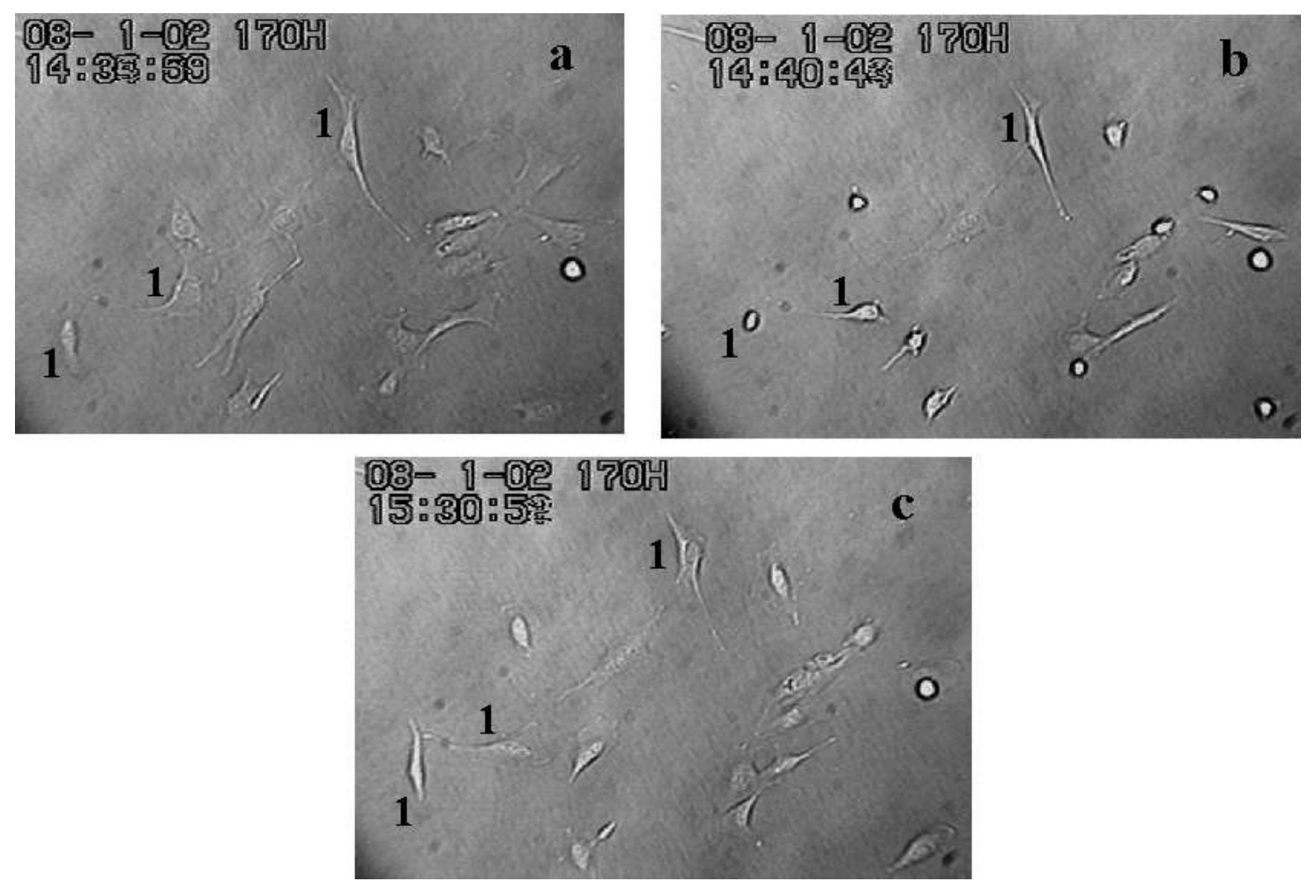

Abbildung 23: Videoexperiment mit 3T3-Zellen

Abbildung 23 zeigt ein typisches Lang-Zeit-Videoexperiment. (a): eine Anzahl 3T3-Zellen, die eine ausgestreckte Morphologie zeigen, welche auf Bewegung der Zellen schließen läßt. (b): 5 min nach der Zugabe des Inhibitors BDM (7,5 mM) haben sich alle Zellen verändert und eine abgerundete (sphärische) Form angenommen. (c): 55 min nach der BDM Zugabe haben sich einige Zellen vollständig regeneriert. Dies ist aber nicht bei allen Zellen zu erwarten. Ein gewisser Prozentsatz erholt sich nur langsam oder ist dauerhaft geschädigt. Die beiden mit 1 gekennzeichneten Zellen zeigen sowohl eine starke Reaktion auf das BDM wie auch eine fast vollständige Regeneration. 
Von den oben beschriebenen 64 Langzeitversuchen wurden insgesamt 42 Experimente innerhalb der jeweiligen Konzentrationsgrenzen durchgeführt. Diese verteilen sich auf die Zelllinien und Inhibitoren wie folgt:

Tabelle 3: Langzeit-Videoexperimente

\begin{tabular}{|l|l|l|}
\hline Zelllinie & Inhibitor & Experimente \\
\hline 3T3 & BDM & 11 \\
\hline NRK & BDM & 8 \\
\hline 3T3 & ML-7 & 8 \\
\hline NRK & ML-7 & 15 \\
\hline
\end{tabular}

Aus diesem Experimenten wurde dann eine Statistik angefertigt, um eine grundsätzliche Aussage über das Verhalten der Zellen auf Mysion-II-Inhibitoren zu erhalten (siehe Kapitel 5.1).

\subsection{AFM-Messungen}

\subsubsection{Fehlerquellen}

Bei den Vorbereitungen und den anschließenden Messungen mit dem AFM gibt es eine große Anzahl von Fehlerquellen - gerade beim Umgang mit lebenden Proben - die zu einer Verfälschung der Ergebnisse bis hin zu einer Beschädigung der Probe oder des AFM führen können.

Folgende Punkte sollten vermieden werden, um nicht das AFM oder das Piezo-Element zu beschädigen:

- Trennen von Kabelverbindungen zwischen AFM, Kontroller oder Steuerungs-PC bei Betrieb der Geräte

- Kontakt des Piezo-Elements mit Flüssigkeit aus der Petrischale oder Flüssigkeitsrückständen an Fluidzelle oder Plastikschutz

Um Beeinträchtigungen der Messungen oder Schädigungen der Zellen zu verhindern müssen folgende Aspekte berücksichtigt werden:

- Sauberes Trennen der Cantilever aus den Wavern

- Reinigung der Canitlever unter einer UV-Lampe (30 min)

- Reinigung der Fluidzelle und des Plastikschutzes

- Regelmässige Kontrolle von Temperatur und $\mathrm{CO}_{2}$-Gehalt der Atmosphäre während der Messsungen

- Ausgleichen der verdunsteten Flüssigkeit des Nährmediums

- Kein zu langer Aufenthalt (> 40 min) der Zellen ausserhalb der optimalen Umweltbedingungen

- Beständige Kontrolle der auf die Zelle wirkenden Kraft 


\subsubsection{Kraftkurven-Modus}

Nach der Auswahl des Meßbereichs wird das AFM zuerst auf eine zellfreie Stelle auf das unterliegende Substrat gefahren. Dort wird eine sog. Kraftkurve aufgenommen und geeicht.
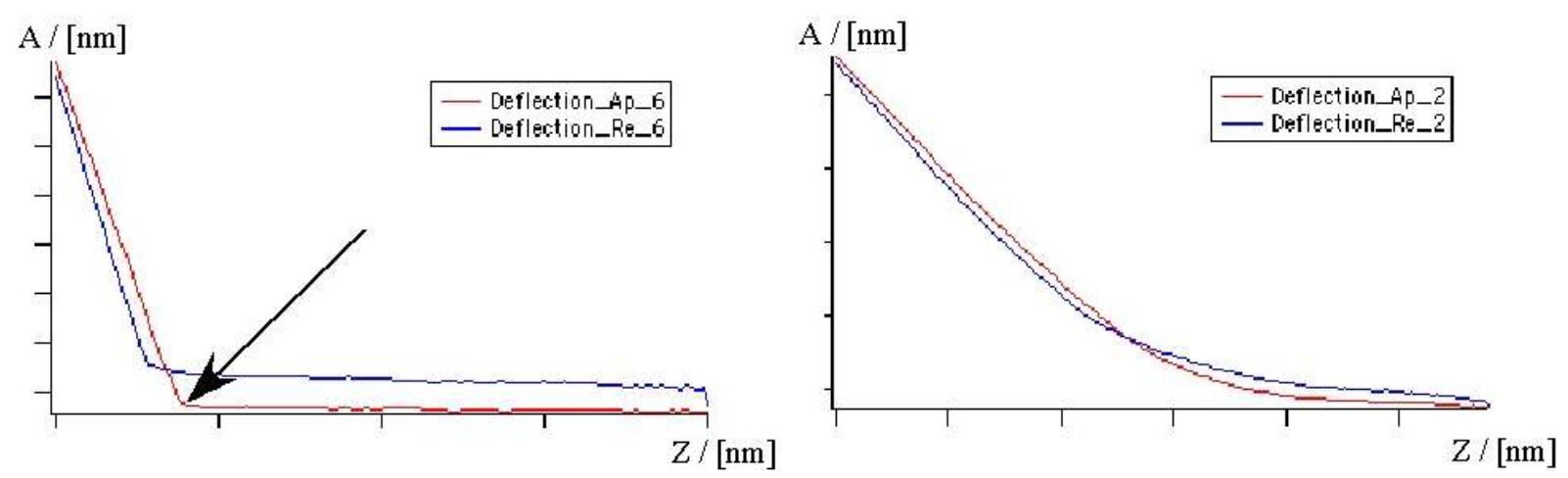

Abbildung 24: links: Kraftkurve auf einem harten Untergrund rechts: Kraftkurve auf einem weichen Untergrund (Zelle)

In dem Kraftkurven-Modus beginnt der Scanner sich nach dem Erreichen der Oberfläche in zRichtung (Vertikal) zu bewegen (die x-y-Position wird nicht verändert). Auf dem Bildschirm wird die Auslenkung des Cantilevers in Abhängigkeit der Bewegung in z-Richtung dargestellt. Dieser Graph wird als Kraftkurve bezeichnet (siehe Abb. 24).

Bei einem harten Untergrund kommt es beim Kontakt der Feder mit der Probenoberfläche zu einem scharfen Knick in der Kurve (in Abb. 24 durch einen Pfeil gekennzeichnet), da der Cantilever sich bei weiterer Bewegung in z-Richtung verbiegt. Die Auslenkung des Cantilevers ist proportional zur Bewegung in z-Achse. Die Steigung des Graphen bei einem harten Untergrund wird zur Eichung benutzt. Die zwei verschieden farbigen Kurven repräsentieren die Auf- und Abbewegung des Scanners. Die Versetzung der Kurven ist auf Hysterese-Erscheinungen zurückzuführen.

Bei einer weichen Oberfläche gibt es in der Kraftkurve keinen scharfen Knick. Bei Kontakt wird sowohl die Feder ausgelenkt, wie auch die Oberfläche eingedrückt. Es kommt zu einem flachen Anstieg und einer deutlich geringeren Steigung (Abb. 24, rechts).

\subsubsection{Bild-Modus}

Der Scanner wird nun mit einer definierten einstellbaren Kraft auf die Probe drücken und sich dabei in der x-y-Ebene bewegen. Die maximale Größe des Meßbereichs beträgt $90 \mu \mathrm{m}$. Die Auslenkung des Cantilevers und die evtl. Hebung und Senkung des Scanners bei zu großen Höhenunterschieden werden auf dem Monitor als Höhen- und Auslenkungsbild dargestellt. Die maximale Nachregelung des Scanners beträgt $6 \mu \mathrm{m}$. 


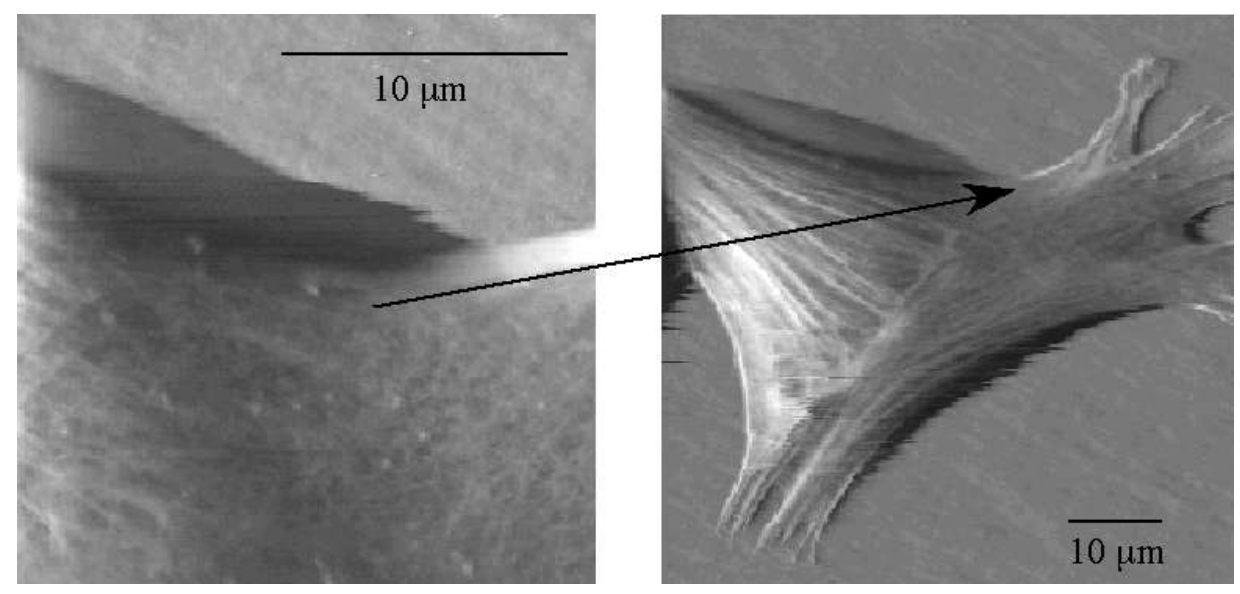

Abbildung 25: AFM-Bild einer 3T3-Zelle in verschiedenen Vergrößerungen

Abbildung 25 zeigt das Auslenkungsbild einer 3T3-Zelle. Rechts sind deutlich die AktinFilamente in der Zelle zu erkennen. Links ist ein Ausschnitt der Zelle vergrößert.

Bei Messungen auf Zellen ist es wichtig eine möglichst geringe Kraft einzustellen, um die Zellmembran und damit die Zelle selbst nicht zu beschädigen. Eine auf diese Art beschädigte Zelle ist für weitere Messungen unbrauchbar. Zellfragmente der beschädigten Zelle können dabei die Meßspitze verunreinigen, so dass diese so ebenfalls ausgewechselt werden muß.

Bei hinreichend geringer Kraft sind AFM-Messungen über mehrere Stunden möglich ohne die Zellmembran zu beschädigen (Haydon et al., 1996).

Während der AFM-Messungen kann man die Reaktion der Zellen und das Rastern des Scanners durch die CCD-Kamera beobachten. Abbildung 26 zeigt eine Aufnahme der Kamera während einer AFM-Messung. Auf der rechten Bildseite ist die dreieckförmige Meßfeder zu sehen und unterhalb der Spitze mit einem Pfeil gekennzeichnet die gerade vermessene Zelle.

Die Aufnahmezeit eines Bildes ist abhängig von der Größe des Meßbereichs, der Anzahl der in dem Bereich abzurasternden Zeilen und der Frequenz der Scannerbewegung. Bei zu hoher Frequenz werden die Bilder unscharf, da die Feder schnell über die Oberfläche gleitet, und die Gefahr, die Zelle zu schädigen steigt.

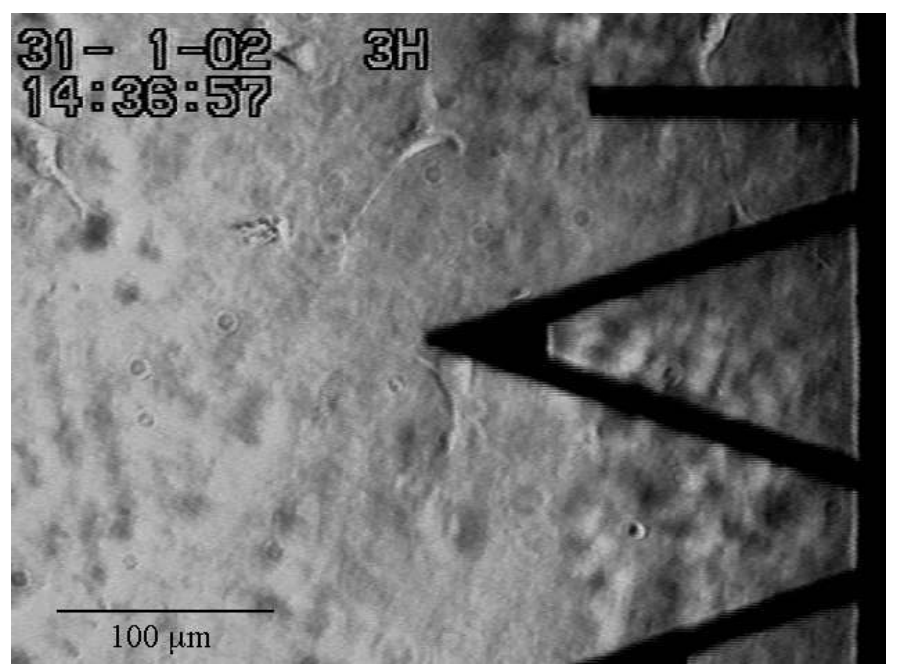

Abbildung 26: AFM in Betrieb

Bei einem Meßbereich von $10 \mu \mathrm{m}$ mit 256 Zeilen und einer Meßzeit von 5 Minuten pro Bild hat man einen guten Kompromiss zwischen zeitlicher und räumlicher Auflösung erreicht. 


\subsubsection{Force-Volume-Mode}

Der Force-Volume-Mode ist eine Kombination aus dem Kraftkurven-Modus und dem BildModus. Wie im oben beschriebenen Bild-Modus wird ein eingestellter 2-dimensionaler Bereich der Probe abgerastert. Allerdings handelt es sich hier nicht um ein kontinuierliches Abfahren der Probe, sondern es werden in jeder Meßzeile eine voreingestellte Anzahl von Kraftkurven aufgenommen (Radmacher et al., 1994 II). Der Force-Volume-Mode liefert also eine große Anzahl von Kraftkurven und damit eine 2-dimensionale Kraft-Karte (Force-Volume-Maps) der Zelle (Radmacher et al. 1996, Hofmann et al. 1997, A-Hassan et al. 1998, Schäfer et al. in Press). Mit dem von Hertz entwickelten und von Sneddon verbesserten Modell kann man aus diesen Kraftkurven den Elastizitäts- oder Young-Modul berechnen (Hertz, 1882; Sneddon, 1965; Johnson, 1994). Das Ergebnis ist eine 2-dimensionale Karte der Härteverteilung der Probe. Da der Meßvorgang einer Kraftkarte mit steigender Auflösung deutlich länger dauert, muß man - wie im Bildmodus - einen Kompromiß zwischen zeitlicher und räumlicher Auflösung finden.

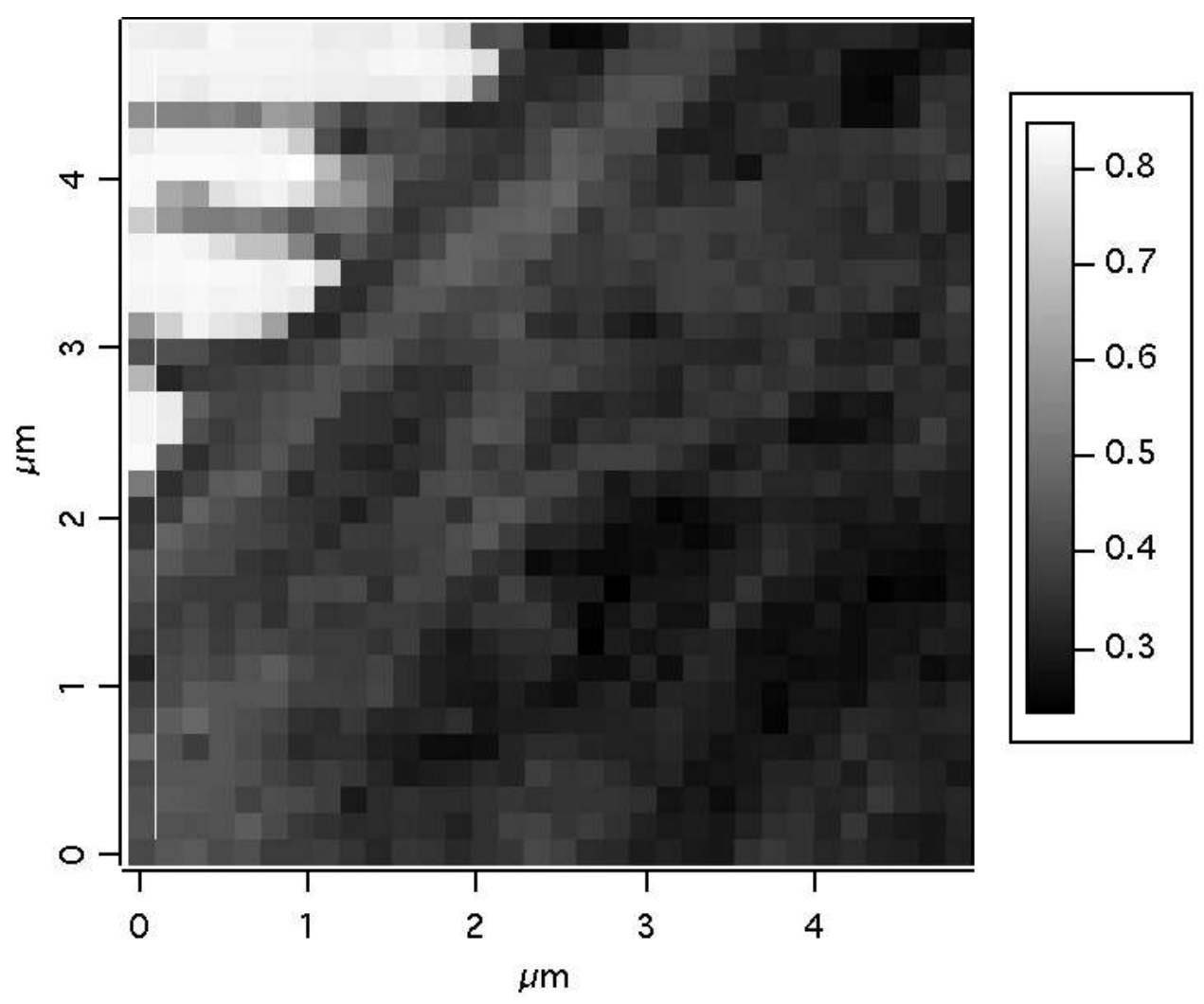

Abbildung 27: Kraftkarte eines Bereichs einer NRK-Zelle

In den vorliegenden Experimenten wurden 32 Zeilen mit je 32 Meßpunkten gewählt, damit ergaben sich für jede Kraft-Karte 1024 Meßpunkte. Bei einem Meßbereich von $5 \mu \mathrm{m}$ erreicht man auf diese Weise eine Auflösung von 0,16 $\mu \mathrm{m}$ bei einer Meßzeit von 6-7 min. Die räumliche Auflösung ist für das Ziel der Experimente vollkommen ausreichend, da eine Veränderung der Zellmechanik im Ganzen oder in Bereichen der Zelle beobachtet werden soll und nicht kleinräumige Veränderungen. Die zeitliche Auflösung von 6-7 Minuten ist ebenfalls ausreichend, da die Messungen über 1-5 Stunden laufen und auf diese Weise genügend Kraftkarten für Auswertungen (siehe Kapitel 4) aufgenommen werden. 
Während der Kraftkurven- und Bildmodus hauptsächlich zum Eichen oder Aussuchen geeigneter Zellen benutzt wurde, ist der Force-Volume-Mode das Hauptwerkzeug für die Elastizitätsmessungen und daher von zentraler Bedeutung für die vorliegende Arbeit. Auf das Auswerten der erhaltenen Daten und den daraus resultierenden Ergebnissen wird in den Kapiteln 4 und 5 eingegangen.

Abbildung 27 zeigt eine typische $5 \times 5 \mu \mathrm{m}$ Kraftkarte eines Bereiches einer NRK-Zelle. Dargestellt in einer 2-dimensionalen Karte sind die Steigungen der einzelnen Kraftkurven, wobei Steigung 1 die ideale $45^{\circ}$ Grad Steigung einer unendlichen harten Oberfläche ist. Der fast weiße Bereich oben links mit Werten von $>0,8$ kennzeichnet das harte unter der Zelle liegende Substrat. Der dunkle Bereich stellt die Kraftstrukturen der Zelle dar. Es ist zu beachten, dass es keine ebenmäßige Fläche ist, sondern es Strukturen zwischen 0,2 und 0,6 gibt. In Kapitel 4 wird das Verfahren erläutert, wie man aus der Kraftkarte die Elastizitätsverteilung bestimmt. Weitere Informationen über den Force-Volume-Mode findet man in Radmacher et al., 1996; Hofmann et al. 1997 und A-Hassan et al., 1998. 


\section{Datenauswertung}

Bevor wir die Ergebnisse dieser Arbeit in Kapitel 5 präsentieren und diskutieren, sollen in diesem Kapitel kurz die verwendeten Theorien und Werkzeuge erläutert werden, die uns aus den Rohdaten der Messung zu verwertbaren Ergebnissen verhalfen.

\subsection{Videostatistik}

Insgesamt wurden etwa 530 Minuten als Zeitraffer-Filme auf Video aufgenommen - das entspricht ca. 500 Stunden realer Meßzeit - und für die Statistik ausgewertet. Bei den einzelnen Experimenten wurden die während der ganzen Versuchsdauer gut sichtbaren, möglichst zentral im Sichtfenster liegenden Zellen ausgezählt. Ihr Bewegungsverhalten und Morphologie vor und nach der Zugabe des Inhibitors beobachtet und klassifiziert.

So erhielten wir eine Statistik aus 42 verschiedenen Versuchen und insgesamt 403 Zellen verteilt auf 2 verschiedene Zelllinien und 2 Inhibitoren.

Die gewonnen Daten werden im Abschnitt 5.1 präsentiert.

\subsection{AFM-Daten}

\subsubsection{Kraft-Karten}

Wie in Abschnitt 3.2.4 beschrieben, ist der Force-Volume-Mode das wichtigste Werkzeug für diese Arbeit, weil wir durch die Aufnahme von 32x32 Kraftkurven eine 2-dimensionale Information über die Härte der Zelle erhalten.

Zuerst haben wir nur 1024 Kraftkurven und müssen daraus den Elastizitäts- oder Young-Modul berechnen. Dazu benutzen wir das von Hertz (Hertz, 1882) entwickelte und von Sneddon (Sneddon, 1965) verbesserte Modell, welchem das Hooksche Gesetz zu Grunde liegt. Voraussetzung für das Modell ist eine unendlich dicke, ausgedehnte, weiche, flache Oberfläche, die von einem harten Kegel eingedrückt wird. Die Zelloberfläche kann lokal als flach und für den jeweiligen Meßbereich auch als unendlich ausgedehnt angenommen werden. Bei den untersuchten Zell-Lamellipodium kann nicht von einer unendlichen Dicke ausgegangen werden. Den Einfluss den das unterliegende Substrat auf das Modell hat, ist kaum abzuschätzen und wird in Abschnitt 4.2.3 behandelt.

Das Modell gibt folgenden Zusammenhang zwischen der anliegenden Kraft $F$ und der Eindrücktiefe $\delta$ :

$E$ ist der zu errechnende Young-Modul; $v$, die Poisson-Zahl für die Probe, wird mit 0.5 angenommen (für inkompressible Materialien) und $a$ der halbe Öffnungswinkel der AFM-Spitze, ist mit $18^{\circ}$ gegeben. 
Auf einer harten Probe ist die Verbiegung des Cantilevers $d(z)$ proportional zu der PiezoBewegung in $z$-Richtung $z$; bei weichen Proben wird die Verbiegung durch die elastische Eindrückung $\delta$ verringert:

$$
d(z)=z-\delta
$$

Die anliegende Kraft $F$ ergibt sich aus der gemessenen Verbiegung des Cantilevers $d(z)$ und der gegebenen Federkonstante des Cantilevers $k$ :

$$
F=k \cdot d(z)
$$

Ersetzt man nun $F$ und $\delta$ in [1] durch die Ausdrücke [2] und [3], so ergibt sich, dass der YoungModul E einzig eine Funktion der gemessenen Werte z und $d(z)$ ist:

$$
E=\frac{\pi \cdot k \cdot d(z) \cdot\left(1-v^{2}\right)}{2 \cdot \tan (\alpha) \cdot(z-d(z))^{2}}
$$

Weitere Details der Rechnung werden beschrieben in Domke\&Radmacher, 1998; Braet et al., 1998; Rotsch et al., 1997, 1999 und Domke et al. 2000.

Aus den Kraft-Karten kann man nun unter Benutzung der Funktion [4] zu jeder Kraftkurve ein Young-Modul errechnen und erhält so eine 2-dimensionale Verteilung der Zell-Elastizität.

Abbildung 28 ist ein Beispiel für eine Elastizitäts-Karte, diese wurde aus der Kraft-Karte errechnet, die unter Abschnitt 3.2.4 (Abb. 27) zu sehen ist. Wegen des großen Wertebereichs wird zur besseren Darstellung eine logarithmische Skala und farbiger Kontrast verwendet.

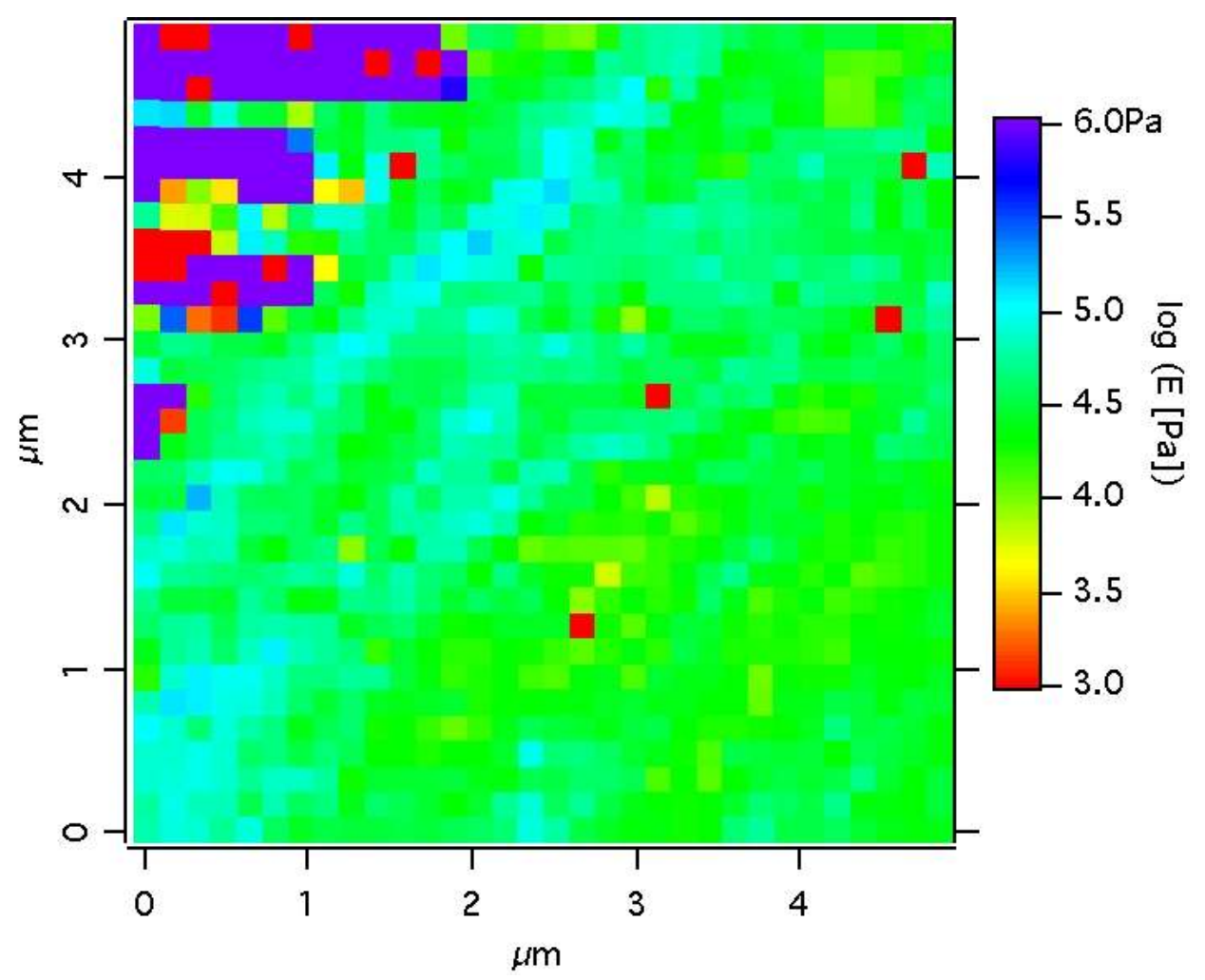

Abbildung 28: Elastizitäts-Karte eines Bereichs einer NRK-Zelle 
Der Bereich oben links mit Werten von $10^{6} \mathrm{~Pa}$ kennzeichnet das unterliegende Substrat. Für die Zelle ergeben sich Werte von $\sim 3-100 \mathrm{kPa}$. Die obere Grenze des Young-Moduls der Zelle ist sehr hoch und läßt uns auf das Problem des Einflusses des unterliegenden Substrats zurückkommen. Die vereinzelt sichtbaren roten Quadrate sind Bereiche, in dem das Model aufgrund von fehlerhaften Messwerten nicht anwendbar war.

Zur besseren Übersicht können die Elastizitäts-Karten auch als 1-dimsionale Graphen dargestellt werden. Abbildung 29 zeigt den zu Abbildung 28 gehörenden Graphen. Es sind deutlich 2 Gebiete innerhalb des Graphen zu unterscheiden: Gebiet (1) mit Werten hauptsächlich zwischen 10 und $100 \mathrm{kPa}$ (die Zelle) und (2) mit Werten von über $10^{6} \mathrm{~Pa}$ (das unterliegende Substrat).

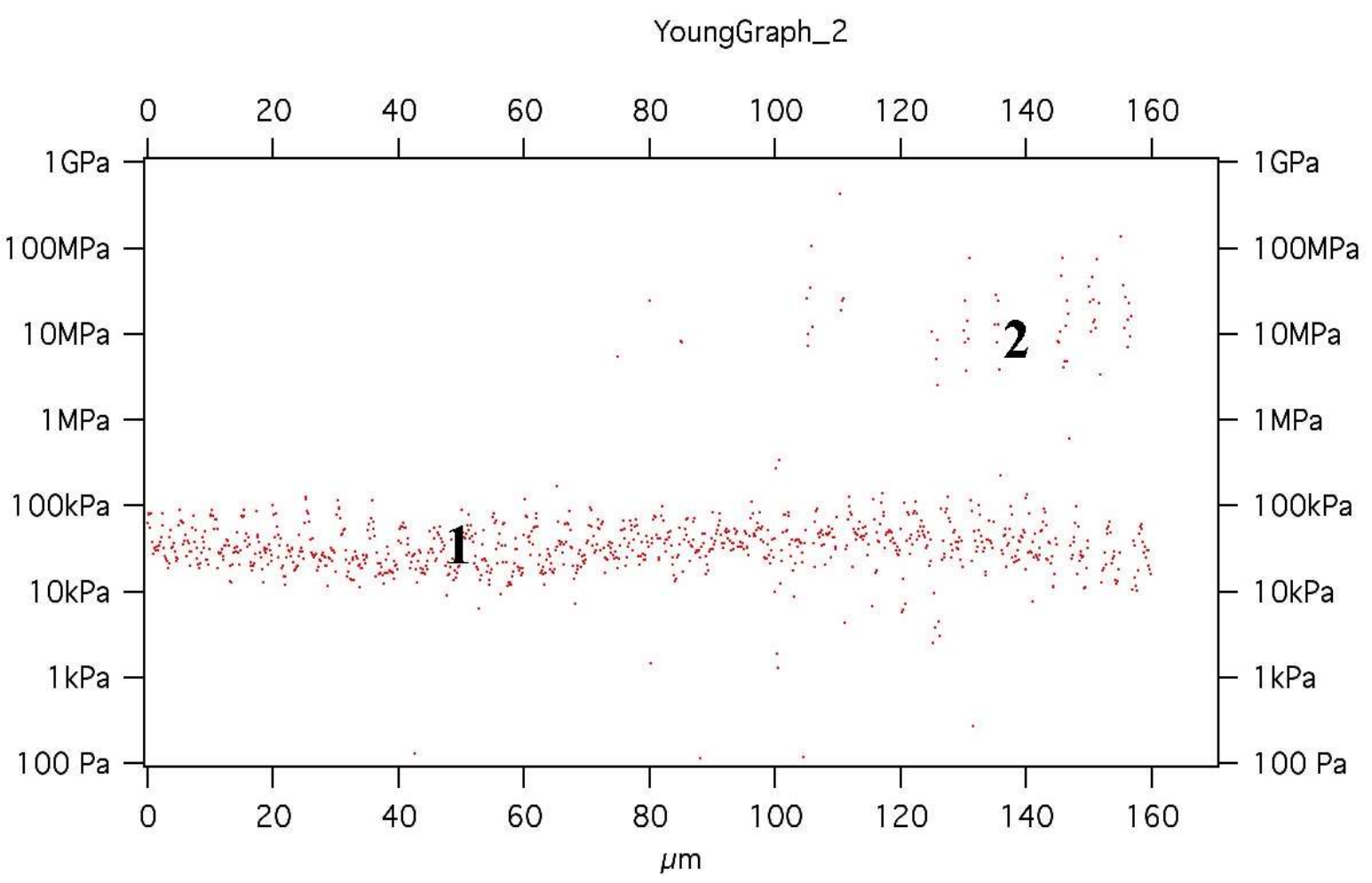

Abbildung 29: 1-dimensionale Darstellung einer Elastizitäts-Karte

\subsubsection{Zeitliche Änderung des Young-Moduls}

Wie im Kapitel 3 beschrieben, werden während des gesamten Experimentes in Abständen von 67 min Kraft-Karten aufgenommen, um die Reaktion der Zelle auf die Inhibitoren zu beobachten. Für ein Experiment erhält man also eine Schar von bis zu $30 \mathrm{Kraft}-\mathrm{Karten}$ und dazu gehörige Graphen.

Aufgrund der vielen Meßwerte innerhalb der 1-dimensionalen Darstellung einer ElastizitätsKarte und der zum Teil großen Streuung dieser Werte ist ein direkter Vergleich der Graphen sehr unübersichtlich.

Histogramme der Graphen sorgen für eine bessere Übersicht und geben einen durchschnittlichen Wert für die Elastizität der Zelle an.

In Abbildung 30 ist der zeitliche Verlauf eines Experiments anhand von Histogrammen veranschaulicht. Der Zeitpunkt $\mathrm{t}=0$ gibt die letzte Messung vor der Zugabe des Inhibitors an. Als Vergleich wurden dann die sich ergebenen Histogramme zu den Zeitpunkten 30, 60, 90 und 120 min nach der Inhibitor-Zugabe hinzugefügt. Die Abnahme des durchschnittlichen YoungModuls von 4,4 - 4,5 (logarithmische Darstellung) auf einen Wert von etwa 3,6/3,7 ist bei dieser 
Darstellung leicht abzulesen Die zeitlichen Abstände von 30 min sind für eine grobe Tendenz ausreichend gewählt, doch werden schnellere zelluläre Prozesse nicht berücksichtigt.

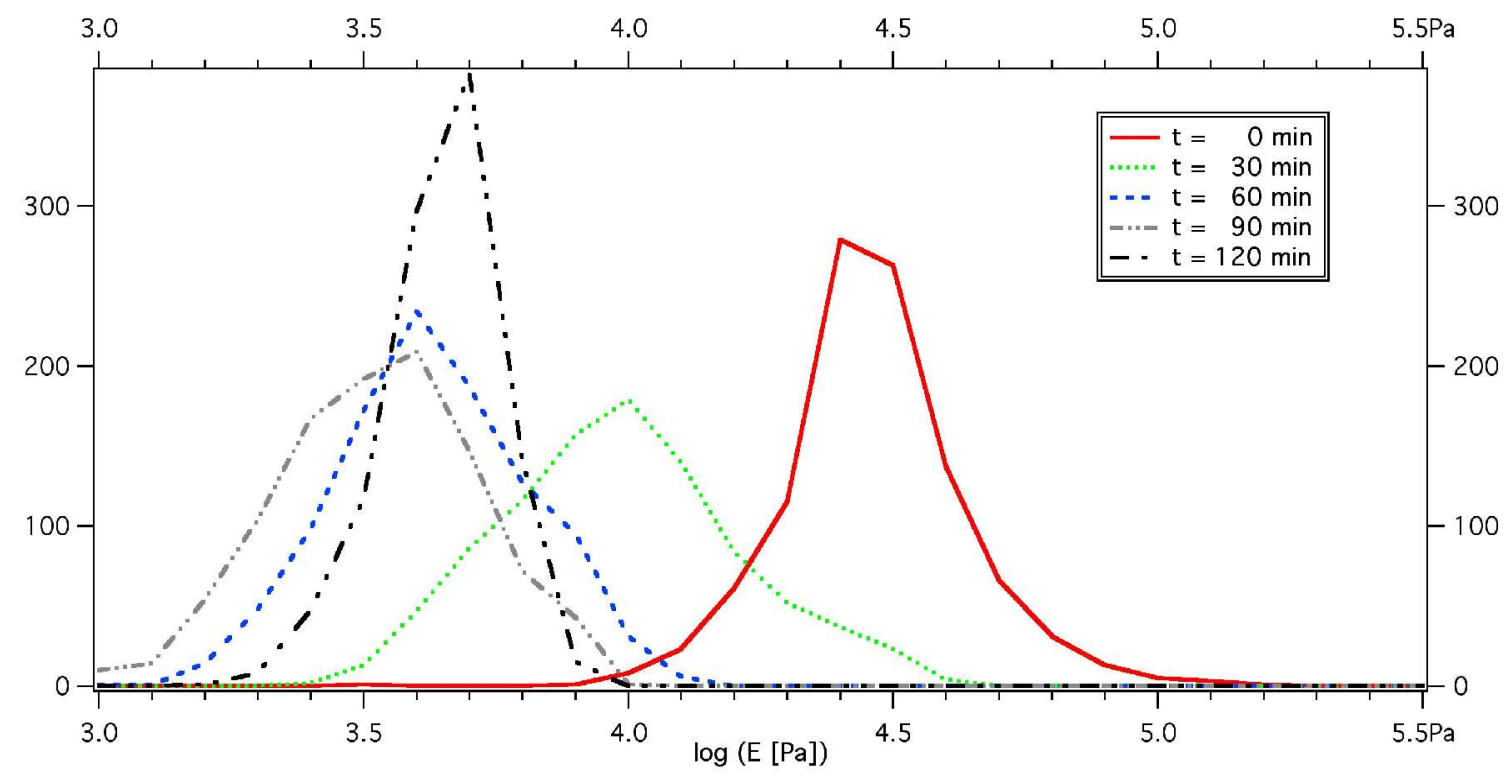

Abbildung 30: Zeitliche Abfolge von Histogrammen

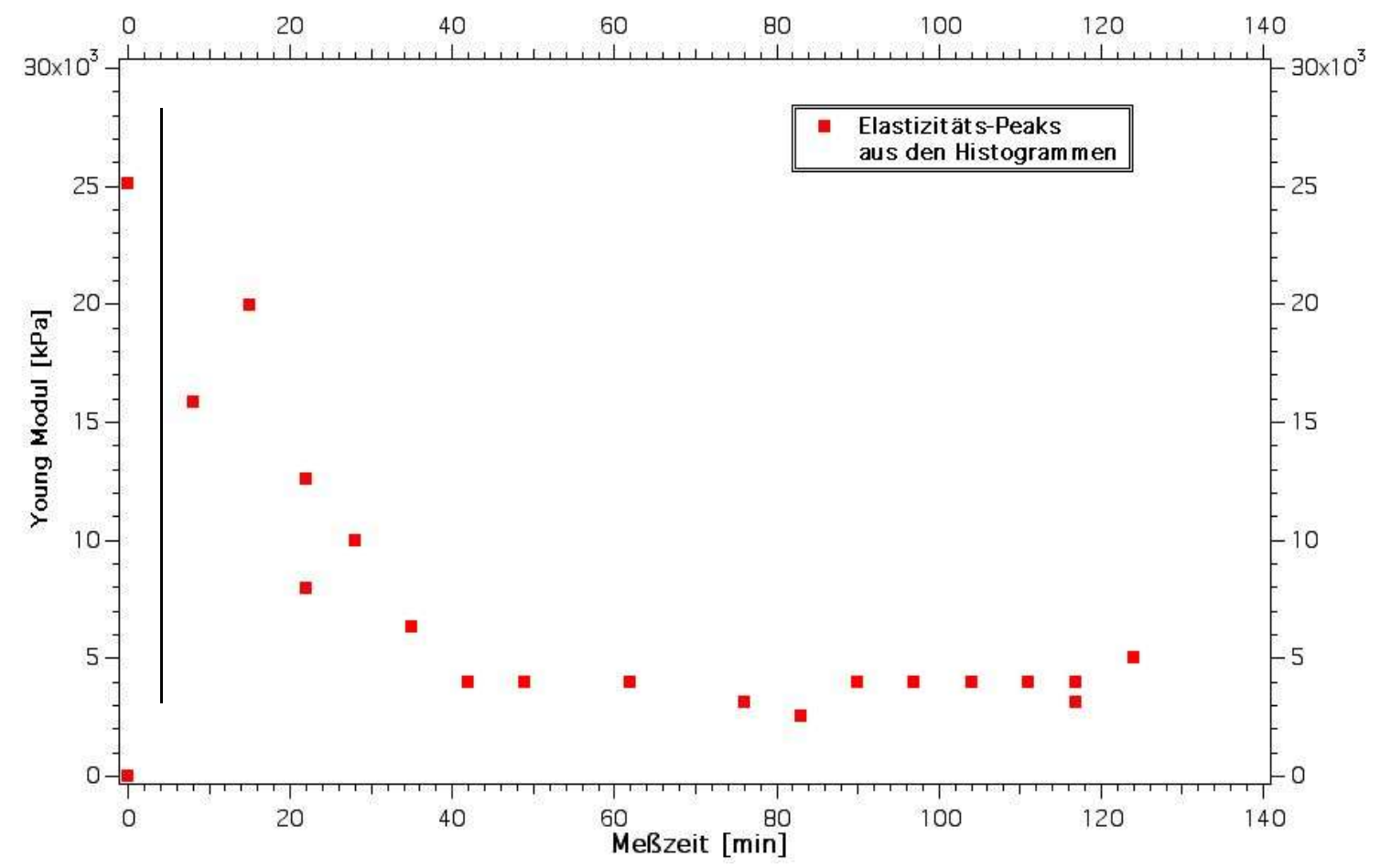

Abbildung 31: Young-Modul in Abhängigkeit der Zeit 
Um die maximale Zeitauflösung von 6-7 Minuten, die uns der Versuch erlaubt, zu nutzen, haben wir die Durchschnittswerte der Zell-Elastizität (die Peaks in den Histogrammen) als Funktion der Zeit aufgetragen. Das Ergebnis ist der Graph $\mathrm{E}=\mathrm{f}(\mathrm{t})$, welcher in Abbildung 31 dargestellt ist. Die roten Punkte sind die Durchschnitts-Elastizitäts-Werte, welche zu jedem Zeitpunkt aus dem dazugehörenden Histogramm gewonnen werden. Der Zeitpunkt der Inhibitor-Zugabe wurde durch einen schwarzen Balken dargestellt. Wie schon in Abbildung 30 ist eine deutliche - aber nicht stetige - Abnahme des Young-Moduls klar sichtbar. Die Meßpunkte E $=0$ zum Zeitpunkt $\mathrm{t}$ $=0$ sind Artefakte der Meßsoftware.

\subsubsection{Höhenabhängigkeit des Young-Moduls}

Ein Nachteil der Messungen mit dem AFM im Kontakt-Modus an dünnen, weichen Proben (z.B. Lamellipodien mit Dicken von wenigen $100 \mathrm{~nm}$ ) ist der unbekannte Einfluß des unterliegenden harten Substrates. Das ist gerade dann von Bedeutung, wenn das AFM nicht zum reinen Abbilden der Oberflächenbeschaffenheit, sondern zur Ermittlung von Elastizitätsinformationen der Probe benutzt wird. Die Meßspitze drückt dabei die Probenoberfläche bis zu einem gewissen Punkt ein (100-150 nm), um einen genügend guten Kontakt mit der Probe herzustellen und ausreichend Elastizitätsdaten zu bekommen. Dadurch „spürt“ die Feder das unterliegende Substrat (wie ein Finger, der auf eine dünne Gummihaut drückt, die auf einem Steinboden liegt) und die Informationen der Elastizität werden verfälscht. Eine dünne, weiche Probe erscheint deutlich härter. Verändert sich während der Messung die Höhe der Probe (z.B. weil sich das Lamellipodium zurückbildet), so verringert sich der Einfluß des unterliegenden Substrat auf die Messung der Probenelastizität.

Da ein Hauptteil dieser Arbeit sich mit der Messung von Zell-Elastizitäten und deren Änderungen beschäftigt, ist dieses Problem ein wichtiger nicht zu vernachlässigender Punkt. Würde sich die Höhe der Lamellipodium während der Messungen nicht ändern, so erhielten wir nur einen systematischen Fehler, der nur die absoluten Werte aber nicht die für uns interessanten Änderungen beträfe. Dies ist jedoch nicht der Fall. Sowohl Morphologien der Zellen als auch ihre Elastizitäten ändern sich zum Teil drastisch während der Messungen und eine Bestimmung oder Eliminierung des Einflusses des unterliegenden Substrats ist so von entscheidender Bedeutung. Untersuchungen zum Einfluss von dem Substrat wurden u.a. durchgeführt von Domke \& Radmacher, 1998 und Domke et al. 2000.

Die in dieser Arbeit beobachteten Zell-Lamellipodien haben eine Dicke im Bereich von 100 $800 \mathrm{~nm}$ und eine Abhängigkeit vom unterliegenden Substrat ist gegeben.

Um diesen Effekt aus unseren Daten zu eliminieren trugen wir den Logarithmus des YoungModuls gegen die Dicke des untersuchten Zellbereichs auf. Ergebnis war der Graph $\log E=f(d)$, wie in Abbildung 32 dargestellt.

Die Meßdaten zeigen sich als diffuse Punktwolke im Koordinatensystem. Diese Darstellung ist keine korrekte Wiedergabe der Messwerte, da viele Datenpunkte übereinander liegen. Um eine bessere Übersicht des mittleren Wertebereichs zu bekommen, wurde eine korrelierte Regressions-Gerade durch die Meßwerte gelegt. Für die Berechnung der Geraden wählten wir den Bereich [0,1] $\mu \mathrm{m}$, dies sind realistische Werte für die Dicke einer Zelle im Randbereich. Auf diese Weise konnten wir den Einfluß von unrealistischen Werten und Meßfehlern in die Berechnung der Gerade minimieren. Die Regressions-Gerade ist keine waagerechte Linie, wie sie bei einer symmetrischen Punktwolke zu erwarten ist, sondern zeigt eine deutliche Steigung der Elastizität zu geringen Dicken der Zelle. Dies bestätigt die Vermutung einer ungenügenden Darstellung der einzelnen Punkte. 


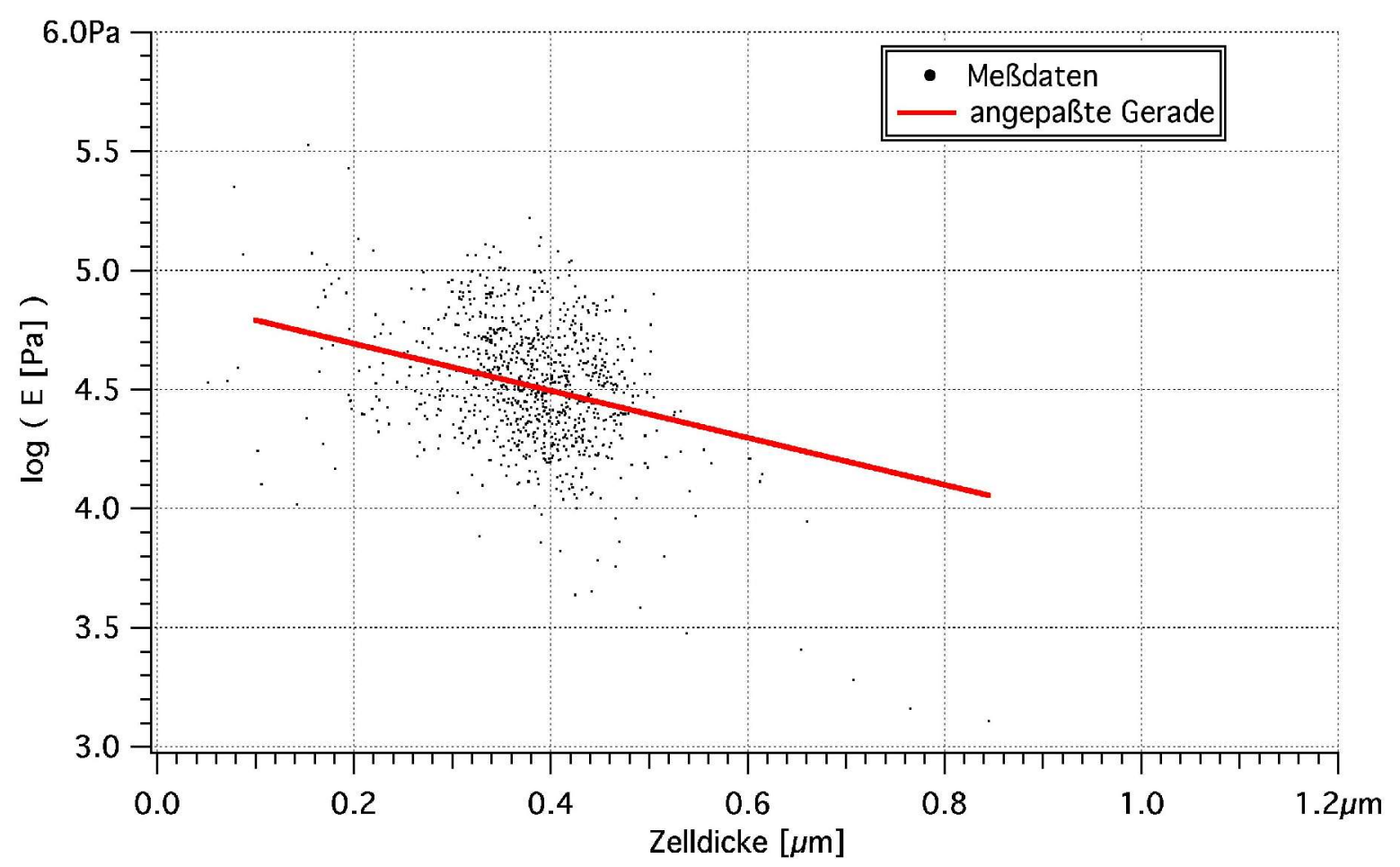

Abbildung 32: Logarithmus des Young-Moduls in Abhängigkeit der Zelldicke

Bei einem Vergleich der korrelierten Regressions-Geraden in Graphen zu verschiedenen Zeitpunkten erhalten wir eine höhenunabhängige Aussage über das Verhalten des Young-Moduls der Zelle während der Messung. 


\section{Ergebnisse und Diskussion}

\subsection{Videostatistik}

Wie in Abschnitt 3.1 beschrieben, wurden 42 Videoexperimente durchgeführt und in die Statistik aufgenommen. Hier noch einmal die Verteilung der Experimente auf die Zelllinien und die Inhibitoren:

Tabelle 3: Langzeit-Videoexperimente

\begin{tabular}{|l|l|l|}
\hline Zelllinie & Inhibitor & Experimente \\
\hline 3T3 & BDM & 11 \\
\hline NRK & BDM & 8 \\
\hline 3T3 & ML-7 & 8 \\
\hline NRK & ML-7 & 15 \\
\hline
\end{tabular}

Insgesamt wurden 92 Videoexperimente durchgeführt. Die verbleibenden 50 Versuche dienten zur Bestimmung der Inhibitor-Konzentrationsgrenzen (siehe Abschnitt 3.1), als Test für die Umgebungsbedingungen und dem Studium der ungehemmten Zellbewegung.

In der folgenden Tabelle ist für die einzelnen Zelllinien und Inhibitoren die Reaktionen der Versuchszellen aufgelistet. Es werden drei Klassen von Zellreaktionen unterschieden: starke, schwache und keine Reaktion. Bei der starken Reaktion stopt die Zelle ihre Bewegung und ändert drastisch innerhalb von 5-10 min ihre Morphologie von der ursprünglich ausgedehnten Form in eine sphärische Gestalt. Bei der schwachen Reaktion ändert die Zelle nur ansatzweise ihre Morphologie innerhalb von $30 \mathrm{~min}$ und die Bewegung wird nur verlangsamt. Bleibt die Zelle unbeeinflußt, so wird sie in die Kategorie „Keine Reaktion“ eingeordnet.

In die Statistik ebenfalls aufgenommen wurde die Regeneration der Zellen, die einen starken Effekt zeigten. Im Idealfall werden die Zellen sich vollständig von den Inhibitoren erholen und wieder zu ihrer ursprünglichen Bewegung und Morphologie zurückkehren. Die Regeneration wurde ebenfalls in drei Klassen unterteilt. Die Zellen, die sich gar nicht erholen und auch nach über einer Stunde in ihrer Bewegungslosigkeit und sphärischen Gestalt verbleiben; Zellen die sich teilweise regenerieren (z.B. wieder Lamellipodien bilden aber ansonsten keine Bewegung zeigen oder nur teilweise wieder ausgedehnte Strukturen zeigen) und Zellen, die sich vollständig wieder herstellen.

In den ersten drei Spalten sind der Zelltyp, der Inhibitor und die Anzahl der insgesamt beobachteten Zellen aufgelistet. In Spalte 4 und 5 sind die Zahlen für die Zellreaktionen und die Regeneration der Zellen angegeben - jeweils aufgeteilt in die drei oben beschriebenen Klassen.

Die in Tabelle 4 aufgelisteten Zahlen ergeben folgende Verteilung:

Tabelle 4: Statistik der Zellreaktionen auf die Inhibitoren

\begin{tabular}{|c|c|c|ccc|ccc|}
\hline Zelllinie & Inhibitor & Zellen & \multicolumn{3}{|c|}{$\begin{array}{c}\text { Zellreaktionen } \\
\text { schwache }\end{array}$} & \multicolumn{3}{c|}{$\begin{array}{c}\text { Regeneration } \\
\text { keine }\end{array}$} \\
\hline 3T3 & BDM & 110 & 72 & 30 & 8 & 33 & 30 & 9 \\
\hline NRK & BDM & 81 & 48 & 32 & 1 & 31 & 16 & 1 \\
\hline 3T3 & ML-7 & 62 & 58 & 4 & 0 & 49 & 3 & 6 \\
\hline NRK & ML-7 & 150 & 107 & 42 & 1 & 60 & 44 & 3 \\
\hline
\end{tabular}


Es wurden insgesamt 403 Zellen beobachtet, davon zeigten 173 Zellen ideal das erwartete Verhalten - die Bewegung wurde gestoppt und die Morphologie sphärisch. Dieser Prozess vollzog sich innerhalb von 5-10 min nach Zugabe des jeweiligen Inhibitors. Nach einer Zeit von 30-60 min zeigten alle Zellen eine vollständige Regeneration.

Weitere 102 Zellen zeigten ebenfalls die beschriebenen Effekte, doch konnten sie ihre Merkmale auch nach 60-120 min nicht wieder vollständig herstellen. Diese Zahlen sind in Tabelle 5 zusammengefaßt.

Tabelle 5: Zusammenfassung der Zellstatistik

\begin{tabular}{|c|c|c|}
\hline $\begin{array}{c}\text { Gesamtzahl der } \\
\text { beobachteten Zellen }\end{array}$ & Ideales Verhalten & $\begin{array}{c}\text { Erwartetes Verhalten ohne } \\
\text { Regeneration }\end{array}$ \\
\hline 403 & $173(43 \%)$ & $285(71 \%)$ \\
\hline
\end{tabular}

Insgesamt zeigen also 71\% der beobachteten Zellen die gewünschte Reaktion auf die Inhibitoren und es konnte wenigstens zum Teil eine Wiederaufnahme der Bewegung und Ausbildung von Lamellipodien beobachtet werden.

Nur $10(2,5 \%)$ von 403 beobachteten Zellen zeigten keinerlei Reaktion.

\subsection{AFM-Daten}

In unseren AFM-Messungen unterschieden wir zwei Bereiche der Zelle: die Lamellipodien, denen unser eigentliches Interesse galt und der Zellkörper, von dem einige Messungen zum Vergleich aufgenommen wurden. Die Lamellipodien zeigen die meiste Bewegung und damit auch die stärkste Reaktion auf die zugefügten Inhibitoren. Der Zellkörper hingegen ist deutlich höher (1-2 $\mu \mathrm{m})$ und wir können annehmen, dass die Meßwerte, die wir hier aufgenommen haben frei von Einflüssen des unterliegenden Substrat sind. Als repräsentative Beispiele werden nun Messungen mit NRK Zellen und dem Inhibitor ML-7 vorgestellt und erläutert.

\subsubsection{Der Zellkörper}

In Abbildung 33 zeigen wir eine Abfolge von Elastizitätskarten (siehe Abschnitt 4.2), die in einem 60 minütigen Experiment gewonnen wurden. Untersucht wurde der Zellkörper einer NRK-Zelle. Es sind keine Details vom Zellinneren auf den Karten zu erkennen, da der Zellkörper sehr weich und empfindlich ist und bei Messungen in diesem Bereich immer die Gefahr einer Schädigung der Zelloberfläche bei Ausübung zu großer Kräfte besteht.

Bild (a) ist eine Referenzabbildung aufgenommen bevor wir den Inhibitor in die Probe gegeben haben. Anhand der Farbkodierung erkennt man ein Young-Modul von ungefähr 6-7 kPa. Im linken Bildbereich ist ein deutlich weicheres Gebiet mit einem Young-Modul von $<3 \mathrm{kPa} z u$ sehen. Bild (b) ist 5 min nach der Zugabe von $12 \mu \mathrm{M}$ ML-7 aufgenommen und der obere Bereich zeigt bereits eine Verringerung des Young-Moduls um ca. 3-4 kPa. Nach 30-60 min (c-d) hat fast der gesamte Meßbereich Werte von 1-2 $\mathrm{kPa}$ angenommen. Oben links ist ein Bereich mit großem Young-Modul entstanden ( $>10 \mathrm{kPa}$ ); dies ist das durch Rückzug der Zelle sichtbar gewordene unterliegende Substrat.

Obwohl in den Elastizitätskarten die räumliche Verteilung der Zellelastizität und deren Veränderung gut zu erkennen ist, ist eine genaue Bestimmung der Werte kaum möglich. Um mehr quantitative Informationen zu erhalten, müssen wir auf die räumlichen Daten verzichten und die Histogramme der Elastizitätskarten betrachten. 

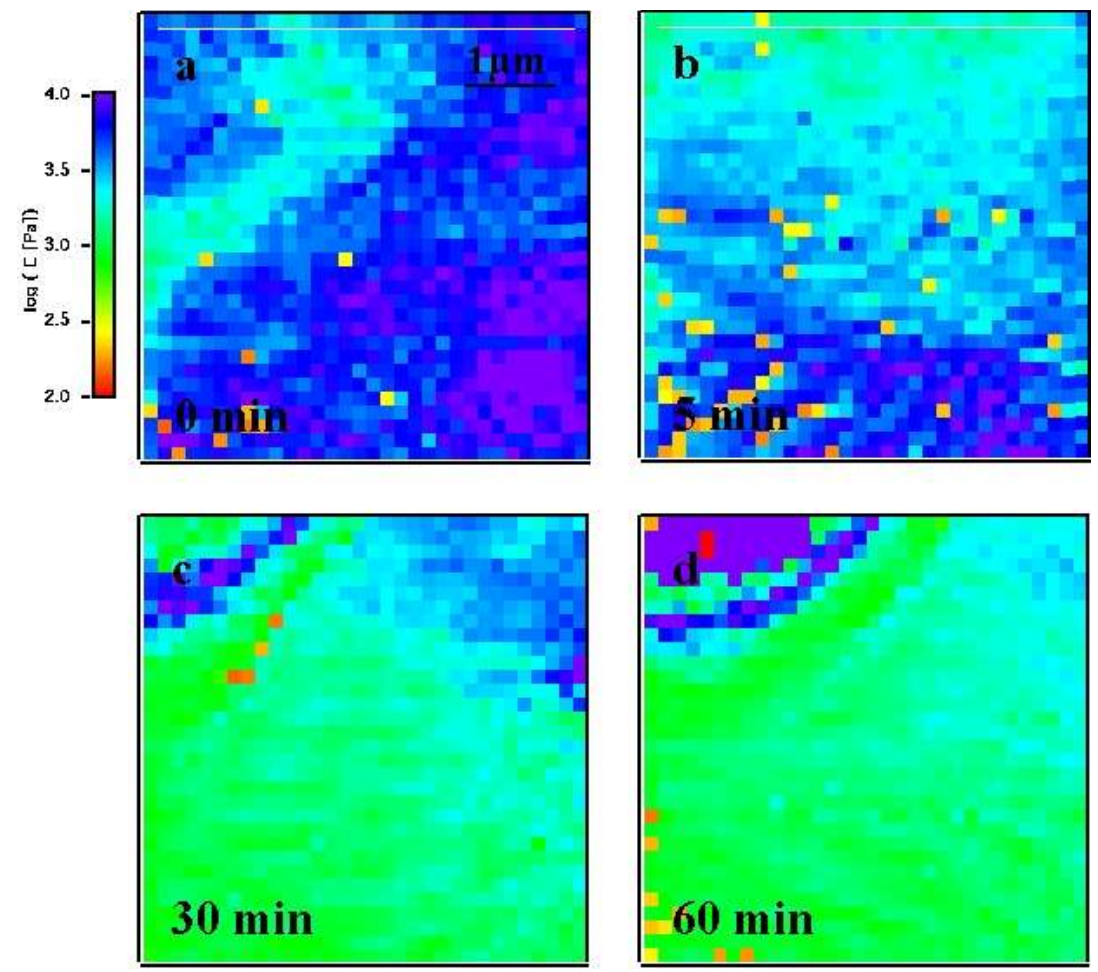

Abbildung 33: Zeitserie von Elastizitätskarten eines NRK-Zellkörpers

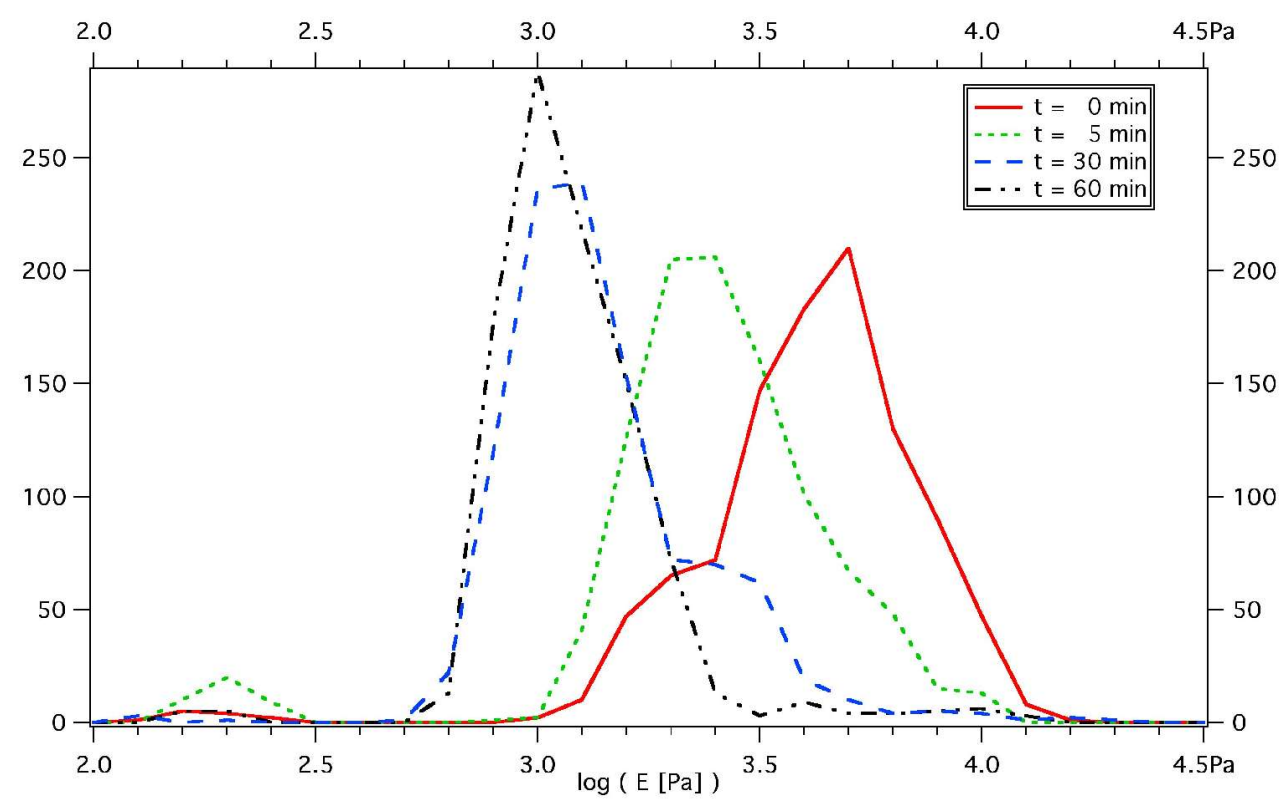

Abbildung 34: Histogramme zu den Elastizitätskarten 
In Abbildung 34 sind die vier Histogramme zu den in Abbildung 33 gezeigten Elastizitätskarten dargestellt. Die Histogramme bestätigen die aus den Elastizitätskarten gewonnen Erkenntnisse und liefern uns einen genauen Wert für der durchschnittliche Young-Modul der Zelle. Aus den Histogrammen entnehmen wir, dass sich der Young-Modul von einem Wert von $5 \mathrm{kPa}(\mathrm{t}=0)$ auf $1 \mathrm{kPa}$ nach 60 min verringert hat.

Die Abnahme des Young-Moduls von $5 \mathrm{kPa}$ vor und $1 \mathrm{kPa}$ nach Zugabe des Inhibitors entspricht einem Faktor 5 und repräsentiert eine großen Einfluß des Myosin II auf die Zellmechanik (siehe Abschnitt 5.4).

In den obigen Zeitserien ist die Zeitauflösung sehr grob gewählt. Um auszuschließen, dass kurzzeitige Schwankungen des Young-Moduls übersehen wurden, haben wir in Abbildung 35 der Young-Modul gegen die Zeit aufgetragen. Obwohl wir dabei eine bessere Auflösung der Zeit erreichen, wird die 2-dimensinale Elastizitätskarte auf einen Punkt reduziert.

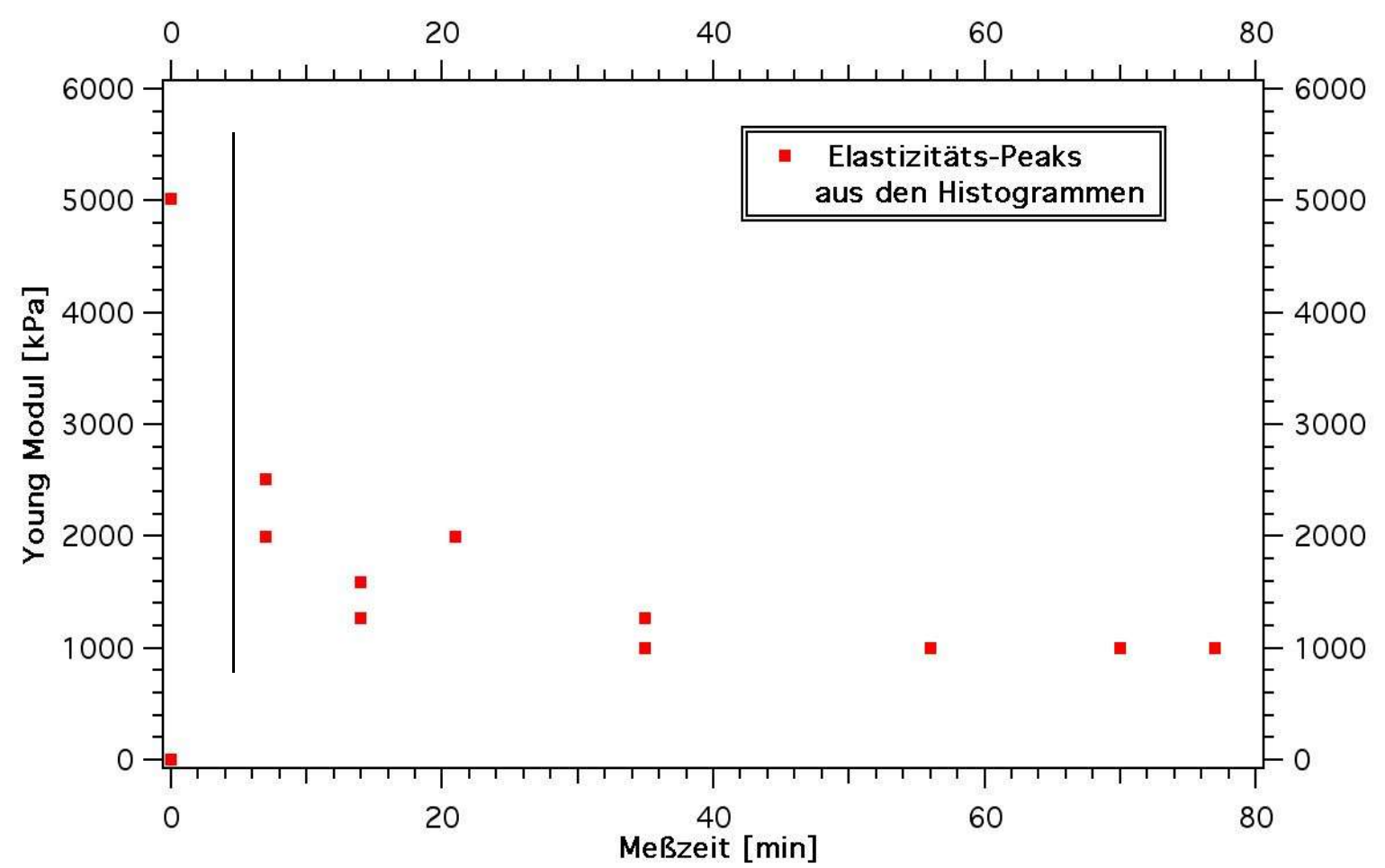

Abbildung 35: Young-Modul in Abhängigkeit der Zeit

Bis auf eine breite Fächerung des Young-Moduls zum Zeitpunkt $t=20$ min bestätigt der Graph die aus den Zeitserien gewonnen Ergebnisse.

Die Betrachtung aller drei Typen von Abbildungen stellt sicher, dass sowohl die Änderungen mit der Zeit als auch die 2-dimensionale Verteilung des Young-Moduls ausreichend Beachtung finden. 


\subsubsection{Die Lamellipodien}

Wie für den Zellkörper wurden für ein Lamellipodium Elastizitätskarten, dazugehörige Histogramme und der zeitliche Verlauf erstellt. Diese werden auf Abbildungen 36, 37 und 38 graphisch dargestellt. In den Elastizitätskarten sind diesmal mehr Details zu erkennen und gerade in Bild (d) kann man die Aktin-Filamente gut erkennen.

Der gesamte Meßbereich ist deutlich härter im Vergleich zum Zellkörper und wir erkennen in dem Referenzbild (a) Young-Module von 25 bis $100 \mathrm{kPa}$. In den folgenden drei Bildern sind die zeitlichen Veränderungen der Zellelastizität der nächsten 120 min nach Zugabe von $15 \mu \mathrm{M}$ ML-7 abgebildet. Der Young-Modul in Bild (d) ist in vielen Bereichen bis auf einen Wert von $\sim 1 \mathrm{kPa}$ abgefallen.
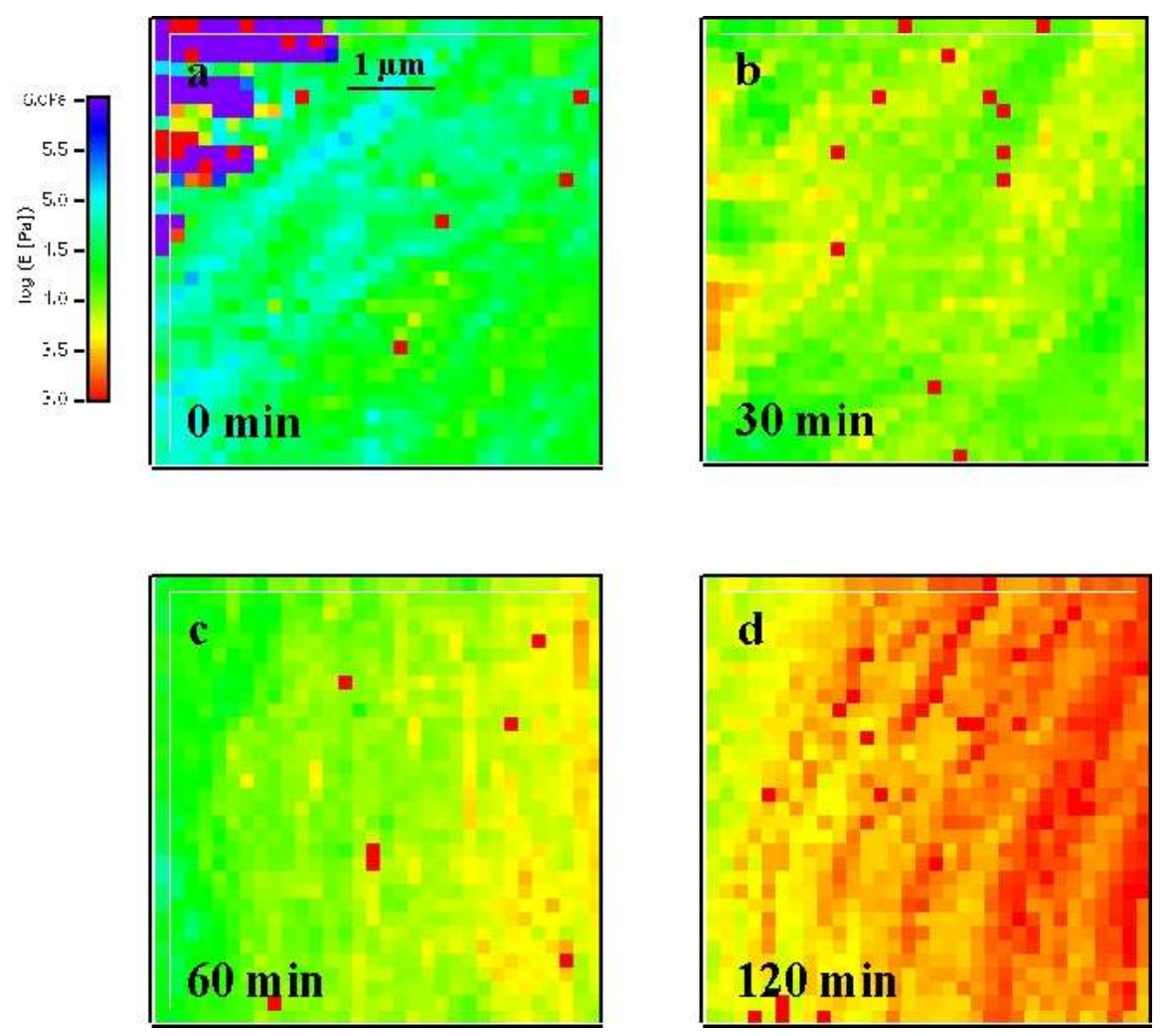

Abbildung 36: Zeitserie von Elastizitätskarten eines NRK-Lamellipodium

Die Histogramme (Abb. 37) bestätigen den drastischen Abfall des Young-Moduls von 25-30 kPa im Mittel zum Zeitpunkt $\mathrm{t}=0$ auf einen Wert von ungefähr $2 \mathrm{kPa}$ nach einer Meßdauer von 120 min. Der Faktor der Abnahme liegt bei 12-15 und damit 2-3 mal höher als beim Zellkörper.

Trotz einiger Schwankungen der Mittelwerte (leichter Anstieg des Young-Moduls bei $\mathrm{t}=35 \mathrm{~min}$ ) sind aus Abbildung 38 die gleichen Ergebnisse abzulesen. 


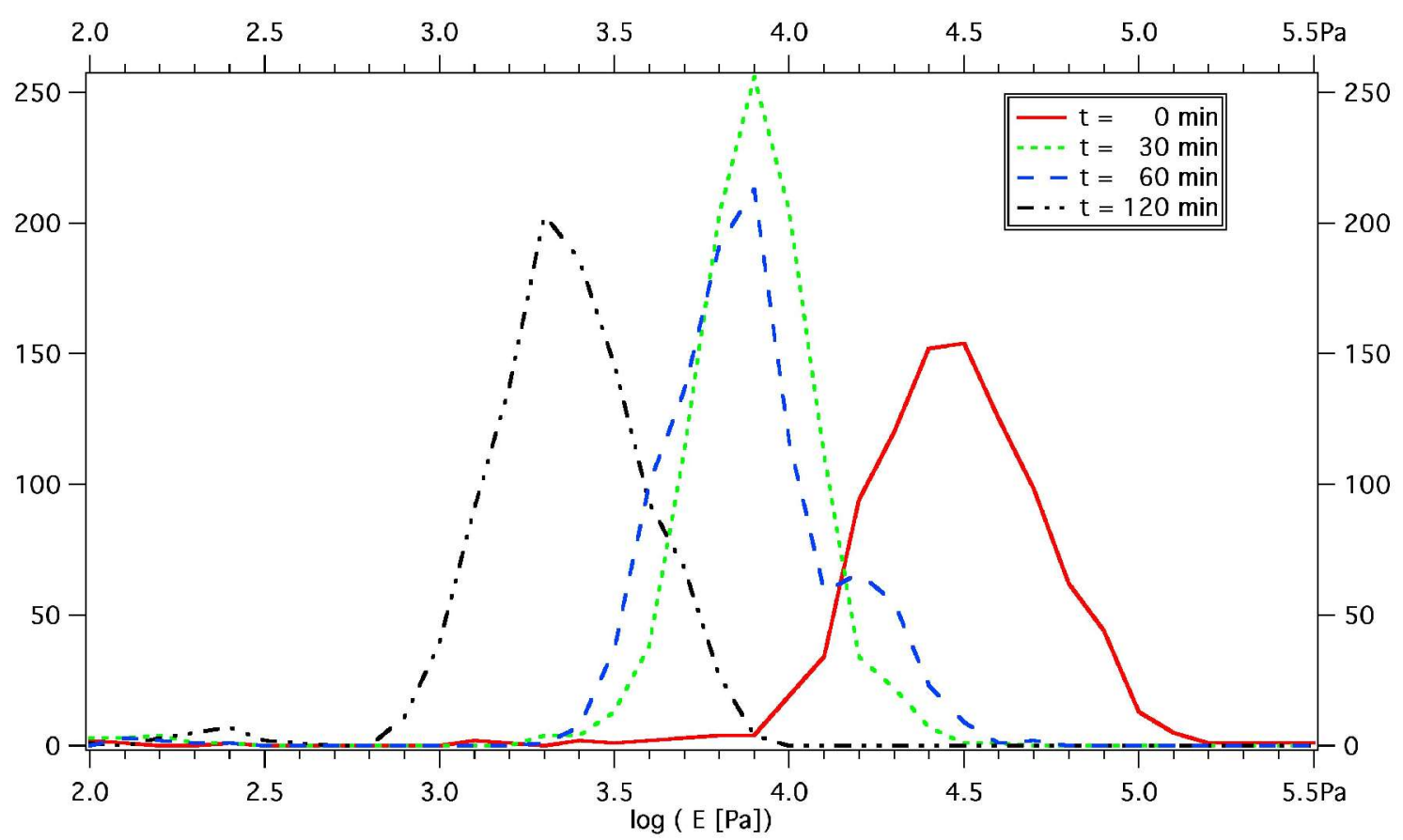

Abbildung 37: Histogramme zu den Elastizitätskarten

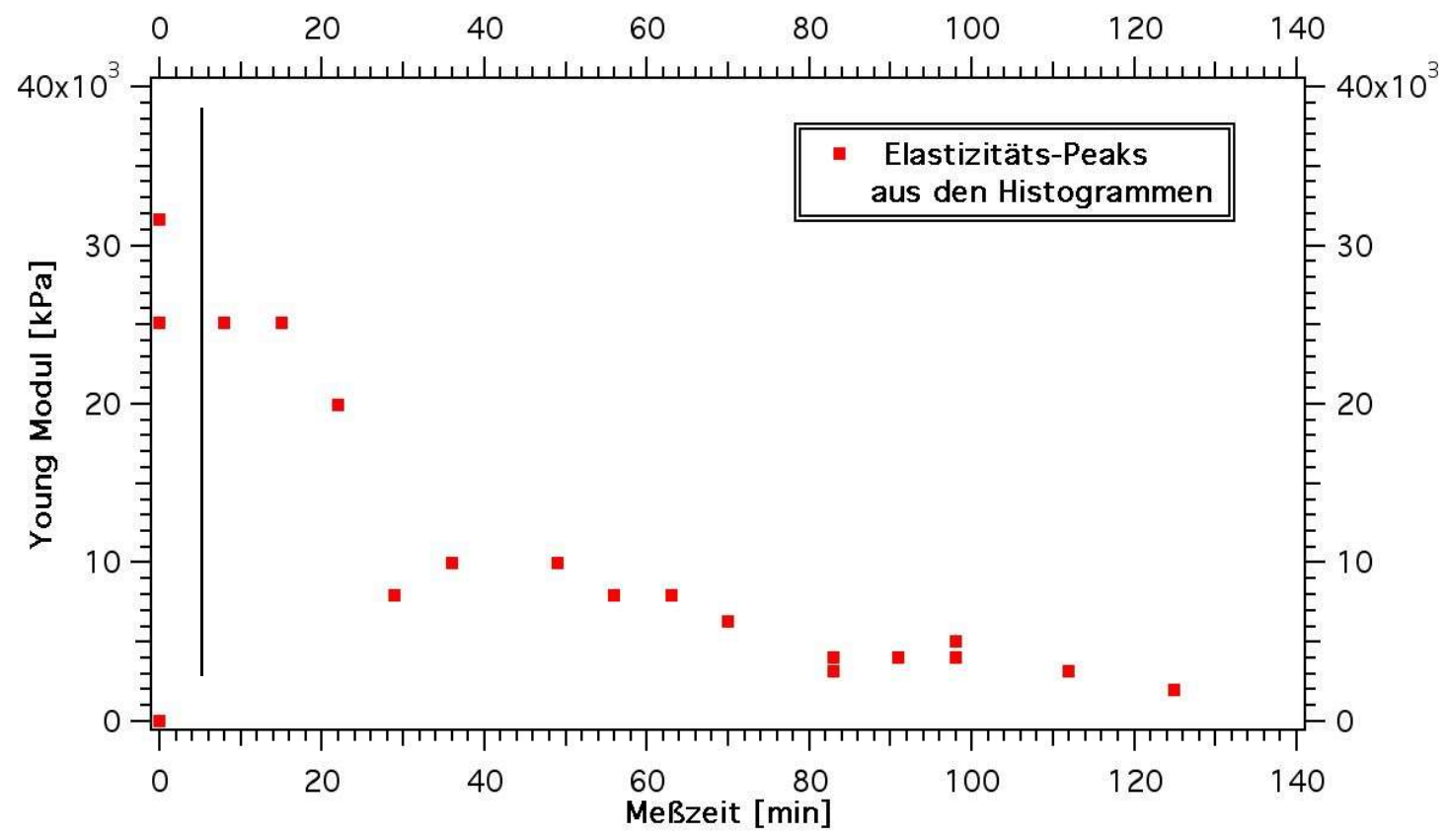

Abbildung 38: Young-Modul in Abhängigkeit der Zeit 
Um den Einfluß des unterliegenden Substrates zu eliminieren, wird der Young-Modul in Abhängigkeit von der Höhe - wie im Abschnitt 4.2.3 beschrieben - aufgetragen.

Die folgenden Abbildungen (39-42) zeigen die Verteilung der Meßwerte in den Graphen $E=f$ (d). Es wurden die gleichen Meßzeitpunkte gewählt, die uns schon die Elastizitätskarten und die Histogramme geliefert haben, so dass ein direkter Vergleich mit diesen möglich ist. Die Pfeile in den vier Graphen markieren die Zelldicke von $0,6 \mu \mathrm{m}$.

Die durch die Punktwolken der Meßwerte gelegten Geraden zeigen eindeutig größere Werte des Young-Moduls bei geringeren Zelldicken. Vergleicht man nun die Young-Module zu den vier verschieden Zeitpunkten bei gleicher Höhe so ergeben sich für die Zelldicke von 0,6 $\mu \mathrm{m}$ folgende Werte:

Tabelle 6: Vergleich des Young-Moduls bei Zelldicke 0,6 $\mu \mathrm{m}$

\begin{tabular}{|c|c|c|}
\hline Zeitpunkt & $\log \mathbf{( E}[\mathbf{P a}])$ & Young-Modul [kPa] \\
\hline $0 \mathrm{~min}$ & 4,3 & 20,0 \\
\hline $30 \mathrm{~min}$ & 3,9 & 7,9 \\
\hline $60 \mathrm{~min}$ & 3,9 & 7,9 \\
\hline $120 \mathrm{~min}$ & 3,8 & 6,3 \\
\hline
\end{tabular}

Der Faktor zwischen dem Wert bei $\mathrm{t}=0 \mathrm{~min}, 20 \mathrm{kPa}$ und dem Wert bei $\mathrm{t}=120 \mathrm{~min}, 6,3 \mathrm{kPa}$ liegt nun nur noch bei 3,2. Dieser höhen-korrigierte Faktor ist deutlich niedriger als die Werte von 12-15, die aus den Histogrammen abgelesen wurden. Dies läßt auf einen deutlichen Einfluß der Zelldicke schließen. Betrachten wir nun zum Vergleich eine Zelldicke von 0,8 $\mu \mathrm{m}$ und 0,4 $\mu \mathrm{m}:$

Tabelle 7: Vergleich des Young-Moduls bei Zelldicke 0,8 $\mu \mathrm{m}$

\begin{tabular}{|c|c|c|}
\hline Zeitpunkt & $\log \mathbf{( E}[\mathbf{P a}])$ & Young-Modul [kPa] \\
\hline $0 \mathrm{~min}$ & 4,1 & 12,6 \\
\hline $30 \mathrm{~min}$ & 3,7 & 5,0 \\
\hline $60 \mathrm{~min}$ & 3,7 & 5,0 \\
\hline $120 \mathrm{~min}$ & 3,6 & 4,0 \\
\hline
\end{tabular}

Tabelle 8: Vergleich des Young-Moduls bei Zelldicke 0,4 $\mu \mathrm{m}$

\begin{tabular}{|c|c|c|}
\hline Zeitpunkt & $\log \mathbf{( E}[\mathbf{P a}])$ & Young-Modul [kPa] \\
\hline $0 \mathrm{~min}$ & 4,5 & 31,6 \\
\hline $30 \mathrm{~min}$ & 4,1 & 12,6 \\
\hline $60 \mathrm{~min}$ & 4,2 & 15,9 \\
\hline $120 \mathrm{~min}$ & 4,0 (extrapoliert) & 10,0 \\
\hline
\end{tabular}

Aus beiden Tabellen erhalten wir einen Faktor von ebenfalls 3,2. Wir können also von der Richtigkeit der Methode ausgehen.

Wie schon an den Geraden in den Abbildungen 39-42 zu sehen war, sind auch die Werte der Referenzmessung $(t=0)$ bei geringerer Zellendicke deutlich höher: 31,6 kPa bei 0,4 $\mu \mathrm{m}$ und nur $12,6 \mathrm{kPa}$ bei $0,8 \mu \mathrm{m}$. Diese Methode bringt uns sowohl realistische Werte für den Young-Modul einer Zelle als auch korrigierte Faktoren der Verringerung der Elastizität.

Diese Ergebnisse und ihre Bedeutung werden in Abschnitt 5.4 noch eingehend diskutiert. 


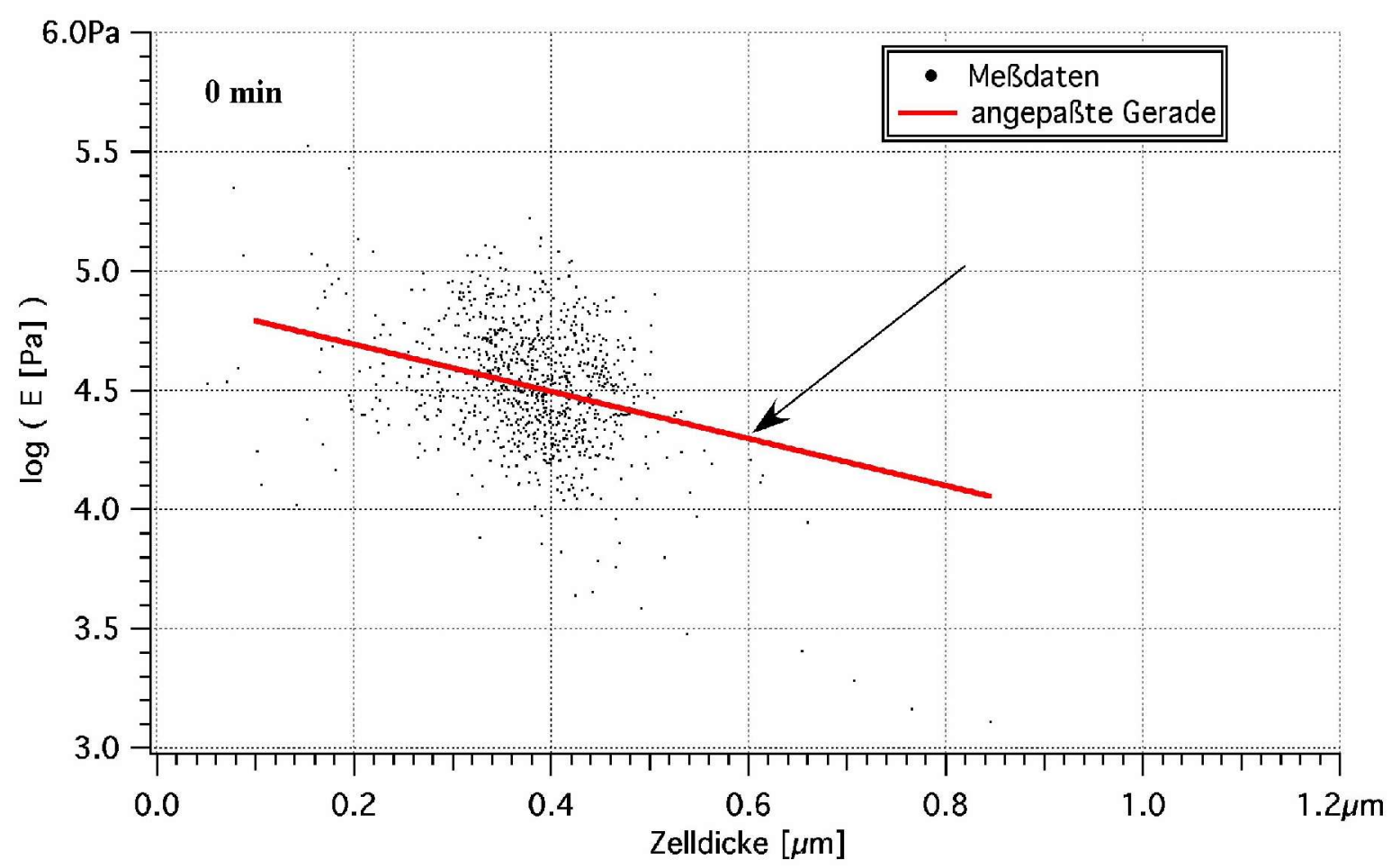

Abbildung 39: Der Logarithmus des Young-Moduls in Abhängigkeit der Dicke ( $\mathrm{t}=0 \mathrm{~min})$

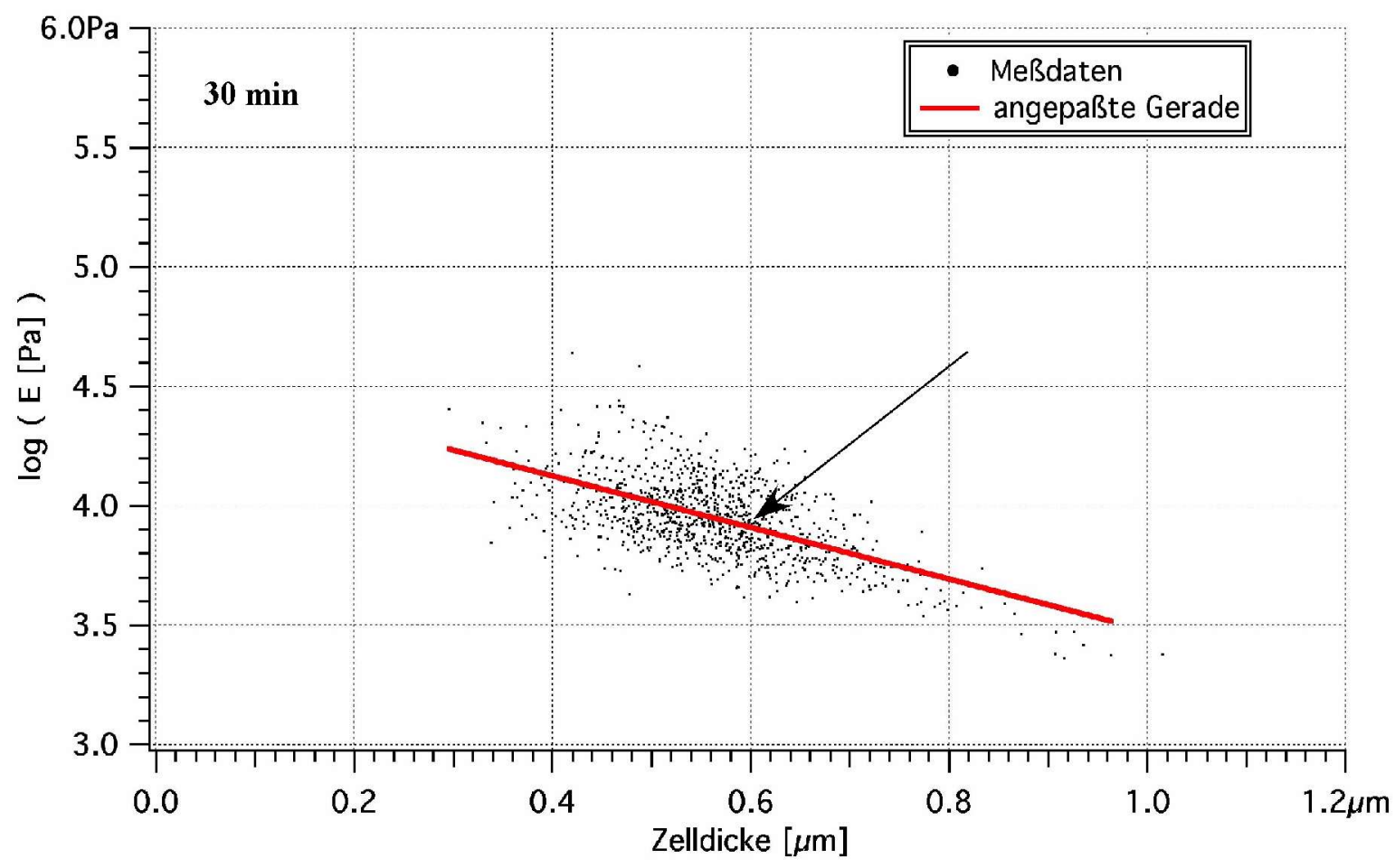

Abbildung 40: Der Logarithmus des Young-Moduls in Abhängigkeit der Dicke $(\mathrm{t}=30 \mathrm{~min})$ 


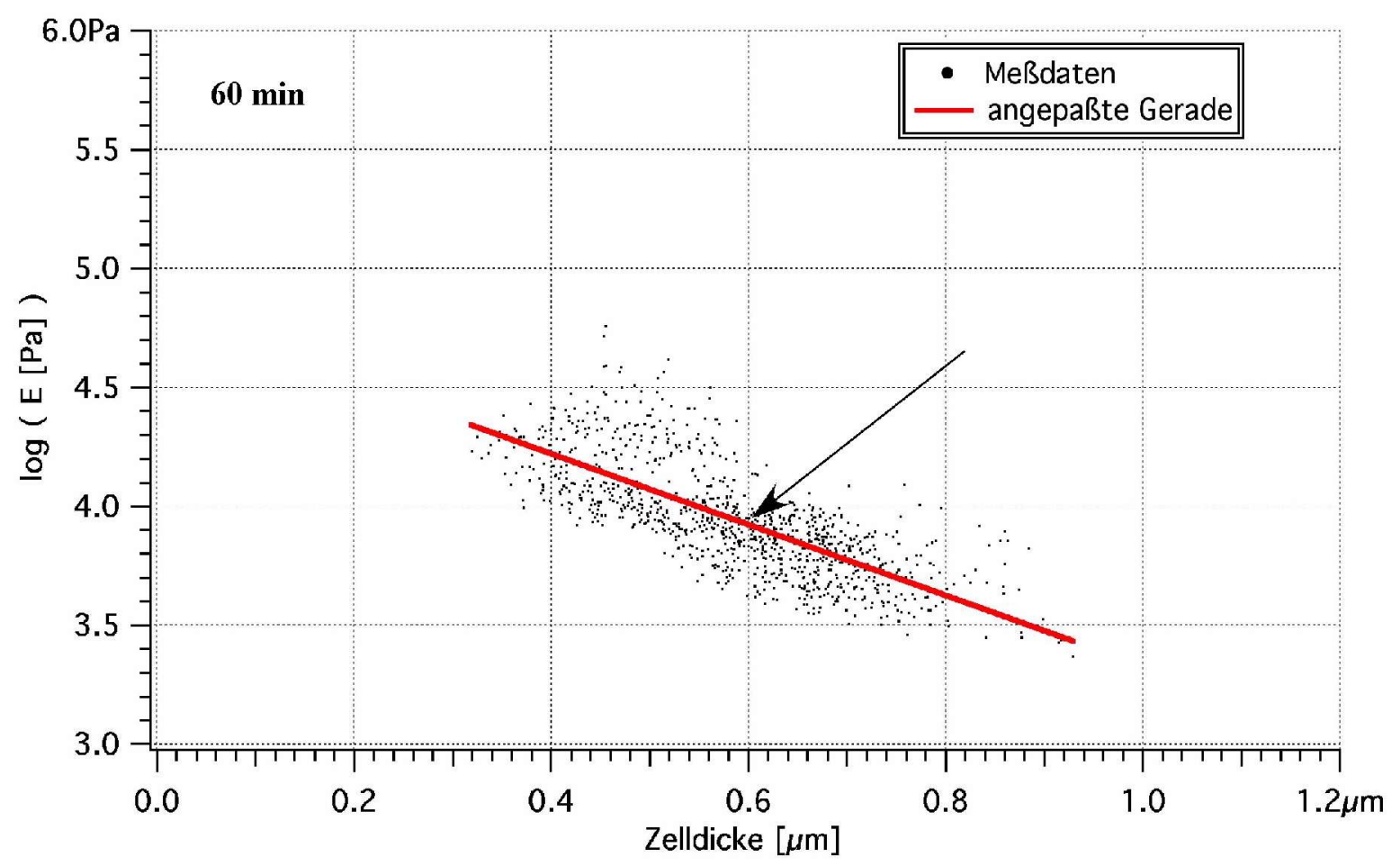

Abbildung 41: Der Logarithmus des Young-Moduls in Abhängigkeit der Dicke $(t=60 \mathrm{~min})$

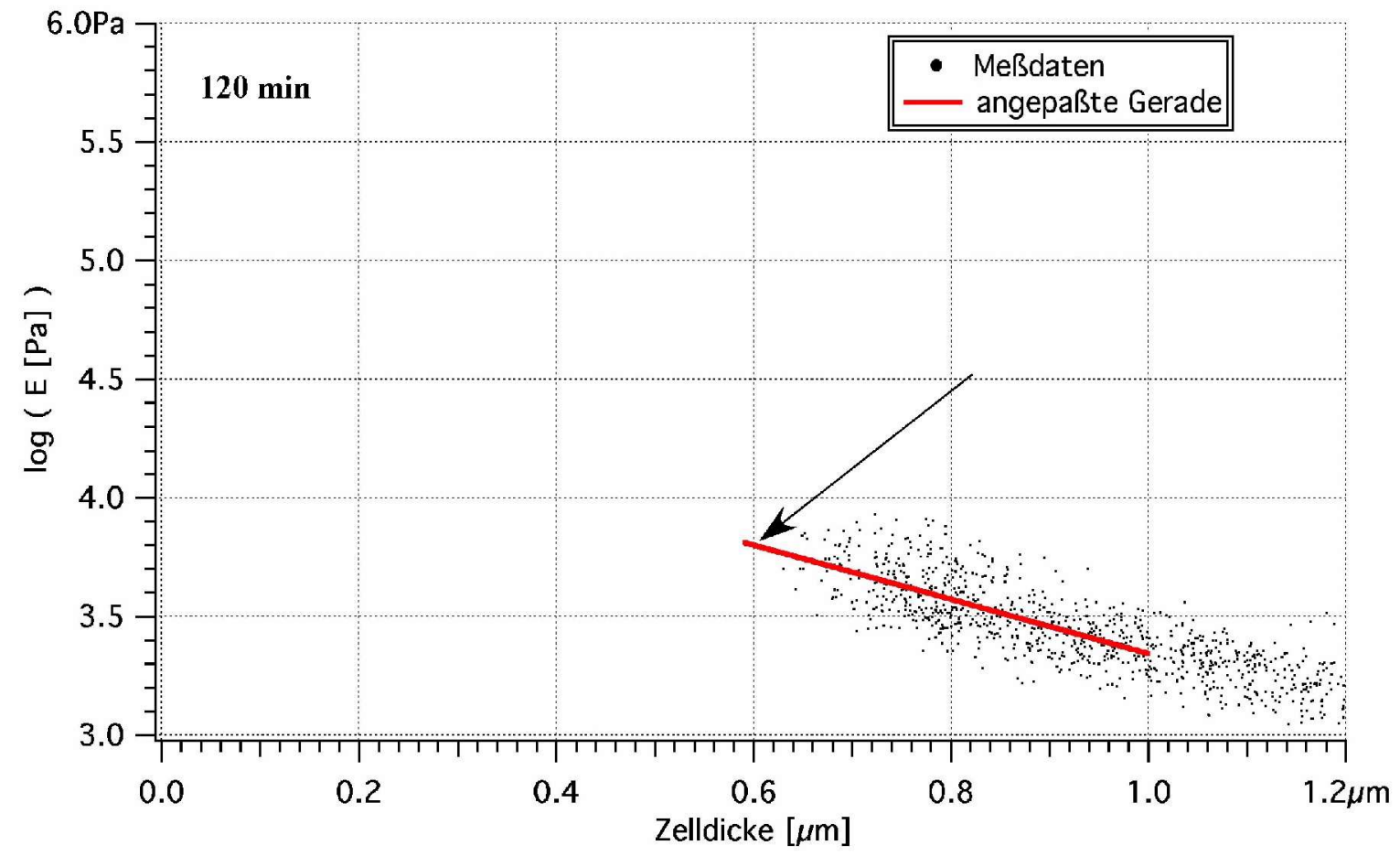

Abbildung 42: Der Logarithmus des Young-Moduls in Abhängigkeit der Dicke $(t=120 \mathrm{~min})$ 


\subsubsection{Vergleichende Ergebnisse}

Bevor eine allgemeine Statistik der durchgeführten Messungen und deren Ergebnisse vorgestellt wird, präsentieren wir hier die Graphen $E=f(d)$, wie sie unter Abschnitt 5.2.2 für die Zelllinie NRK unter dem Einfluß des Inhibitors ML-7 vorgestellt wurden, für die anderen Permutationen der verwendeten Zelllinien und Inhibitoren.

In den drei Abbildungen 43-45 ist jeweils der gesamte Zeitverlauf einer Messung in einem Graphen beschrieben und die verschiedenen Zeitpunkte durch unterschiedliche Darstellung der Geraden markiert. Man beachte die unterschiedliche Skalierung der y-Achsen zur besseren Übersicht.

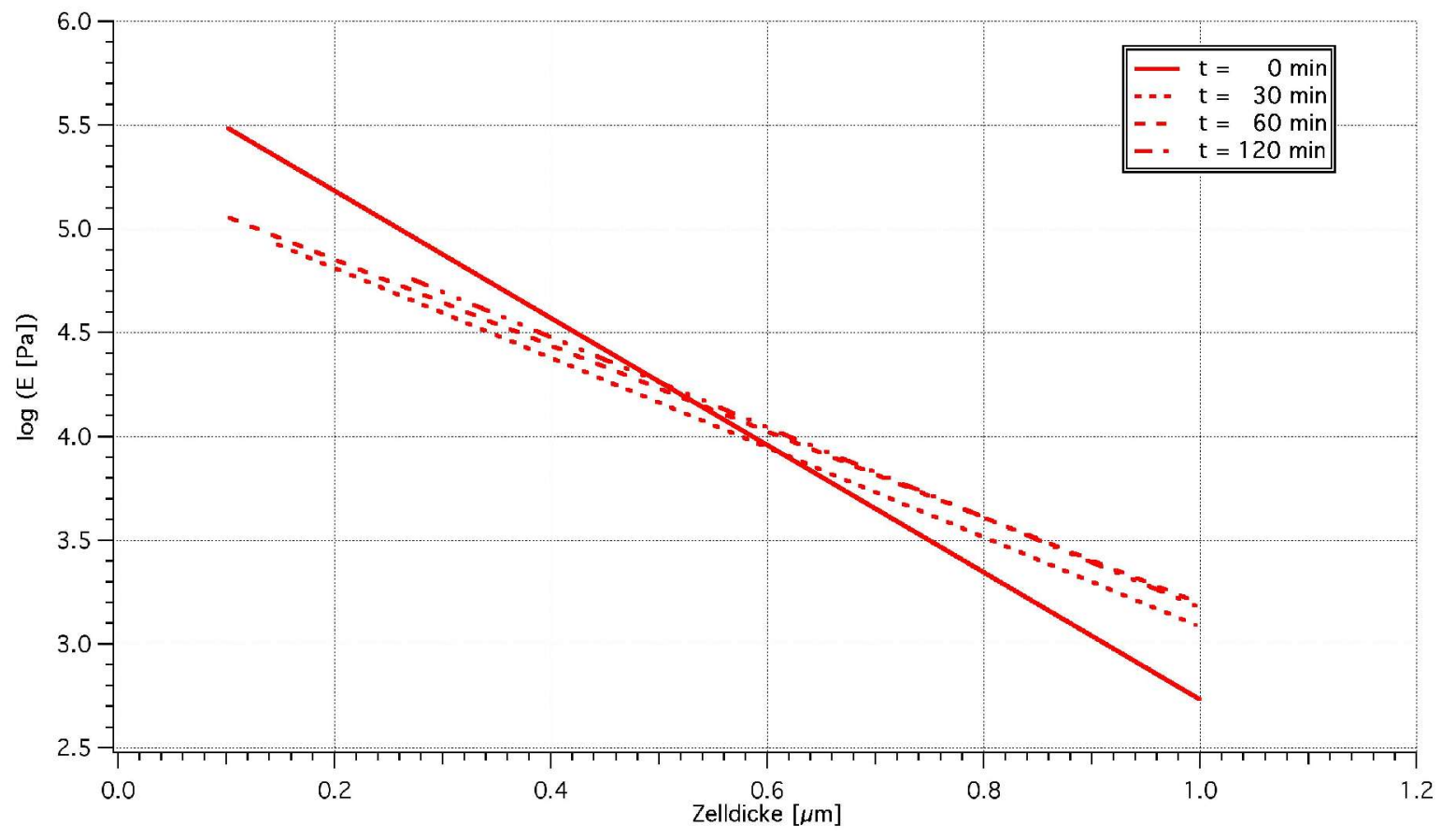

Abbildung 43: Höhenabhängige Darstellung für NRK-Zelle und BDM-Inhibitor

Nach dem unter Abschnitt 5.2.2 vorgestellten Verfahren werden die Faktoren der Elastizitätsverringerung bei gleicher Höhe ermittelt. Als Standarddicke wird 0,6 $\mu \mathrm{m}$ verwendet. So erhalten wir folgende Ergebnisse:

Tabelle 9: Faktoren der Elastizitätsverringerung

\begin{tabular}{|c|c|c|}
\hline Zelllinie & Inhibitor & Faktoren bei gleicher Höhe \\
\hline NRK & ML-7 & 3,2 \\
\hline NRK & BDM & 2,8 \\
\hline 3T3 & ML-7 & 3,6 \\
\hline 3T3 & BDM & 2,4 \\
\hline
\end{tabular}

Wir erhalten für alle Permutationen einen ähnlichen Wert für den Faktor. Damit scheint der Wertebereich von $\sim 2,5-3,5$ eine Allgemeingültigkeit für die Verringerung der Zellelastizität nach „Deaktivierung“ des Myosin II zu haben. Mehr dazu unter Abschnitt 5.4. 


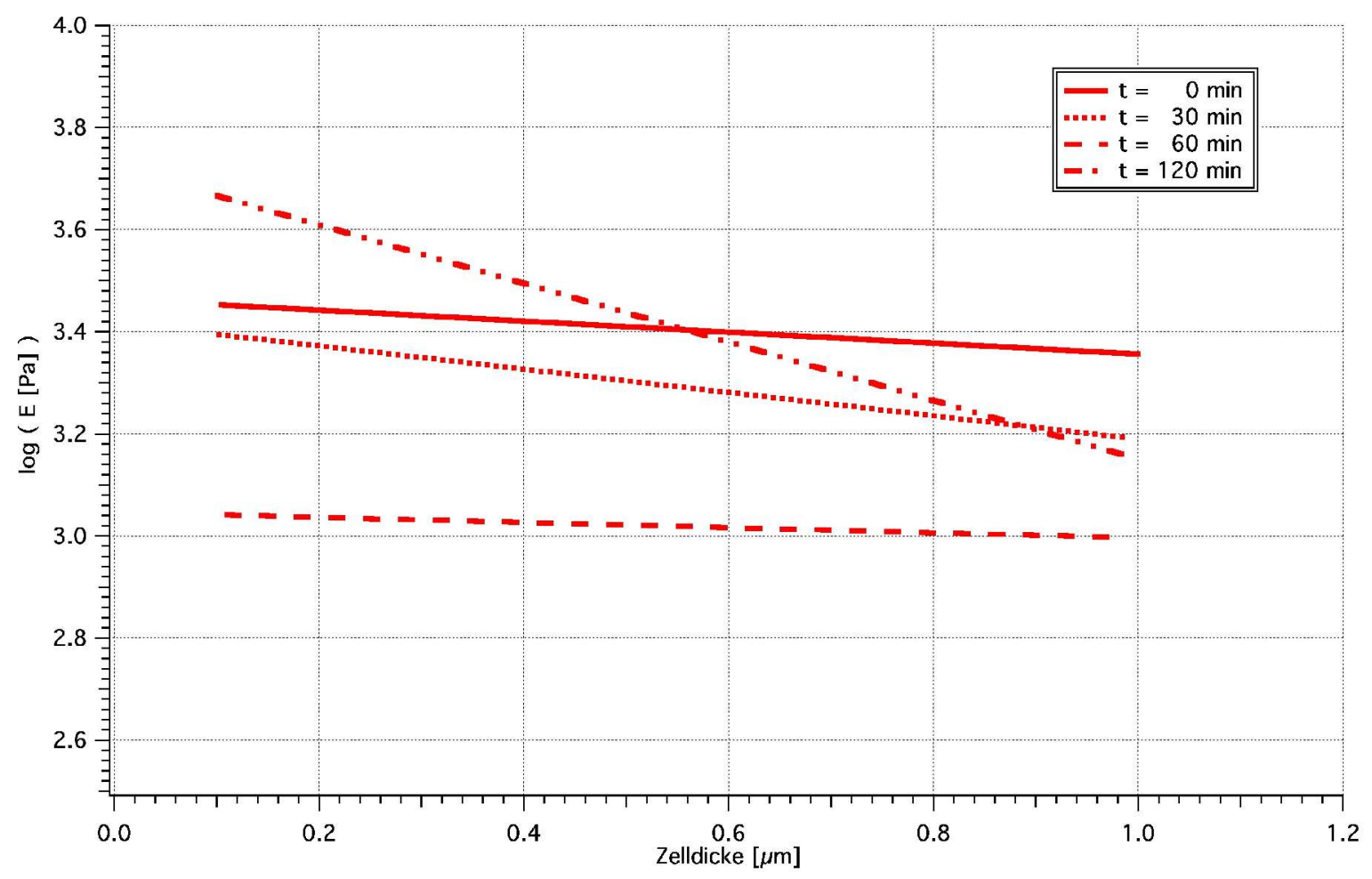

Abbildung 44: Höhenabhängige Darstellung für 3T3-Zelle und BDM-Inhibitor

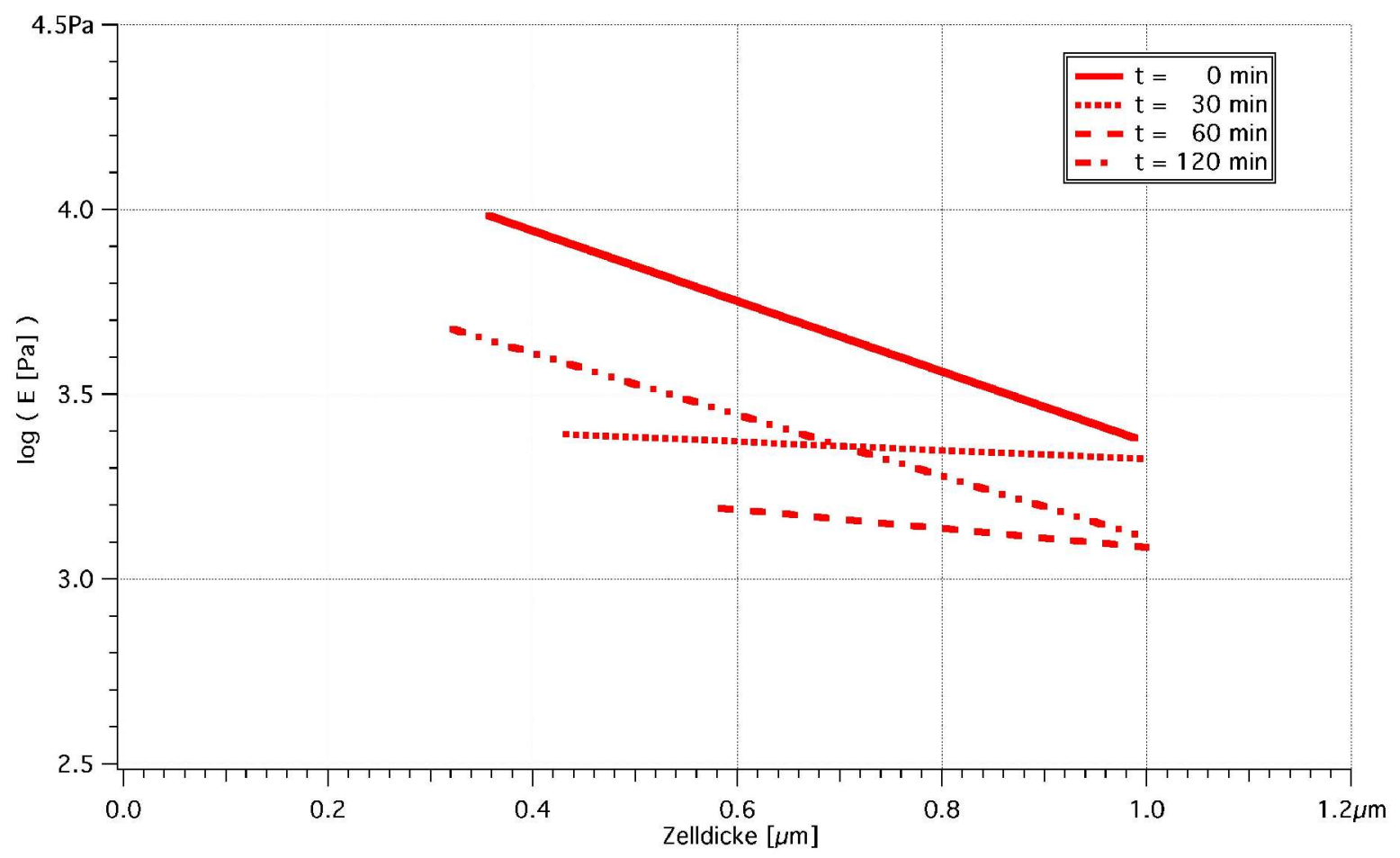

Abbildung 45: Höhenabhängige Darstellung für 3T3-Zelle und ML-7-Inhibitor 


\subsection{Statistik der AFM-Messungen}

Für diese Arbeit wurden 73 AFM-Messungen durchgeführt. 51 von diesem Experimenten gingen in die folgende Statistik ein - das entspricht 10 bis 15 pro Zelllinie und Inhibitor. Die verbleibenden 22 Experimente wurden wegen zu kurzer Versuchsdauer oder Problemen mit den zu untersuchenden Zellen oder dem Versuchsaufbau während der Messungen nicht einbezogen.

Wir fanden durchschnittlich bei 61\% unserer Beobachtungen eine Verringerung des YoungModuls der Zelle nach Zugabe des Inhibitors. In den anderen Fällen zeigten die Zellen keine Reaktion oder sogar eine Erhöhung des Young-Moduls. Das Resultat von 61\% liegt in der Nähe der durch die Videomessungen vorgebenden 71\% . Der zusätzliche Stress der durch die AFMMessungen auf die Zellen ausgeübt wird, ist eine Erklärung für die geringere Anzahl von positiven Reaktionen.

In den folgenden Tabellen sind alle 51 verwendeten Experimente und die durch sie erhaltenden Ergebnisse aufgelistet:

Tabelle 10: Zusammenfassung der AFM-Experimente

\begin{tabular}{cccc}
\hline Zelllinie & Inhibitor & Anzahl der Experimente & Reaktion der Probe \\
\hline 3T3 & BDM & 7 & Verringerung \\
& & 2 & Erhöhung \\
NRK & BDM & 6 & keine \\
& & 6 & Verringerung \\
& \multirow{3}{*}{ 3T3 } & 3 & Erhöhung \\
& & 1 & keine \\
& & 8 & Verringerung \\
NRK & ML-7 & 3 & Erhöhung \\
& & 1 & keine \\
& & 2 & Verringerung \\
& & 2 & Erhöhung \\
\end{tabular}

In den Spalten 1 und 2 sind die Zelllinien und die Inhibitoren aufgelistet und in Spalte 3 und 4 die Anzahl der dazugehörigen Experimente und die Reaktion der Probe. Eingeteilt wurden diese Reaktionen in Verringerung, Erhöhung und keiner Änderung des Young-Moduls.

Betrachten wir nur die für unsere Arbeit positiven Effekte der Proben (Verringerung des YoungModuls) und ihre Verteilung, so ergibt sich folgende Tabelle:

Tabelle 11: Zusammenfassung der positiven Ergebnisse

\begin{tabular}{|c|c|c|c|}
\hline Zelllinie & Inhibitor & Anzahl der Experimente & $\begin{array}{c}\text { Anzahl der positiven } \\
\text { Experimente }\end{array}$ \\
\hline 3T3 & BDM & 15 & $7(47 \%)$ \\
\hline NRK & BDM & 10 & $6(60 \%)$ \\
\hline 3T3 & ML-7 & 12 & $8(67 \%)$ \\
\hline NRK & ML-7 & 14 & $10(71 \%)$ \\
\hline
\end{tabular}

In Spalte 3 ist die Gesamtanzahl der durchgeführten und in die Statistik aufgenommenen Messungen aufgelistet. Spalte 4 gibt die Anzahl der positiven Reaktionen und ihre prozentuale Verteilung wieder. 
Die einzige deutlich unter dem Durchschnitt liegende Kombination ist 3T3+BDM. Dort liegt die Anzahl der positiven Reaktionen nur bei 47\%.

Aus jedem der 31 Experimente, die eine Verringerung des Young-Moduls zeigen, kann nun ein Faktor der Abnahme der Zellelastizität errechnet werden. Ein Vergleich der Elastizitäten bei gleicher Höhe liefert eine höhenunabhängige Betrachtung der Faktoren. Dies liefert uns folgende Ergebnisse:

Tabelle 12: Faktoren der Verringerung des Young-Moduls

\begin{tabular}{|c|c|c|c|}
\hline Zelllinie & Inhibitor & errechneter Faktor & $\begin{array}{c}\text { errechneter Faktor bei } \\
\text { gleicher Höhe }\end{array}$ \\
\hline 3T3 & BDM & $6,1 \pm 1,8$ & $5,2 \pm 1,3$ \\
\hline NRK & BDM & $6,6 \pm 2,5$ & $3,3 \pm 1,1$ \\
\hline 3T3 & ML-7 & $4,0 \pm 0,6$ & $2,4 \pm 0,4$ \\
\hline NRK & ML-7 & $7,8 \pm 1,4$ & $2,5 \pm 0,2$ \\
\hline
\end{tabular}

In Spalte 3 sind die Durchschnittswerte der errechneten Faktoren für die einzelnen Meßreihen mit dazu gehörenden Fehler angegeben. In Spalte 4 der jeweilige Wert für den Faktor bei gleicher Höhe, ebenfalls mit einer Fehlerangabe.

Bis auf die Kombination 3T3+BDM liegen alle Faktoren gleicher Höhe sehr eng beieinander. Dies läßt es zu, dass wir für alle 31 Experimente Mittelwerte bilden; unabhängig von der Zelllinie oder des Inhibitors. Daraus ergeben sich folgende zwei Werte:

- Gesamtfaktor:

- Gesamtfaktor bei gleicher Höhe:

$$
6,1 \pm 0,8
$$

$$
3,4 \pm 0,4
$$

Es ist durch die Statistik also gezeigt worden, dass sich das Young-Modul der 31 untersuchten Fibroblasten unter dem Einfluss von 2 verschiedenen MLCK-Inhibitoren um den Faktor 2,4-5,2 verringert.

\subsection{Diskussion}

In unserer Videomikroskopie konnten wir das grundsätzliche Verhalten der verwendeten Fibroblasten auf die beiden Inhibitoren beobachten. Die Auswertung zeigt ein von Zelllinie und Inhibitor unabhängiges Verhalten der Zellen. Die von uns erwartete Reaktion, dass Einstellen der Bewegung und die Änderung der ausgedehnten Morphologie in eine einfache sphärische Form, konnte bei $71 \%$ der 403 untersuchten Zellen deutlich beobachtet werden. Die Reaktion der Zellen auf den Inhibitor setzte sofort ein und war 5-10 min nach Zugabe des Inhibitors beendet. Durch Variation der Inhibitor-Konzentration innerhalb der Konzentrationsgrenzen (siehe Abschnitt 3.1) konnte die Reaktionsgeschwindigkeit verlangsamt oder beschleunigt werden. 108 Zellen zeigten nur eine schwache Reaktion, das bedeutet: nur eine Änderung der Form, Stoppen der Bewegung oder geringere Ausprägung von beiden Veränderungen. Nur insgesamt 10 Zellen $(2,5 \%)$ zeigten keinerlei Reaktion. Da Zellen als lebende Objekte zum Teil verschiedene Verhaltensmuster zeigen (trotz gleicher Zelllinie), ist eine einheitliche Reaktion von $71 \%$ der untersuchten Zellen ein sehr eindeutiges Ergebnis. Besonders, wenn man bedenkt, dass die einzelnen Zellen zu verschiedenen Zeitpunkten ihres Zellzyklus untersucht wurden. Wir fanden auch keinen wesentlichen Unterschied in den einzelnen Variationen von Inhibitoren und Zelllinien. 
Da wir zwei verschiedene Inhibitoren benutzen, die unterschiedlich in die Zellprozesse eingreifen (siehe Abschnitt 1.3), und auch zwei verschiedene Zelllinien, ist sehr wahrscheinlich, dass der beobachtete Effekt eine von Zellline unabhängige Reaktion auf die Hemmung des Motorproteins Myosin II ist.

Eine weitere Beobachtung der Videomikroskopie war die Regeneration der Zellen nach Zeiträumen von 30-60 Minuten. Sie bildeten wieder Lamellipodien aus und die zelluläre Bewegung setzt erneut ein. $\mathrm{Zu}$ einer vollständigen Wiederherstellung der ursprünglichen Zelleigenschaften kam es aber nur bei 43\% der untersuchten 403 Zellen. Die restlichen Zellen zeigten keine oder nur eine teilweise Wiederaufnahme der ursprünglichen Aktivität. Also ist eine endgültige Aussage über die Umkehrbarkeit des Eingriffs der Inhibitoren noch unklar.

Insgesamt lässt sich aus den optischen Experimenten schliessen, dass das Myosin II eine elementare Bedeutung für die Fähigkeit der Zelle hat, Strukturen zu bilden, diese zu erhalten und somit eine Bewegung auszuführen.

In den AFM-Experimenten wollten wir prüfen, ob das oben beschriebene Verhalten der Zellen mit einer Änderung der Zellelastizität korreliert ist.

In der Arbeit von „Rotsch\&Radmacher, 2000“ wurden mit Chemikalien die Aktin-FilamentNetzwerke von NRK- und 3T3-Zellen zerstört und dabei eine Verringerung des Young-Moduls der Zellen um Faktor 2,4-3,1 gefunden. Das Ergebnis war die Aussage, dass das Aktin-Netzwerk im Allgemeinen eine wichtige Aufgabe innerhalb der Zelle für Struktur und Stabilität übernimmt.

Unsere Experimente gehen einen Schritt weiter und beschränken sich gezielt auf einen Teil der Aktin-Netzwerk-Struktur: auf das Motorprotein Myosin II.

Messungen mit dem AFM vor und nach der Zugabe des Inhibitors lieferten uns zwei Ergebnisse. Als Erstes beobachteten wir eine deutlich später einsetzende Reaktion der Zellen. Während bei der Videomikroskopie die Wirkung der Inhibitoren beinahe sofort einsetzte, zeigten bei AFMVersuchen die Zellen erst nach 5-10 Minuten die erste Reaktion und einen deutlich langsameren Veränderungsprozess über bis zu 90 Minuten. Bei den Videoexperimenten konnte der Inhibitor direkt auf die zu untersuchende Region der Petrischale gegeben werden, während bei den AFMExperimenten aufbaubedingt nur eine Zugabe am Schalenrand möglich war. Dies führt zu einer diffusionsbegrenzten Ausbreitungsgeschwindigkeit des Inhibitors innerhalb der Petrischale (Rotsch\&Radmacher, 2000), welche durch Änderung der Inhibitor-Konzentration nur geringfügig verändert werden konnte.

Das zweite Ergebnis war die von uns erwartete Verringerung der Zellelastizität. KontrollMessungen auf verschiedenen Teilen von NRK-Zellen brachten uns sehr unterschiedliche Resultate: Messungen auf dem Zellkörper lieferten uns Werte für den Young-Modul vor der Zugabe eines Inhibitors von 3-7 kPa und 60 Minuten nach Zugabe 1-2 kPa. Vergleichende Experiment bei einem flachen Zellbereich (Lamellipodium) ergab ein Young-Modul von $25 \mathrm{kPa}$ in einigen Gebieten bis $100 \mathrm{kPa}$. Im Verlauf des Experiments verringerte sich der Young-Moduls als Reaktion auf den Inhibitor auf durchschnittlich $\sim 2 \mathrm{kPa}$. Beide Ergebnisse zeigen generell den von uns erwarteten Effekt: eine deutliche Verringerung der Zellelastizität nach Zugabe eines Inhibitors, einhergehend mit den oben beschriebenen optisch sichtbaren Veränderungen (siehe Abschnitt 5.2). Der große Unterschied der Young-Module für flache $(>800 \mu \mathrm{m})$ und hohe (bis $2 \mu \mathrm{m})$ Zellbereiche vor der Zugabe eines Inhibitors, lässt sich auf den unter Abschnitt 1.4 und 4.2.3 angesprochenen Einfluss des harten unterliegenden Substrat zurückführen (Domke\&Radmacher, 1998; Rotsch et al., 1999, Rotsch\&Radmacher, 2000). Der Einfluss des unterliegenden Substrats ändert sich mit Verlauf des Experiments: die flachen Zellränder bilden sich zurück und die vermessenen Gebiete werden somit höher. Dadurch ändert sich während der Messung der Einfluss des unterliegenden Substrats bis er fast vollkommen verschwindet. Die Endwerte für Messungen auf dem Zellkörper und Messungen auf den Zellrandbereichen sind so nahezu identisch. 
Die für uns interessanten Zellbereiche waren die Randgebiete mit den Lamellipodien, da dort die Bewegung und damit die Reaktion der Zelle auf die Inhibitoren am stärksten ausgeprägt ist. Um die Abhängigkeit des Young-Moduls von der Zelldicke zu eliminieren, trugen wir die Zellelastizität gegen die Zelldicke auf und betrachteten die Werte der Elastizität bei gleicher Höhe (siehe Abschnitt 4.2.3, 5.5.2 und 5.2.3). Auf diese Weise gehen uns die 2-dimensionalen Informationen der Elastizitätskarten verloren, aber wir erreichen höhenkorrigierte Werte des Young-Moduls.

Die Auswertung von 51 durchgeführten AFM-Experimente ergab eine positive Reaktion von 61\% der untersuchten Zellen. Die einzelnen Ergebnisse liegen zum Teil niedriger (47\% bei der BDM-3T3-Kombination) siehe Tabelle 11. Diese Abweichung zum Ergebnis der Videostatistik lässt sich auf die zusätzlichen Belastung der Zellen während der AFM-Messungen zurückführen und war von uns erwartet worden. Da die verbleibenden $39 \%$ keine grundsätzlichen gegenteiligen Effekte zeigen, ist eine Allgemeingültigkeit der Ergebnisse weiterhin gegeben.

Aus den 31 positiven Experimenten wurde die durchschnittliche Verringerung der Zellelastizität bestimmt. Wir errechneten aus allen Messungen für jede Inhibitor- und Zelllinien-Kombination einen Faktor, um den sich der Young-Modul der Zelle verringert hatte. Daraus ergaben sich Werte von $4 \pm 0,6$ bis 7,8 $\pm 1,4$ (siehe Tabelle 12). Eine wie oben beschriebene Höhenkorrektur (Standardhöhe: 0,6 $\mu \mathrm{m}$ ) veränderte den Wertebereich auf 2,4 $\pm 0,4$ bis 5,2 $\pm 1,3$. Da sich die Werte für die einzelnen Kombinationen zumeist nicht wesentlich unterscheiden, wurde ein Mittelwert für alle 31 Experimente bestimmt: 6,1 \pm 0,8. Daraus ergab sich durch die Höhenkorrektur ein Mittelwert von 3,4 \pm 0,4 (siehe Abschnitt 5.3). Dieser Wert ist vergleichbar mit dem Ergebnis von „Rotsch\&Radmacher, 2000“, die eine Verringerung des Young-Moduls von $\sim 3$ nach Schädigung des Aktin-Netzwerkes fanden.

Wir konnten also zeigen, dass eine Verringerung der Zellelastizität, einhergehend mit der Einstellung der Zellbewegung und Änderung der Morphologie, durch Hemmen der Myosin II-Aktivität zu erreichen ist. Die Bedeutung des Myosin II für die Spannungserzeugung und die Stabilität der Zelle und damit für die Bewegung und Morphologie konnte durch Video- und AFM-Experimente nachgewiesen werden.

In den Arbeiten von MacKintosh et al., 1995; Janmey et al., 1988 und 1994 und Tang et al. 1999 wird die Elastizität von semiflexiblen Biopolymer-Netzwerken und Aktin-Gelen diskutiert. MacKintosh et al., 1995 geben ein Plateu-Young-Modul für eine Aktin-Lösung $(1 \mathrm{mg} / \mathrm{ml}$ AktinMonomer-Konzerntration) von $\sim 100 \mathrm{~Pa}$ an.

Dieser Wert liegt immer noch deutlich unter den von uns bestimmten Werten für den YoungModul einer Zelle; auch nach Einsatz eines Inhibitors (1-6 kPa).

Dafür gibt es folgende mögliche Erklärungen: das von uns benutzte Modell von Hertz (siehe Abschnitt 4.2.1) gibt weiche, unendlich dicke, ausgedehnte Flächen als Voraussetzungen. Lokal kann die Zelloberfläche als weich und unendlich ausgedehnt angesehen werden, aber das unterliegende harte Substrat wie auch die inhomogene Struktur des Aktin-Netzwerks wird in dem Model nicht berücksichtigt (Rotsch et al., 1999; Domke\&Radmacher, 1998). Die absoluten Werte für die Zellelastizitäten sind also mit nicht abzuschätzenden modellbedingten Fehlern behaftet. Die Kontroll-Messungen an den Zellkörpern, die die Voraussetzungen deutlich besser erfüllen, zeigen, dass die Werte für die Lamellipodien nach der Höhenbetrachtung zumindest in der Größenordnung korrekt sind. 
Wenn die Größenordnung der bestimmten Young-Module korrekt ist und die Zelle auch nach der Ausschaltung des Mysion II deutlich höhere Werte für die Young-Module zeigt, als für eine Aktin-Monomere-Lösung, so muss es noch andere Mechanismen für die Zellelastizität geben. Die Aktinfilamente in den Zellen erhalten ihren Zusammenhalt ausser durch das Myosin II durch eine Vielzahl von Proteinen, die als Quervernetzern oder Bündler fungieren. Diese Mechanismen unterscheiden eine tierische Zelle in ihrer Elastizität auch ohne den Einfluss von Mysion II von der von MacKintosh et al., 1995 untersuchten Aktin-Lösung.

In lebenden Zellen ist ausserdem eine Konzentration von Aktin bis $10 \mathrm{mg} / \mathrm{ml}$ denkbar. Dies würde das Yong-Modul der Zelle deutlich erhöhen, so dass sie Werte von $\sim 10 \mathrm{kPa}$ erreichen (MacKintosh et al., 1995) könnten. Diese Werte liegen in dem von uns gemessenen Bereich der Zellelastizität.

Wir haben uns in dieser Arbeit auf die Veränderungen der Zelleigenschaften nach Zugabe der Inhibitoren konzentriert. Die fehlerbehafteten Absolutwerte der Zellelastizität sind für die von uns gewonnenen Ergebnisse kaum von Bedeutung, da wir nur die Änderungen (Differenzen) des Young-Moduls betrachteten. Die modellbedingten Fehler der Absolutwerte dabei herausfallen. Die Gültigkeit der von uns getroffenen Aussagen über die Bedeutung des Motorproteins Myosin II in Zusammenhang mit dem Aktinfilament-Netzwerk werden also nicht betroffen.

Wir konnten mit dem Kraftmikroskop eine neue Untersuchungsmethode für die Bestimmung des Einflusses von Myosin II auf die Mechanik der Zelle vorstellen. Die Untersuchungen von Myosin II und den Einfluss dieses Proteins auf die Zelle war bis jetzt nur mit biochemischen Methoden, optische Mikroskopie oder Elektronenmikroskopie durchgeführt worden. 


\section{Zusammenfassung}

In der vorliegenden Arbeit wurde der Einfluss des Motorproteins Myosin II auf die Zellmechanik untersucht. Dazu wurden die Fibroblasten Zelllinien NRK und 3T3 ausgewählt, da sie für ihre einfache Kultivierung und ihrer Fähigkeit der fortlaufenden Bewegung und der weitläufigen Ausbildung von Lamellipodien bekannt sind. Die Zellen wurden dann den Mysion II-Inhibitoren BDM und ML-7 ausgesetzt, die beide mit verschiedenen Eingriffen in die zellulären Prozesse das Myosins II an seiner Aktivität oder die Anheftung an das Aktin-Filament hemmen.

Zuerst wurden durch Kontroll-Messungen das allgemeine Verhalten der Fibroblasten innerhalb des Versuchsaufbaus festgestellt und anschließend die Inhibitor-Parameter bestimmt.

Das Verhalten der Zellen vor und nach Zugabe der Inhibitoren wurde video- und kraftmikroskopisch beobachtet.

Unabhängig von der Zelllinie und dem Inhibitor wurde bei 71\% der 403 videomikroskopisch beobachteten Zellen eine starke Reaktion auf die Inhibitoren registriert: eine Einstellung der Bewegung und Änderung der ausgedehnten Morphologie in eine einfache sphärische Form. Die restlichen Zellen zeigten nur eine abgeschwächte Form der Reaktion und nur 10 Zellen reagierten gar nicht.

$\mathrm{Zu}$ einer vollständigen Wiederherstellung der ursprünglichen Zelleigenschaften kam es bei nur 43\% der 403 untersuchten Zellen.

Mit AFM konnten wir anhand von 2-dimensionalen Kraftkarten und den dazugehörigen Histogrammen zeigen, dass parallel zu den optischen Effekten der Young-Modul der Zellen deutlich absinkt.

Von den 51 unter dem AFM untersuchten Zellen zeigten 61\% diesen erwarteten Effekt. Die geringere Anzahl der positiven Zellreaktionen im Vergleich zu den Videomessungen führen wir auf die zusätzliche Belastung der Zellen unter dem AFM zurück.

Durch Vergleich der Young-Module vor und nach Zugabe des Inhibitors bei gleicher Zelldicke, konnten wir den Einfluss des unterliegenden Substrats herausmitteln und so die durchschnittliche Verringerung des Young-Moduls bestimmen. Aus den 31 in die Auswertung eingegangenen Experimente ergab sich ein Faktor von 3,4 $\pm 0,4$.

Diese deutlichen Veränderungen der Zellmechanik nach dem Hemmen der Myosin II Aktivität lässt auf die Wichtigkeit dieses Motorproteins für die Struktur, Stabilität und für die Ausbildung der Bewegung einer Zelle schliessen. Es wurde gezeigt, dass das Myosin II einen maßgeblichen Anteil an dem Aufbau der Zellspannung und dem Prozess der zellularen Bewegung besitzt. 


\section{Literatur}

A-Hassan, E., W. F. Heinz, M. D. Antonik, N. P. D'Costa, S. Nagaswaran, C.- A. Schoenberger, and J. H. Hoh, 1998, „Relative micro-elastic mapping of living cells by atomic force microscopy“, Biophys. J., 74:1564-1578

Alberts, B., D. Bray, J. Lewis, et al., 1994, Molcular Biology of the cell, Garland Publishing Inc.

Binnig, G., and H. Rohrer, 1982, „Scanning tunneling microscope“, Helv. Phys. Acta

Binnig, G., C. F. Quate, and C. Gerber, 1986, „Atomic force microscope“, Phys. Rev. Lett., 56:930-933

Braet, F., C. Rotsch, E. Wisse, and M. Radmacher, 1997, „Comparsion of fixed and living liver endothelial cells by atomic force microscopy“, Appl. Phys. A, 66:575-578

Domke, J., and M. Radmacher, 1998, „Measuring the elastic properties of thin polymer films with the AFM“", Langmuir, 14:3320-3325

Domke, J, W. J. Dannöhl, O. Müller, W. K. Aicher, and M. Radmacher, 2000, „Substrate dependent differences in morphology and elasticity of living osteoblasts investigated by atomic force microscopy“", Colloids and Surfaces, 19:367-379

Drake, B., C. B. Prater, A. L. Weisenhorn, S. A. C. Gould, T. R. Albrecht, C. F. Quate, D. S. Cannell, H. G. Hansma, and P. K. Hansma, 1989, „Imaging crystals, polymers and biological processes in water with afm“, Science, 243:1586-1589

Fritz, M., M. Radmacher, and H. E. Gaub, 1994, „Granula motion and membrane spreading during activation of human platelets imaged by atomic force microscopy", Biophys. J., 66:1328-1334

Haydon, P. G., R. Lartius, V. Parpura, and S. P. Marchese-Regona, 1996, „Membrane deformation of living cells using atomic force microscopy“", J. Microsc., 182:114-120

Hertz, H., 1882, „Über die Berührung fester elastischer Körper“, J. Reine Angew. Mathematik, 92:156-171

Higuchi, H., and S. Takemori, 1989, „Butanedione monoxime suppresses contraction and ATPase activity of rabbit skeletal muscle“, J. Biochem., 105:638-643

Hofmann, U. G., C. Rotsch, W. J. Parak, and M. Radmacher, 1997, „Investigating the cytoskeleton of chicken cardiocytes with the atomic force microscope“, J. Struct. Biol., 119:84-91 
Hoh, J. H., and C.- A. Schoenberger, 1994, „Surface morphology and mechanical properties of MDCK monolayers by atomic force microscopy“, J. Cell. Sci., 107:1105-11

Janmey, P. A., S. Hvidt, J. Peetermans, J. Lamb, J. D. Ferry, and T. P. Stossel, 1988, „Viscoelasticity of F-actin and F-actin/gelsolin complexes“, Biochem, 27:8218-8227

Janmey, P. A., S. Hvidt, J. Käs, D. Lerche, A. Maggs, E. Sackmann, M. Schliwa, and T. P. Stossel, 1994, „The mechanical properties of actin gels. Elastic modulus and filament motions", J Biol Chem., 269:32503-32513

Johnson, K. L., 1994, „Contact mechanics“, Cambridge University Press, Cambridge

Kelley, S. J., R. Thomas, and P. B. Dunham, 2000, „Candidate inhibitor of the volume-sensitive kinase regulating $\mathrm{K}-\mathrm{Cl}$ cotransport: the mysion light chain kinase inhibitor ML-7“, J. Mem. Biol., 178:31-41

Kolb, H.-A., O. Enders, and R. Schauer, 1999, „Morphology of native and reconstituted biological membranes and their components analysed with atomic force microscopy", Appl. Phys. A, 68:247-254

Krarup, T., L. D. Jakobsen, B. S. Jensen, and E. K. Hoffmann, 1998, „Na $\mathrm{Na}^{+}-\mathrm{K}^{+}-2 \mathrm{Cl}^{-}$cotransport in ehrlich cells: regulation by protein phosphatases and kinases“, Am. J. Physiol., 275:C239-250

Lo, C.- M, H.- B. Wang, M. Dembo, and Y.- L. Wang, 2000, „Cell movement is guides by the rigidity of the substrate“, Biophys. J., 79:144-152

MacKintosh, F. C., J. Käs, and P. A. Janmey, 1995, „Elasticity of semiflexible biopolymer networks“, Physical Review Letters, 75:4425-4428

Pelham, R. J., and Y.- L. Wang, 1997, „Cell locomotion and focal adhesion are regulated by substrate flexibility“, Proc. Natl. Acad. Sci. USA., 94:13661-13665

Pelham, R. J., and Y.- L. Wang, 1999, „High resolution detection of mechanical forces exerted by locomoting fibroblasts on the substrate", Molecular Biology of the Cell, 10:935-945

Phillips, R. M., and R. A. Altschuld, 1996, „2,3-Butanedione 2-Monoxime (BDM) induces calcium release from canine cardiac sarcoplasmic reticulum", Biochem. Biophys. Res. Commun., 229:154-157

Radmacher, M., R. W. Tillmann, M. Fritz, and H. E. Gaub, 1992, „From molecules to cells: imaging soft samples with the AFM“, Science, 257:1900-1905

Radmacher, M., J. P. Cleveland, M. Fritz, H. G. Hansma, and P. K. Hansma, 1994 I, „Mapping interaction forces with atomic force microscope“, Biophys. J., 66:2159-2165

Radmacher, M., M. Fritz, H. G. Hansma, and P. K. Hansma, 1994 II, „Direct observation of enzyme activity with the atomic force microscope“, Science, 265:1577-1579 
Radmacher, M., M. Fritz, C. M. Kacher, J. P. Cleveland, and P. K. Hansma, 1996, „Measuring the elastic properties of human platelets with the atomic force microscope“, Biophys. J., 70:556-567

Radmacher, M., 1997, „Measuring the elastic properties of biological samples with the atomic force microscope“, IEEE Eng. in Med. and Biol.

Rotsch, C., F. Braet, E. Wisse, and M. Radmacher, 1997a, „AFM imaging and elasticity measurement of living rat liver macrophages“, Cell Biol. Int., 21:685-696

Rotsch, C., K. Jacobson, and M. Radmacher, 1997b, „Investigation living cells with the atomic force microscope“, ScanningMicrosc.,

Rotsch, C., K. Jacobson, and M. Radmacher, 1999, „Dimensional and mechanical dynamics of active and stable edges in motile fibroblasts by atomic force microscopy", Proc. Natl. Acad. Sci. USA., 96:921-926

Rotsch, C., and M. Radmacher, 2000, „Drug-induced changes of cytosceletal structures and mechanics in fibroblasts - an atomic force microscopy study“, Biophys. J., 78:520-535

Saitoh, M., T. Ishikawa, S. Matsushima, M. Naka, and H. Hidaka, 1987, „Selective inhibition of catalytic activity of smooth muscle mysion light chain kinase", J. Biol. Chem., 262:7796-7801

Schäfer et al. in preparation

Sneddon, I. N., 1965, „The relation between load and penetration in the axisymmetric boussinesq problem for a punch of arbitrary profile“, Int.J. Eng. Sci. 3:47-57

Stossel, T. P., 1993, „On the crawling of animal cells“, Science, 260:1086-1094

Tang, J. X., P. A., Janmey, T. P., Stossel, and T. Ido, 1999, „Thiol oxidation of actin produces dimers that enhance the elasticity of the F-actin network“", Biophys. J., 76:2208-2215

Walters, D. A., B. L. Smith, A. M. Belcher, et al., 1997, „Modification of calcite crystal growth by abalone shell proteins: an atomic force microscope study“, Biophys. J., 72:1425-1433 


\section{Danksagung}

Ich möchte mich an dieser Stelle bei allen Personen herzlich bedanken, die mich bei meiner Dissertation und den dazugehörigen Arbeiten und Messungen unterstützt haben.

Prof. Dr. Manfred Radmacher möchte ich besonders danken, für die Aufnahme in seine Arbeitsgruppe und die Ermöglichung dieser Arbeit; für die vielen hilfreichen Diskussionen und Anregungen, sowie das freundliche und nette Arbeitsklima.

Prof. Dr. Tim Salditt für die Übernahme des Korreferates dieser Arbeit.

Prof. Dr. Werner Lauterborn für die Bereitstellung der Arbeitsmaterialien und Räumlichkeiten, die für die Beendigung meiner Arbeit in Göttingen nötig waren.

Marcus Prass, Sven Blank, Dr. Monika Fritz und der gesamten Arbeitsgruppe Biophysik für die nette Arbeitsatmosphäre, die interessanten Gespräche und die Hilfe bei anliegenden Dingen.

Kerstin von Roden und Ulrike Schulz, die mich in der Zellkultur mit Rat und Tat unterstützten.

Dr. Georg Grabitz, Petra Schäfer, Ulrike Schulz und Marcus Schwammberger, für die Hilfe bei der Korrektur dieser Arbeit.

Meinen Eltern Petra und Bernd Schäfer für Ihre Unterstützung während meines gesamten Studiums, ohne die ich nie soweit gekommen wäre.

Meiner Freundin Kathrin Herden, die mich immer unterstützt hat und es immer wieder geschafft hat, mich zu motivieren, meine Arbeit in einem anderen Blickwinkel zu sehen. 


\section{Lebenslauf}

\section{Angaben zur Person}

$\begin{array}{ll}\text { Name: } & \text { Schäfer } \\ \text { Vorname: } & \text { Arne } \\ \text { Strasse: } & \text { Lange Geismarstr. 10 } \\ \text { Wohnart: } & \text { 37073 Göttingen } \\ \text { Telefon: } & 0551 / 3706460 \\ \text { Mobiltelefon: } & \text { 0170-4224446 } \\ \text { e-mail: } & \text { schaefer_arne@gmx.de } \\ \text { Geburtsdatum/-ort: } & 15.06 .1974 \text { in Göttingen } \\ \text { Familienstand: } & \text { ledig } \\ \text { Staatsangehörigkeit: } & \text { deutsch }\end{array}$

\section{Schulbildung}

1980-1984 Grundschule Bovenden

1984-1986 Orientierungsschule Bovenden

1986-1990 Realschule Bovenden

1990-1993 Fachgymnasium Technik Göttingen

1993 allgemeine Hochschulreife (Note: 1.5)

\section{Studium}

1993-1996 Grundstudium Physik in Göttingen

1996-1999 Hauptstudium Physik in Göttingen

ab 1998

Diplomarbeit in der Universitätssternwarte

29.10.1999

Diplomprüfung (Note: 1.7)

2000.2003 Promotion, III. Physikalisches Institut, Abt. Biophysik, Universität Göttingen davon ein Jahr Mitglied im Graduiertenkolleg „Raumzeitlich Signalprozesse in Neuronen und zelluläre Biophysik“"

04.11.2003 Disputation (Note: magna cum laude (1.0))

\section{Studienbegleitende Tätigkeit}

seit $10 / 98$

01/1999-03/1999

06/1999-09/1999

\section{Praktika}

08/1999-09/1999 Beschäftigung in der Strahlentherapie studentische Bürohilfskraft im Evang. Krankenhaus Weende studentische Hilfskraft an der Universitätssternwarte Göttingen studentische Hilfskraft an der Universitätssternwarte Göttingen 


\section{Computerkentnisse}

Betriebssysteme:

UNIX, LINUX, WINDOWS \& MAC OS als User

Anwendungen:

Word, Works, Excel, PowerPoint, Adobe Acrobat \& Photostudio für Windows

HTML, MIDAS \& LATEX für LINUX

Igor, Canvas, Image für MAC OS IX

Netscape, Internet Explorer, Mozilla, FTP

\section{weitere Kenntnisse}

1 Semester Sozialpsychologie als Gasthörer

BWL für Naturwissenschaftler (Abschlussnote: 1.0)

\section{weitere Aktivitäten}

seit 1994

1. Vorsitzender und Jugendwart des Schachsport „Plesse“

Bovenden

seit 1994

Trainertätigkeit: Breitensport Schach für Kinder und

1995.1996

Jugendliche

$12 / 2000-09 / 2001$

2. Vorsitzender des Gemeinde Jugendrings e.V. Bovenden

1. Vorsitzender der Laienspielgruppe „Göttinger Verein für Live-

Rollenspiele“

\section{Hobbys}

Schach, Jugendbetreuung, lesen, Kino, Mittelalter 